\title{
Lithospheric Dynamics of Earth's Subduction Zones and Martian Tectonic Provinces
}

\author{
By \\ Min Ding \\ B.S. Geophysics \\ University of Science and Technology of China, 2009 \\ SUBMITTED TO THE MIT/WHOI JOINT PROGRAM IN PARTIALLY FULFILLMENT \\ OF THE REQUIREMENTS FOR THE DEGREE OF \\ DOCTOR OF PHILOSOPHY IN MARINE GEOPHYSICS \\ AT THE \\ MASSACHUSETTS INSTITUTE OF TECHNOLOGY \\ AND THE \\ WOODS HOLE OCEANOGRAPHIC INSTITUTION
}

FEBRUARY 2015

(C) 2015 Min Ding. All rights reserved.

The author hereby grants to MIT and WHOI permission to reproduce and distribute publicly paper and electronic copies of this thesis document in whole or in part in any medium known or hereafter created.

Signature of Author:

MIT/WHOI Joint Program in Oceanography/Applied Ocean Science and Engineering December 29, 2014

Certified by:

Jian Lin

Senior Scientist, Department of Geology and Geophysics, WHOI

Thesis Supervisor

Accepted by:

Timothy L. Grove

Professor of Geology, MIT

Chair, Joint Committee for Marine Geology and Geophysics 


\title{
Lithospheric Dynamics of Earth's Subduction Zones and Martian Tectonic Provinces
}

\begin{abstract}
By
Min Ding

Submitted to the MIT/WHOI Joint Program in Oceanography/Applied Ocean Science and Engineering on November 20, 2014 in partial fulfillment of the requirements for the degree of Doctor of Philosophy in Geophysics
\end{abstract}

\begin{abstract}
This thesis investigates lithospheric dynamics of Earth's subduction zones and Martian tectonic provinces on multiple time scales ranging from short-term earthquake deformation to long-term tectonic loading. In Chapter 2, I use geodetic observations to constrain the postseismic viscoelastic deformation following the 1960 M9.5 Valdivia, Chile earthquake and quantify its stress loading on the rupture zone of the 2010 M8.8 Maule, Chile earthquake. Results of analysis reveal that the post-1960 viscoelastic process might have contributed to the triggering of the 2010 earthquake. Chapter 3 presents numerical experiments to investigate elastoplastic deformation and faulting in the overriding plates of subduction zones caused by the movement of subducted seamounts. Numerical simulations show that a group of normal faults would first appear on the seaward side of a subducted seamount, followed by a group of thrust faults on the landward side of the seamount. In Chapter 4, I use the most recent Martian gravity and topography data to constrain spatial variations in lithospheric flexural deformation for various tectonic regions on Mars. The effective lithospheric thickness is estimated to be relatively small for the plain regions in the southern highland, but relatively large for the impact basins in the northern lowland as well as for volcanic montes in the Tharis province. The regional variations in the estimated effective lithospheric thickness might reflect both spatial and temporal changes in the thermal state of Mars.
\end{abstract}

\section{Thesis Supervisor:}

Dr. Jian Lin

Senior Scientist, Department of Geology and Geophysics, WHOI

Chair of the Defense:

Dr. Daniel Lizarralde, Associate Scientist with Tenure, WHOI

\section{Thesis Committee:}

Prof. Maria T. Zuber, MIT

Dr. Rob L. Evans, Senior Scientist, WHOI

Dr. Mark D. Behn, Associate Scientist with Tenure, WHOI

Dr. Jeff J. McGuire, Associate Scientist with Tenure, WHOI

Dr. Brian E. Tucholke, Scientist Emeritus, WHOI 


\section{Contents}

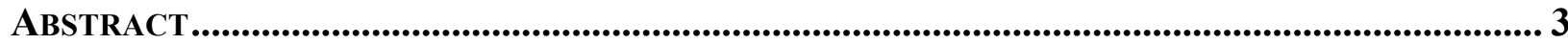

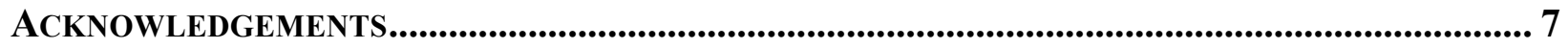

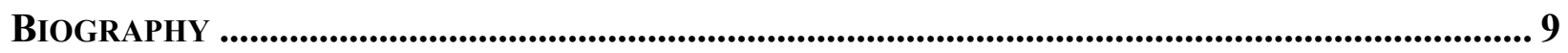

CHAPTER 1: INTRODUCTION ............................................................................................. 11

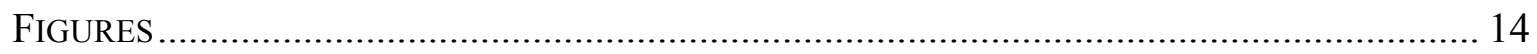

Chapter 2: Post-seismic Viscoelastic Deformation and Stress Transfer After the 1960 M9.5

Valdivia, Chile Earthquake: Effects on the 2010 M8.8 Maule, Chile Earthquake....................... 18

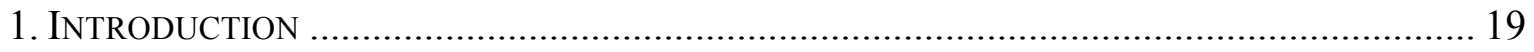

2. Post-1960 Viscoelastic Deformation............................................................... 20

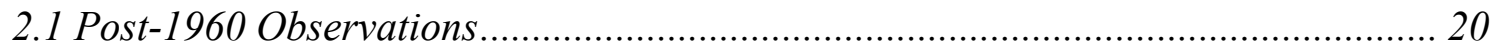

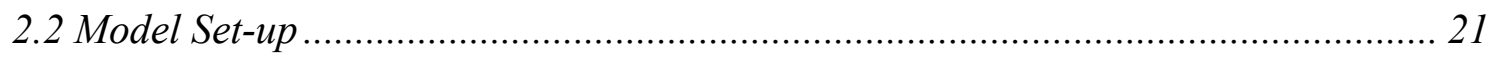

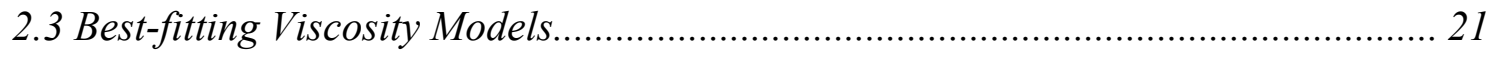

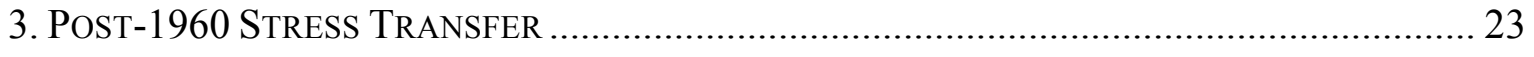

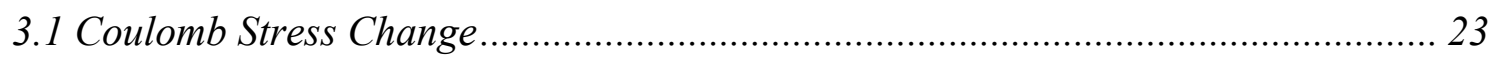

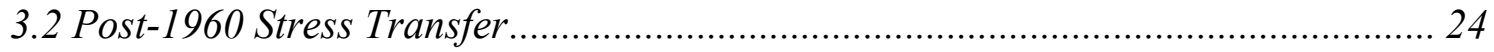

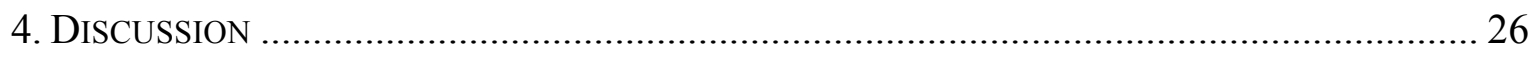

4.1 Uncertainties in the Type 1 and 2 Post-seismic Deformation Data ....................... 26

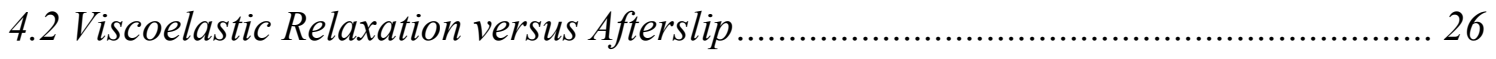

4.3 Stress Transfer versus Tectonic Loading ..................................................... 27

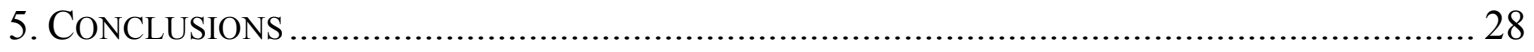

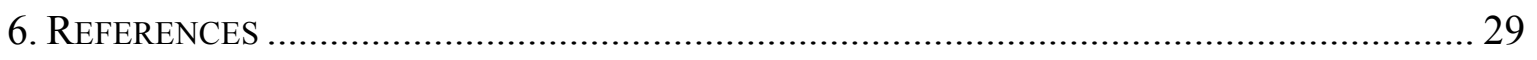

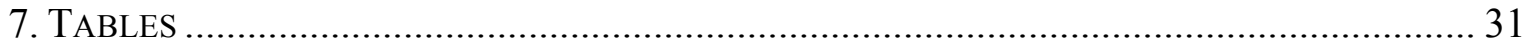




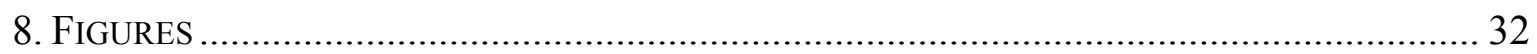

9. APPENDIX A: Model Sensitivity of Viscoelastic Deformation ………………………..... 42

10. APPENDIX B: Layered Earth Viscosity Model ……………....................................... 46

ChaPTer 3: Elastoplastic Deformation and Faulting in the Overriding Plate Caused By a Subducted Seamount ........................................................................................................................... 48

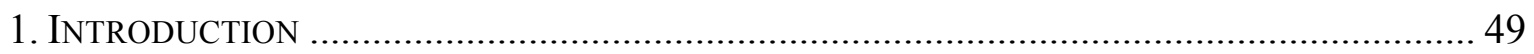

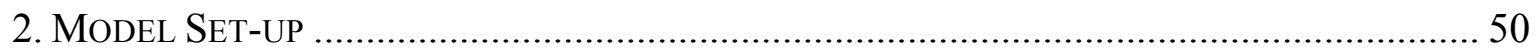

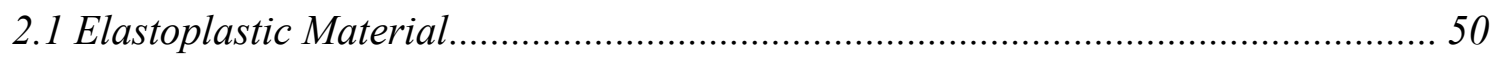

2.2 Model Geometry and Boundary Condition...................................................... 52

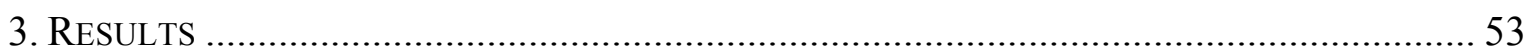

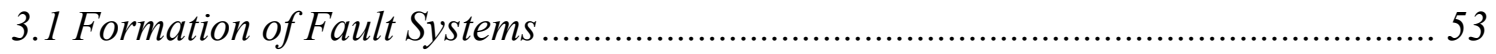

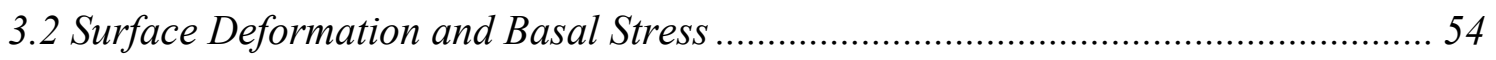

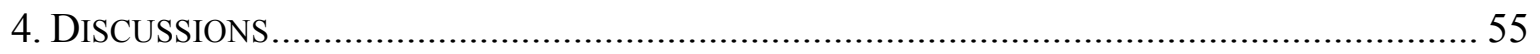

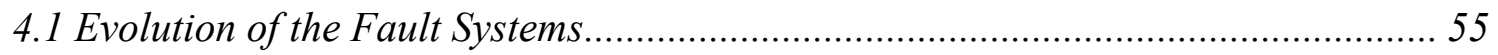

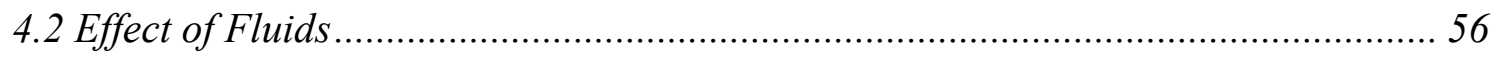

4.3 Comparison with Compressional Wedge Model.................................................. 56

4.4 Interaction with Pre-existing Splay Faults …………………............................ 57

4.5 Influence on Megathrust Earthquakes ............................................................... 57

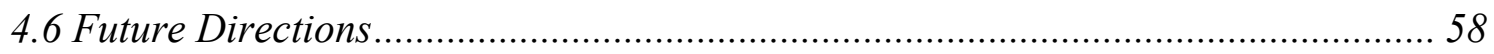

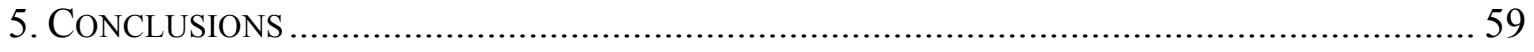

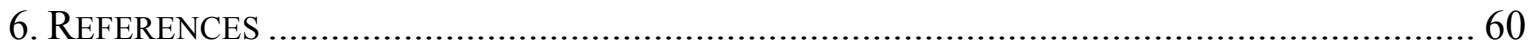

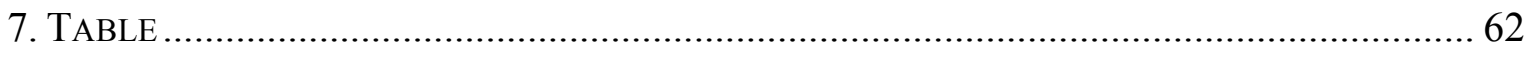

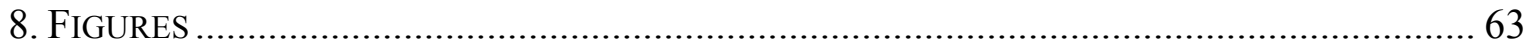


CHAPTER 4: Variations in Lithospheric Strength and Sub-surface Loading on Mars

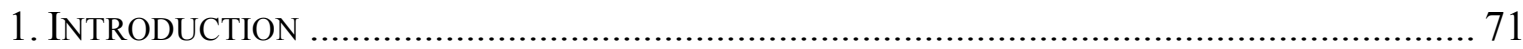

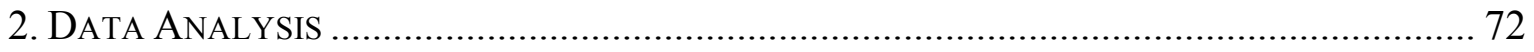

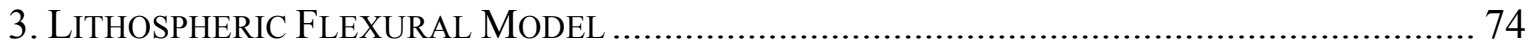

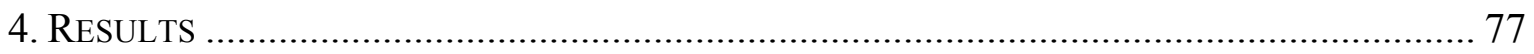

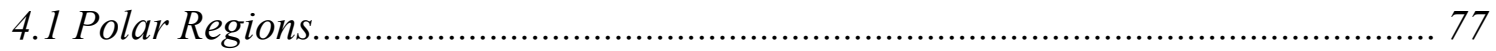

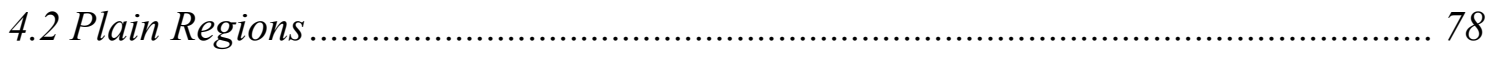

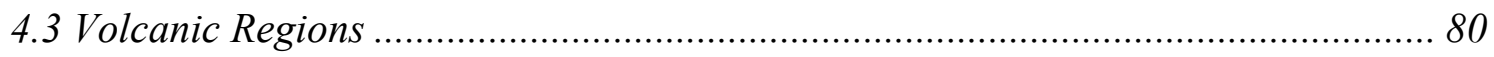

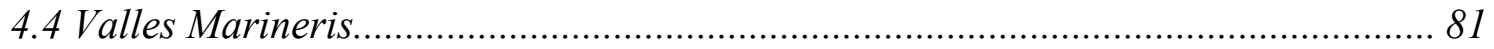

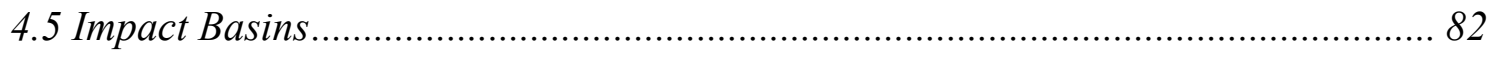

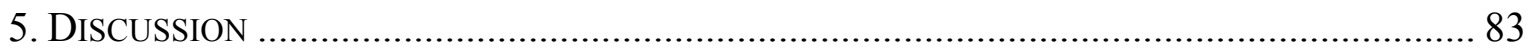

5.1 Wavelength Dependence of the Effective Lithospheric Thickness Estimates ........... 83

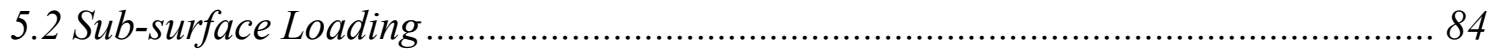

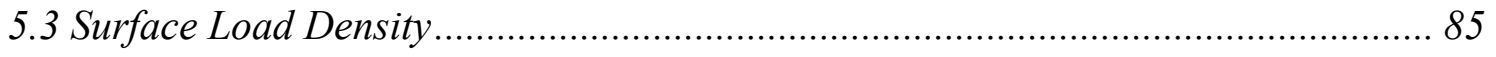

5.4 Comparison with Previous Lithospheric Thickness Estimates ............................. 85

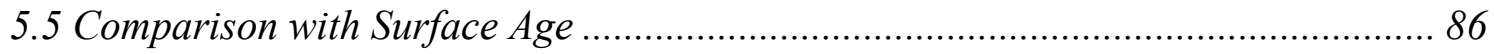

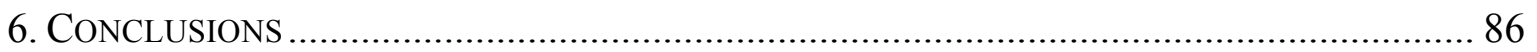

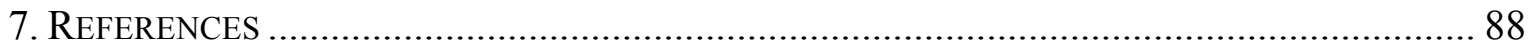

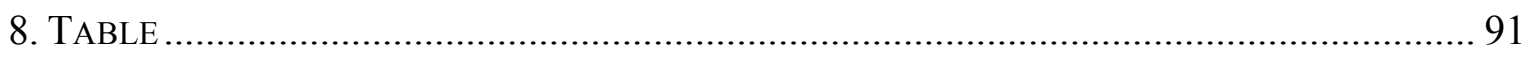

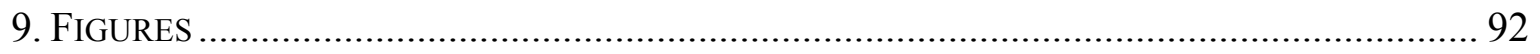

10. Appendix A: Calculation of Flexural Admittance and Correlation ......................... 103

11. ApPENDIX B: Model Sensitivity to Flexural Parameters ......................................... 107 


\section{Acknowledgements}

An ancient Chinese proverb says, "it takes ten years to grow trees but a hundred years to rear people". Since 2009, the MIT/WHOI Joint Program has been teaching me the art of scientific research, as I grow from a student fresh out of college to an enthusiastic young scientist. My growth would not have been possible without the prodigious guidance, help, support, and encouragement from advisors, committee members, teachers, friends, and family.

First and foremost, I wish to thank my thesis advisor, Jian Lin. It has been an honor and a pleasure to work with you. Your guidance is critical for the completion of this thesis, from the most basic data analysis and numerical benchmarking, to geologic interpretation of observations, and to hand-on dissertation preparation. Your unyielding support is shown not only through research guidance with extreme patience and immense knowledge, but also through your contagious enthusiasm to solve the most important science problems in marine geodynamics. I would like to thank you for encouraging me to explore research areas that I feel most interested in, and to broaden my scientific vision through participating in research cruises and workshops. I also thank you and Kelan for welcoming me to your home with wonderful meals and introducing me to colleagues and distinguished scientists. I could not have imagined having a better advisor and mentor than you for a Ph.D. study.

I am thankful to Maria Zuber who introduced me to explore the field of planetary science. I thank you for co-advising Chapter 4 and as my MIT academic advisor. Your love for science and scientific insights have greatly inspired me. Your scientific leadership and effective collaboration with a large community of scientists and engineers have set an example for me in future career development.

I would like to thank my thesis committee members Mark Behn, Jeff McGuire, Brian Tucholke, and Rob Evans, and thesis defense committee chair Dan Lizarralde. Mark and Jeff have been outstanding examples of the scientists I am striving to become. Both of you have very strong quantitative analysis and numerical skills, and have the wisdom to apply these skills to scientific investigations, in seismicity or geodynamics. I have learnt greatly from you from two inspiring classes, Computational Geophysical Modeling and Oceanic Faulting and Earthquakes. I thank Jeff for offering me a research cruise opportunity to deploy arrays of ocean bottom seismometers during the Cascadia Initiative 2012 Leg 6 OC-1209A. I thank Mark for organizing the weekly Geophysics/Geochemistry seminar at WHOI, which provided me the opportunity to learn about a wide range of research topics. Brian has been an indispensable advising colleague. Thank you for bringing tremendous marine geological insights into my geodynamical models. I thank Rob for continuous strong encouragement on my research and scientific progress. I am grateful to Dan who agreed to chair the thesis defense. I have learnt the basics of marine geophysics from your class, Introduction to Geology and Geophysics, which laid the ground for research of this thesis.

The WHOI scientific community is extremely supportive, inspiring and encouraging. I thank Ikuko Wada, Matt Wei, Carl Bowin, Jean-Arthur L. Olive, Yajing Liu, Hongfeng Yang, and Zhiyuan Zhou for many enlightening discussions pertinent to this thesis. Special thanks go to Nathan Miller and Shane McGary for detailed comments that improved the revision of Chapter 2. I would like to thank visiting scholar and student friends, including Jasmine Zhu, Tingting Wang, 
Tao Zhang, Fan Zhang, Jianmin Lin, and Songtang Liu for inspiring discussions and friendship. I also appreciate members of the WHOI geophysics and geochemistry seminar group for sharing enthusiastic research interests, including among others, Rob Sohn, Henry Dick, Juan Pablo Canales, Xiaowei Chen, Nan Zhang, Min Xu, Greg Horning, and Helen Feng. I thank my officemates and neighbors at MIT for their supports, and especially thank Peter James, Junlun Li, and Haoyue Wang for many discussions.

I would like to acknowledge the support of the MIT/WHOI Joint Program Academic Program Office (APO) and the Joint Committee of Marine Geology and Geophysics (JCMGG). I am thankful to the current chair of JCMGG, Tim Grove, as well as the APO friends, Valarie Caron, Julia Westwater, Leanora Fraser, and Christine Charette. I thank my WHOI neighbor, Andrew Daly, for organization of Geodynamics Seminars, International Buffets, and other activities. I also appreciate the help of Tim Barber at the WHOI Computer Information and Services Helpdesk for helping to solve my computer and software problems.

My appreciation also goes to other friends who share times of happiness and difficulty with me. I thank Chen Gu, Ping Zhai, Ru Chen, Wen Shen, Yan Zhao, and other fellow students at MIT, and Jiangxi Laoxiangs in Boston for having lots of fun and meals together. I thank Ruixin Huang and Lvping for years of support and friendship. My thanks also go to many other friends at the MIT Chinese Student and Scholars Association and in the WHOI Chinese community. I am grateful to the Upper Cape Toastmasters group for teaching me how to give presentations, especially my mentor, Marilyn Hill, for all her support and encouragement.

Finally I owe my deep gratitude to my family. My parents, Jintao Ding and Ying Cheng, encouraged me to follow my own enthusiasm and go abroad for Ph.D. study. My father told me not to pursue quick success and instant benefits and always keep calm in times of difficulty. His wisdom proves to be helpful in the years leading to the completion of this dissertation. My grandparents are also very supportive, as well as my uncles, aunts and cousins who take care of my parents when I am in the U.S. Without their continuous support and help, I would not be able to come to the U.S. and accomplish this thesis. 


\section{Biography}

\section{Min Ding}

Education

2009-Present MIT/WHOI Joint Program, Ph.D. Geology \& Geophysics

2005-2009 U. of Science and Tech. of China, B.S. Geophysics (Major), Finance (Minor)

\section{Publications and Conference Abstracts}

Science Chapter 1: Post-seismic viscoelastic deformation and stress transfer after the 1960 M9.5 Valdivia, Chile earthquake: Effects on the 2010 M8.8 Maule, Chile earthquake

- Ding, M., and J. Lin, Post-seismic viscoelastic deformation and stress transfer after the 1960 M9.5 Valdivia, Chile earthquake: Effects on the 2010 M8.8 Maule, Chile earthquake, Geophys. J. Int., doi:10.1093/gji/ggu048, 2014.

- Ding, M., and J. Lin, Post-seismic deformation and stress changes following the 1960 M9.5 Valdivia Chile earthquake: Implications for its relationship with the 2010 M8.8 Offshore Bio-Bio, Chile earthquake, Deep-Sea Research and Earth System Science Symposium, Shanghai, China, July 2012

- Ding, M., and J. Lin, Post-seismic deformation following the 1960 M9.5 Chile earthquake: Interpretations by visco-elastic processes, AGU Fall Meeting, San Francisco, CA, Dec. 2011

- Ding, M., and J. Lin, Post-seismic viscoelastic stress changes following the1960 M9.5 Chile earthquake: Implications for its relationship with the 2010 M8.8 Chile earthquake, AGU Fall Meeting, San Francisco, CA, Dec. 2010

Science Chapter 2: Elastoplastic deformation and faulting in the overriding plate caused by a subducted seamount

- Ding, M., and J. Lin, Elastoplastic deformation and faulting in the overriding plate caused by a subducted seamount, manuscript for submission to Geophys. Res. Lett.

- Ding, M., and J. Lin, Elastoplastic deformation in a wedge-shaped plate caused by a subducting seamount, Proceedings of the 2012 COMSOL Conference, Boston, MA, Oct. 2012.

- Ding, M., and J. Lin, Elatoplastic deformation in the overriding plate caused by a subducted seamount, AGU Fall Meeting, San Francisco, CA, Dec. 2012

Science Chapter 3: Variations in lithospheric strength and sub-surface loading on Mars

- Ding, M., J. Lin, and M. T. Zuber, Variations in lithospheric strength and sub-surface loading on Mars, manuscript for submission to J. Geophys. Res.: Planets.

- Ding, M., J. Lin, and M. T. Zuber, Variations in crustal structure, lithospheric flexural strength, and isostatic compensation mechanisms of Mars, AGU Fall Meeting, San Francisco, CA, Dec. 2014.

- Lin, J., and M. Ding, Crustal structure of the terrestrial planets and the moon from gravity and topography models, Deep-Sea Research and Earth System Science Symposium, Shanghai, China, July 2012

\section{Awards and Honors}

- Deep Ocean Exploration Institute (DOEI) Graduate Student Fellowship, WHOI, 2012

- Student Research Funds, WHOI Coastal Ocean Institute, for field research in Chile, 2011

- Outstanding Student Scholarship, U. of Science-Tech. of China, 2006, 2008

- Zhao Jiuzhang Scholarship, U. of Science-Tech. of China, 2007

- Outstanding Freshman Scholarship, U. of Science-Tech. of China, 2005

\section{Research Cruises}

- Cascadia Initiative 2012 Leg 6 OC-1209A, Deployment of Ocean Bottom Seismometer Arrays, R/V Oceanus, 1020 Sept. 2012 
- WHOI/MIT Joint Program Orientation Cruise, SSV Corwith Cramer, 25 June-4 July 2009

Workshops

- The Science of Predicting and Understanding Tsunamis, Storm Surges and Tidal Phenomena, Sponsored by PanAmerican Advanced Studies Institute, Valparaiso, Chile, Jan. 2013

- Crustal Deformation Modeling Workshop, Sponsored by Computational Infrastructure for Geodynamics, Golden, CO, June 2012

- Evolution and Dynamics of Oceanic Lithosphere Summer Course, Sponsored by Integrated Ocean Drilling Program-China, Shanghai, China, Aug. 2010

\section{Field Trips and Camps}

- Shell Drilling and Production Camp, New Orleans, 12-17 May 2013

- Gravity: A Dominant Force in the Universe, WHOI Geodynamics Program field trip, Big Island of Hawaii, 11-20 July 2012

- Crust: Planetary, Continental and Oceanic, WHOI Geodynamics Program field trip, Swiss and Italian Alps, 31 May-8 June 2010

\section{Computational Skills}

- Programing Languages: C, Fortran 77 and 95, Matlab, Unix Shell

- Softwares: COMSOL, ANSYS, PyLith, GMT, SAC, Adobe Illustrator, Adobe InDesign, Adobe Dreamweaver, Google SketchUp, Oracle 9i SQL, Mathematica, Origin, Microsoft Office

\section{MIT/WHOI Courses Taken}

\section{Geophysics:}

- 12.521 Computational Geophysical Modeling (Unit 9), Spring 2011, Lin, Behn, and Marchal

- 12.510 Introduction to Seismology (Unit 12), Spring 2010, van der Hilst

- 12.520 Geodynamics (Unit 12), Fall 2009, Hager

-12.752 Oceanic Faulting and Earthquakes (Unit 6), Fall 2010, McGuire, Lin, and Liu

- 12.753 Mechanisms of Faulting and Earthquakes (Unit 6), Spring 2010, Lin, McGuire, and Liu

\section{Data Analysis:}

- 12.714 Computational Data Analysis (Unit 12), Spring 2010, Chave and Herring

\section{Geochemistry:}

- 12.759 Marine Geochemistry Seminar (Unit 6), Spring 2011, Grove and Stanley

- 12.749 Solid Earth Geochemistry (audited), Fall 2010, Gaetani and Shimizu

- HAA.5940 Marine Petrology and Geochemistry (Harvard, audited), Spring 2012, Langmuir

Geology:

- 12.710 Marine Geology \& Geophysics I (Unit 12), Behn, Lizarralde, Shaw, and Ashton 


\section{Chapter 1: Introduction}

The elastic lithosphere is the outermost layer of a terrestrial planet. The lithosphere supports the overlying massive landform and loading and shields the heat from the planetary interior. The brittle lithosphere is also where destructive earthquakes are generated, and most of the largest earthquakes occur at the convergence plate boundaries (Figure 1). The purpose of my thesis is to better understand lithospheric dynamics on multiple time scales through focused investigations of Earth's subduction zones and Martian tectonic provinces.

In the Chile subduction zone off South America, the 2010 M8.8 Maule earthquake struck immediately to the north of the 1960 M9.5 Valdivia earthquake (see Chapter 2, Figure 2). Previous investigations have suggested that the elastic lithosphere has transferred the co-seismic stress of the 1960 earthquake to the future rupture region of the 2010 main shock. However, the immediate elastic response can not explain a time lag of five decades between the two neighboring great quakes. In Chapter 2, I propose that the time-dependent post-seismic processes could explain the observed time lag. Using multiple types of geodetic data, I analyze the postseismic viscoelastic relaxation of the asthenosphere following the 1960 quake (Figure 2c). Stress is calculated to have accumulated through time on the 2010 rupture plane, therefore might have contributed to the triggering of the 2010 rupture. Post-1960 afterslip (Figure 2d) might also play a role in stressing the 2010 rupture zone.

While earthquake deformation and post-seismic creep occur on time scales of minutes to tens of years (Figure 2), formation of major tectonic faults could take thousands to millions of years. Heterogeneity in the topography and physical properties of a subducting plate, e.g., a subducting seamount (see Chapter 3, Figure 1a), could lead to regional and local stress accumulation and lithospheric deformation near subduction zones. Marine geophysical studies have revealed more 
than 100,000 seamounts in the global ocean basins [Sandwell et al., 2014]. When these seamounts are carried to the subduction zones and interact with the overriding plate, they will cause a significant stress perturbation in the overriding plate, leading to complex fault systems. In Chapter 3, I conduct numerical simulations to investigate the elastoplastic deformation and fault formation caused by the movement of a subducted seamount. Results show that a group of normal faults would first form on the seaward side of the seamount, followed by a group of thrust faults on the landward side of the seamount, thus generating significant topographic uplift and subsidence as well as earthquakes. The buried seamounts and the associated complex fault systems might act as either asperities or barriers (Figure 3), and thus trigger or delay megathrust earthquakes.

A diverse types of landforms have been observed on the surface of the planet Mars, including polar caps, plains, volcanoes, rift valley system, and impact basins (see Chapter 4, Figure 1a). Investigations of the lithospheric flexure in response to various types of regional tectonic loading (Figure 4) can provide important insight into the lithospheric dynamics of this neighboring terrestrial planet. In Chapter 4, I use the most recent Martian gravity and topography observations to investigate the lithospheric flexure in 20 tectonic sub-regions of Mars. The effective lithospheric thickness is estimated to be relatively small for the plain regions in the southern highland, but relatively large for the impact basins in the northern lowland as well as for volcanic montes in the Tharis province. The regional variations in the estimated effective lithospheric thickness might reflect both spatial and temporal changes in the thermal state of Mars.

In sum, the lithosphere reflects the thermal state of terrestrial planets and reveals the dynamic processes of outermost layers of the planets. By combining the state-of-the-art numerical 
modeling approaches with analysis of multiple observations, this thesis helps to better understand the lithospheric dynamics of both Earth and Mars.

\section{References}

Bird, P. (2003) An updated digital model of plate boundaries, Geochem. Geophys Geosys., 4, 1027, doi:10.1029/2001GC000252.

Lay, T., and S. Bilek (2007), Anomalous earthquake ruptures at shallow depths on subduction zone megathrusts, in The Seismogenic Zone of Subduction Thrust Faults, edited by T. Dixon and C. Moore, pp. 476-511, Columbia University Press.

Sandwell, D. T., R. D. Müller, W. H. F. Smith, E. Garcia, and R. Francis (2014), New global marine gravity model from CryoSat-2 and Jason-1 reveals buried tectonic structure, Science, 346, 65-67, doi:10.1126/science.1258213. 
Figures

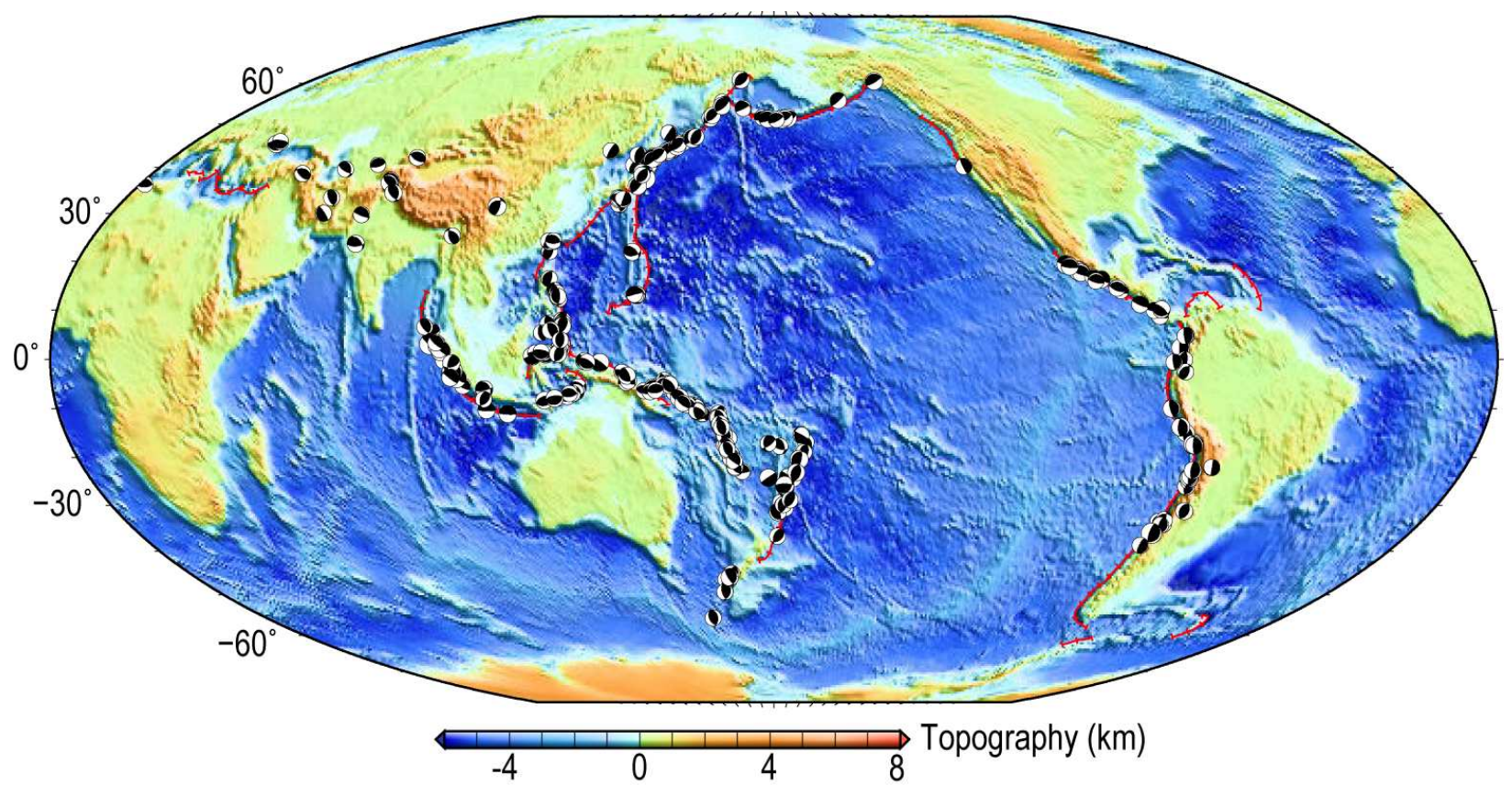

Figure 1. Global distribution of thrust earthquakes (black circles) with magnitude greater than 7 after 1976. Red lines indicate trench locations [Bird, 2003]. 

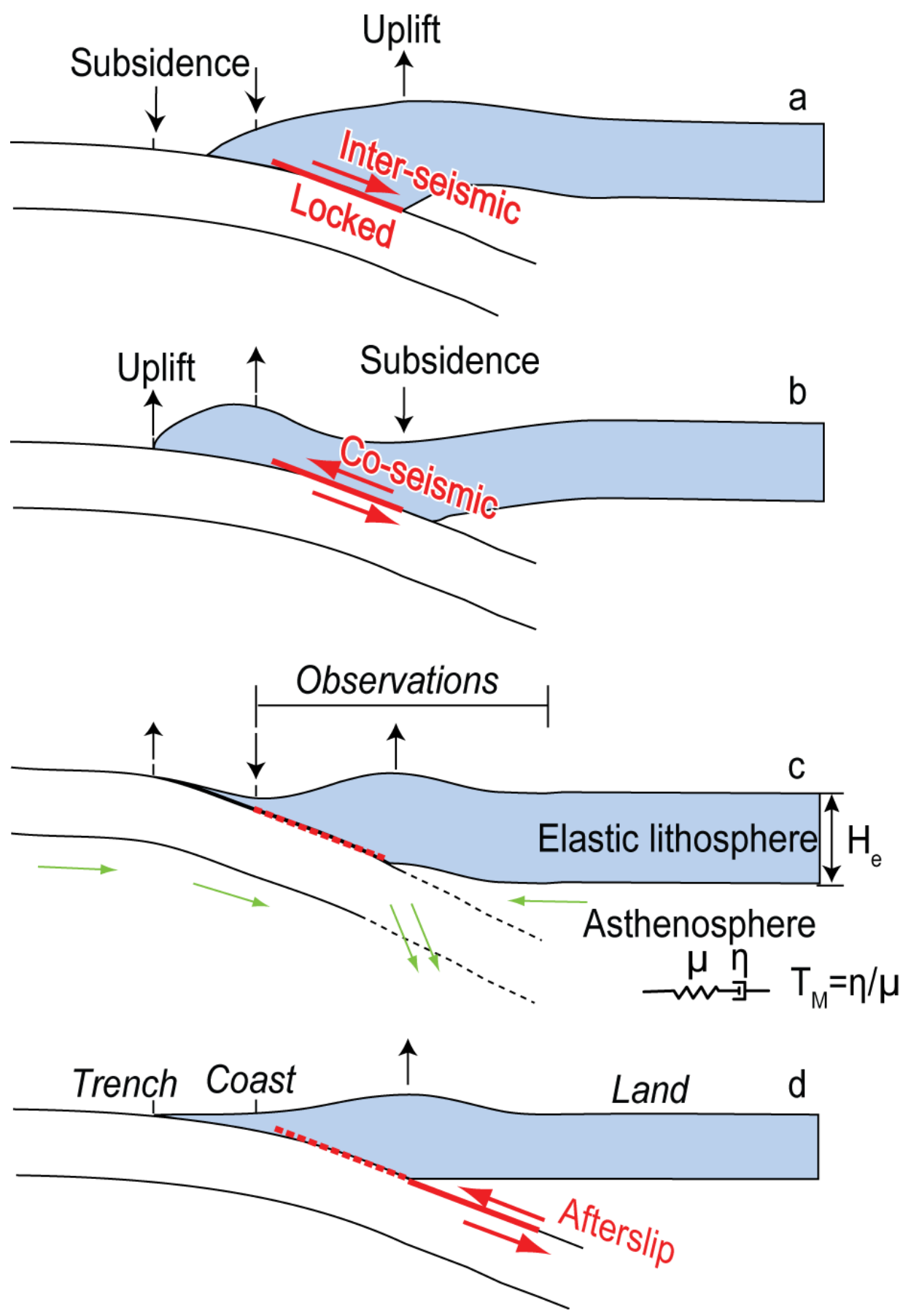

Figure 2. Four primary processes within a megathrust earthquake cycle on a subduction interface. (a) The fault is locked and tectonic stress is accumulated within the inter-seismic time period of $10 \mathrm{~s}$ to $100 \mathrm{~s}$ of years. (b) Accumulated stress is released co-seismically when a magathrust event ruptures on time scales of seconds to minutes. (c) After the megathrust earthquake, viscoelastic relaxation of the asthenosphere continues loading the overlying lithosphere on time scales of 10 s to 1000 s of years. (d) Aseismic aftership on the subduction interface might also occur within years after the intial megathrust earthquake. 


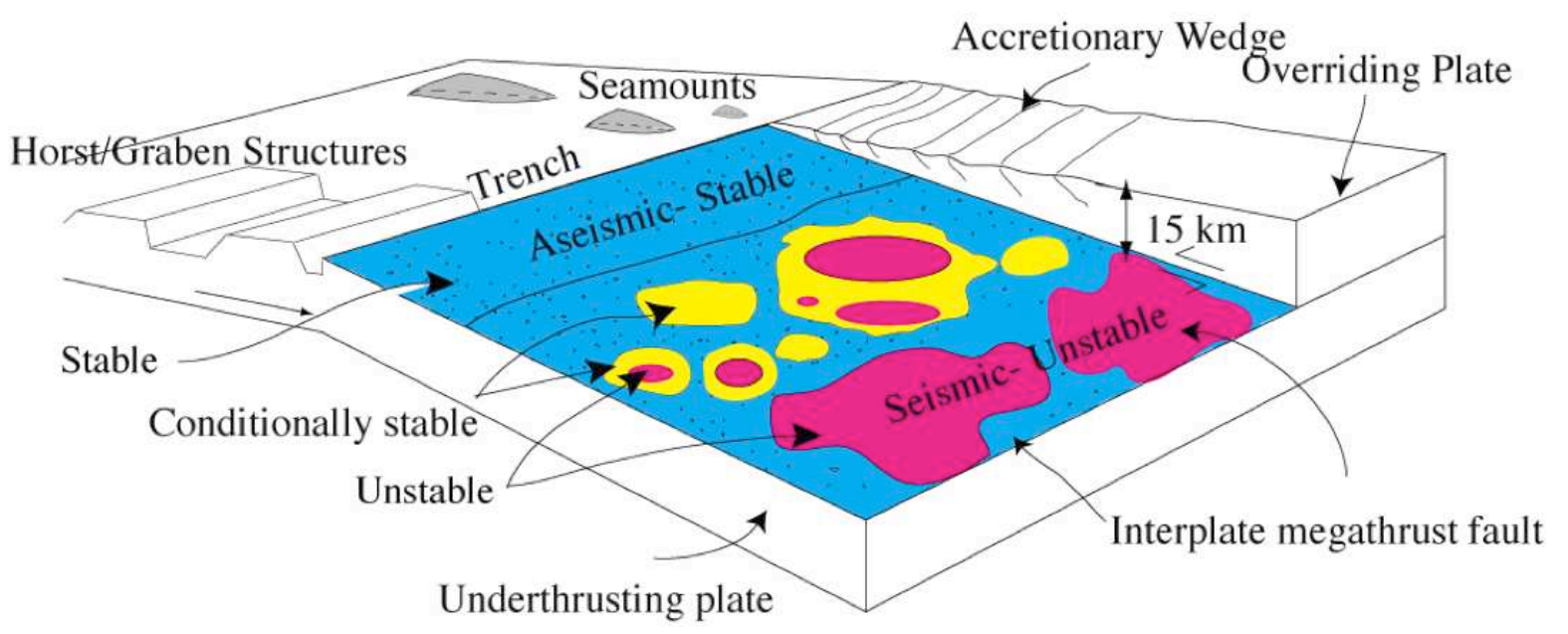

Figure 3. Subducted seamounts might act as either asperities (seismically unstable patches, red) or barriers (seismically stable patches, blue) for megathrust earthquakes, modified after Lay and Bilek [2007]. 


\section{a. Plain}
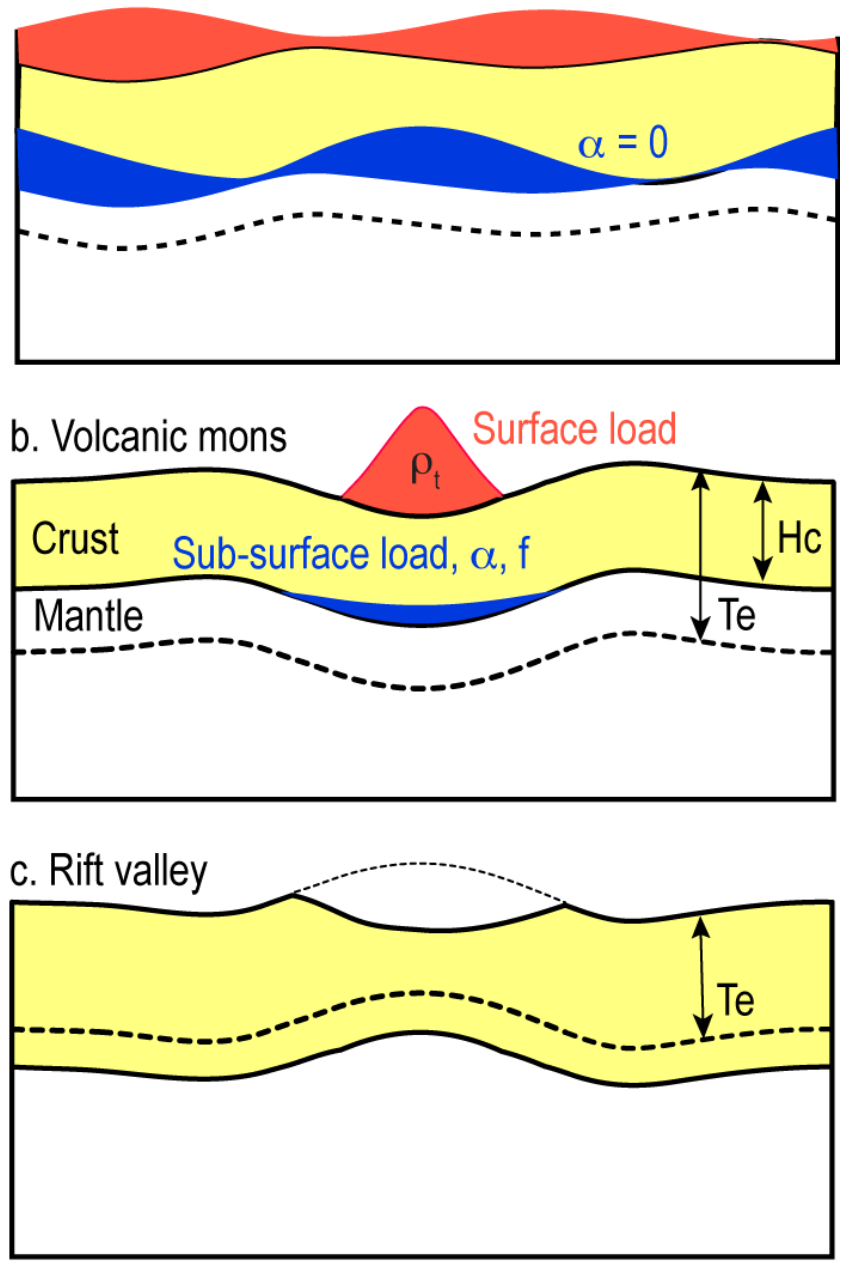

d. Impact crater

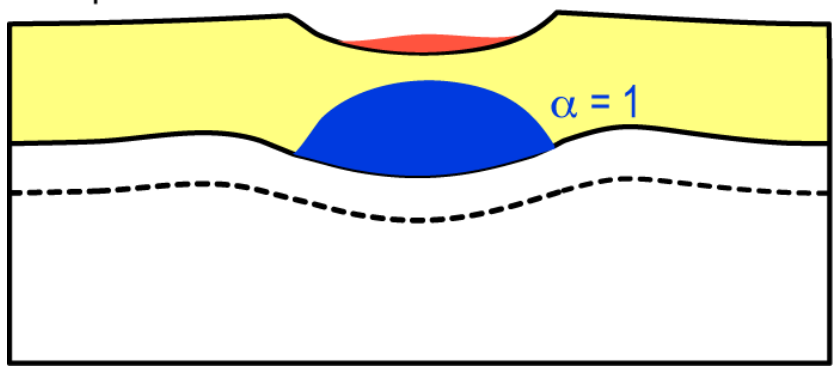

Figure 4. Loading modes and lithospheric flexure for different tectonic terrains on Mars. Red, blue, and yellow colors indicate the surface loading, sub-surface loading, and crust, respectively. Dashed lines indicate the bottom of the deformed lithosphere with a thickness Te. (a) For plain regions, surface and sub-surface loads are assumed to be uncorrelated. (b) For volcanic mons, the sub-surface loading from the intruded dense material might be correlated with surface volcanic loads. (c) For rift valley, topographic depression from rifting results in negative surface loading. (d) For impact craters, surface sediment/mare basalt might be in phase with the sub-surface mascon, while the topography subsidence caused by impact excavation might be out of phase with the sub-surface mascon. 


\title{
Chapter 2: Post-seismic Viscoelastic Deformation and Stress Transfer After the 1960 M9.5 Valdivia, Chile Earthquake: Effects on the 2010 M8.8 Maule, Chile Earthquake ${ }^{1}$
}

\begin{abstract}
After the 1960 M9.5 Valdivia, Chile earthquake, three types of geodetic observations were made during four time periods at nearby locations. These post-seismic observations were previously explained by post-seismic afterslip on the down-dip extension of the 1960 rupture plane. In this study, we demonstrate that the post-seismic observations can be explained alternatively by volumetric viscoelastic relaxation of the asthenosphere mantle. In searching for the best-fitting viscosity model, we invert for two variables, the thickness of the elastic lithosphere, $\mathrm{H}_{\mathrm{e}}$, and the effective Maxwell decay time of the asthenosphere mantle, $\mathrm{T}_{\mathrm{M}}$, assuming a 100-km-thick asthenosphere mantle. The best solutions to fit the observations in four sequential time periods, 1960-1964, 1960-1968, 1965-1973, and 1980-2010, each yield a similar $\mathrm{H}_{\mathrm{e}}$ value of about $65 \mathrm{~km}$ but significantly increasing $\mathrm{T}_{\mathrm{M}}$ values of $0.7,6,10$, and $80 \mathrm{yrs}$, respectively. We calculate the corresponding viscoelastic Coulomb stress increase since 1960 on the future rupture plane of the 2010 M8.8 Maule, Chile earthquake. The calculated viscoelastic stress increase on the 2010 rupture plane varies gradually from 13.1 bars at the southern end to 0.1 bars at the northern end. In contrast, the stress increase caused by an afterslip model has a similar spatial distribution but slightly smaller values of $0.1-3.2$ bars on the 2010 rupture plane.
\end{abstract}

\footnotetext{
${ }^{1}$ Originally published as: Ding, M. and J. Lin (2014), Post-seismic viscoelastic deformation and stress transfer after the 1960 M9.5 Valdivia, Chile earthquake: Effects on the 2010 M8.8 Maule, Chile earthquake, Geophys. J. Int., doi:10.1093/gji/ggu048.

Reprinted by permission from Oxford University Press.
} 


\section{Introduction}

Post-seismic deformation is frequently observed following large earthquakes, which might be associated with post-seismic afterslip and/or volumetric viscoelasic relaxation [Freed, 2005; Wang, 2007]. However, the relative importance of the different mechanisms is still an open issue, mainly because the spatial and temporal coverage of the post-seismic deformation observations is very limited. The world's largest earthquake ever recorded, the 1960 M9.5 Valdivia, Chile earthquake, provides a unique opportunity to investigate the post-seismic deformation and the processes that contribute to the deformation.

This study uses three types of geodetic observations collected after the 1960 Chile earthquake near the rupture zone (Figure 1). Type 1 observations are land-level changes during 1957-1964 along a leveling line in the Central Valley (triangles in Figure 1) [Plafker and Savage, 1970]. Type 2 observations are land-level changes during 1960-1968 at 155 survey sites along the Chilean coastline and Corcovado Gulf (dots in Figure 1) [Plafker and Savage, 1970]. Type 3 observations are tidal records at Puerto Montt, which is only available within two time periods, 1965-1973 (Figure 6a) and 1980-2010 (Figure 6b), on the Corcovado Gulf coast (downloadable from http://www.psmsl.org/data/obtaining).

Barrientos and Ward [1990] solved for a slip model that explains the Types 1 and 2 observations. Their inverted slip patches concentrate at two depth ranges, 0-50 km (solid lines in Figure 1) and 70-150 km (dashed lines in Figure 1). Co-seismic slip is thought to occur only within the seismogenic zone, whose lower bound has been estimated to be in the range of 48-53 $\mathrm{km}$ for the Chilean region [Tichelaar and Ruff, 1991]. Barrientos and Ward [1990] thus suggested that the upper patches $(0-50 \mathrm{~km})$ correspond to co-seismic slip, while the deeper patches $(70-150 \mathrm{~km})$ are associated with post-seismic "afterslip". In this way, Barrientos and 
Ward [1990] proposed an afterslip model, i.e., the deeper patches of their slip model (70-150 $\mathrm{km}$ ), to explain the post-seismic signals in Types 1 and 2 observations. For Type 3 observations, Barrientos et al. [1992] inverted for another afterslip model at the depth of 50-100 km.

In this study, we show that volumetric viscoelastic relaxation of the asthenosphere mantle, as opposed to the post-seismic afterslip models [Barrientos and Ward, 1990; Barrientos et al., 1992], can explain the Types 1, 2, and 3 geodetic observations equally well. We first invert for a viscosity model that can best explain the post-seismic deformation data. We then calculate the corresponding viscoelastic stress transfer onto the future rupture plane of the 2010 Maule earthquake (Figure 2), as well as stress changes associated with an afterslip model.

\section{Post-1960 Viscoelastic Deformation}

\subsection{Post-1960 Observations}

The Type 1 and 2 observations include both co-seismic and post-seismic components. We derive the post-seismic deformation by subtracting co-seismic deformation from the total observations. The co-seismic deformation is calculated as that caused by the co-seismic slip model of Barrientos and Ward [1990] (upper patches, 0-50 km) using the Coulomb 3.3 software (http://earthquake.usgs.gov/research/modeling/coulomb/) [Lin and Stein, 2004; Toda et al., 2005]. We then assume that the remaining signals in the Type 1 and 2 data are caused by volumetric viscoelastic relaxation after the 1960 earthquake. The regions of inferred positive post-seismic deformation are located about 100-300 km away from the Chile trench axis (Figure 4b), in the Central Valley for the Type 1 sites and Corcovado Gulf for the Type 2 sites (Figure 1). Because the Type 1 and 2 observations were obtained in 1957-1964 and 1960-1968 [Plafker and Savage, 1970], we interpret the inferred post-seismic deformation to occur within 1960-1964 and 1960-1968, respectively. 
For Type 3 observations, we use the tidal records at the Puerto Montt station in the time periods of 1965-1973 and 1980-1988 from Barrientos et al. [1992] as well as 1988-2010 from the PSMSL website (http://www.psmsl.org/data/obtaining). Linear regression yields uplift rates of $4.5 \mathrm{~cm} / \mathrm{yr}$ in 1965-1973 (Period a, Figure 6a) and $0.8 \mathrm{~cm} / \mathrm{yr}$ in 1980-2010 (Period b, Figure 6b).

\subsection{Model Set-up}

We calculate the volumetric viscoelastic deformation on a layered spherical Earth using the VISCO1D code of Pollitz [1992] (http://earthquake.usgs.gov/research/software/\#VISCO1D). In this code, a co-seismic slip model and a series of Earth viscosity models are specified. The coseismic slip model is assumed to be the same as the upper slip patches of Barrientos and Ward [1990] for the 1960 earthquake (solid contours in Figure 1). We define a three-layered Earth viscosity model that includes a low-viscosity asthenosphere mantle layer with a Maxwell rheology. The asthenosphere mantle layer is sandwiched between overlying elastic lithosphere and underlying lower mantle, both of which are of high viscosities (Table 1). The shear modulus and densities of the lithosphere and asthenosphere are based on the Preliminary Reference Earth Model (PREM) [Dziewonshi and Anderson, 1981], increasing with depth from $2.49 \times 10^{10}$ to $6.82 \times 10^{10} \mathrm{~Pa}$ and $2.6 \times 10^{3}$ to $3.44 \times 10^{3} \mathrm{~kg} / \mathrm{m}^{3}$, respectively. Other physical parameters in our models are listed in Table 1. We invert for two variables: the thickness of the elastic lithosphere, $\mathrm{H}_{\mathrm{e}}$, and the effective Maxwell decay time of the asthenospheric mantle, $\mathrm{T}_{\mathrm{M}}$. We hold the thickness of the asthenospheric mantle, $\mathrm{H}_{\mathrm{a}}$, fixed at $100 \mathrm{~km}$. We define $\mathrm{T}_{\mathrm{M}}$ as $2 \eta_{\boldsymbol{a}} / \mu_{\boldsymbol{a}}$, where $\eta_{\boldsymbol{a}}$ and $\mu_{a}$, are the viscosity and shear modulus of the asthenospheric mantle, respectively (Table 1).

\subsection{Best-fitting Viscosity Models}

We search for viscosity models that minimize the root-mean-square (RMS) misfits between viscoelasic relaxation models and post-seismic observations. Four best-fitting solutions for the 
post-seismic observations in Type 1, Type 2, and Type 3 (Periods a and b), are searched within the variable domain of $\mathrm{H}_{\mathrm{e}}$ between 50 and $80 \mathrm{~km}$ and $\mathrm{T}_{\mathrm{M}}$ between 0.3 and $640 \mathrm{yrs}$.

The best-fitting solution for the Type 1 post-seismic observations is $\mathrm{H}_{\mathrm{e}}=65 \mathrm{~km}$ and $\mathrm{T}_{\mathrm{M}}=0.7$ yrs with a RMS misfit of $0.25 \mathrm{~m}$ (Solution 1, Figure 3a). It is slightly smaller than the $0.35 \mathrm{~m}$ RMS misfit that we calculate for the afterslip model of Barrientos and Ward [1990]. The observation error for Type 1 data is $0.1 \mathrm{~m}$ [Plafker and Savage, 1970]. We define an acceptable range for $\mathrm{T}_{\mathrm{M}}$ values, 0.4 to $1.8 \mathrm{yrs}$, with RMS misfits of less than $0.4 \mathrm{~m}$ (horizontal error bar in Figure 3a). The best-fitting solution for the Type 2 post-seismic observations corresponds to $\mathrm{H}_{\mathrm{e}}=$ $67 \mathrm{~km}$ and $\mathrm{T}_{\mathrm{M}}=6 \mathrm{yrs}$ with a RMS misfit of $0.67 \mathrm{~m}$ (Solution 2, Figure $3 \mathrm{~b}$ ), similar to the $0.68 \mathrm{~m}$ RMS misfit for the afterslip model of Barrientos and Ward [1990]. The observation error for Type 2 data is $0.34 \mathrm{~m}$ [Plafker and Savage, 1970]. An acceptable range for $\mathrm{T}_{\mathrm{M}}$ values defined by RMS misfits of less than $0.7 \mathrm{~m}$ is between 2.9 and 14 yrs (horizontal error bar in Figure $3 \mathrm{~b}$ ). Figures $4 \mathrm{a}$ and $\mathrm{b}$ compare the best-fitting viscoelastic solutions, afterslip model, and corresponding observations for Types 1 and 2 data, respectively.

Best-fitting solutions for the Type 3 tidal records yield larger best-fitting $\mathrm{T}_{\mathrm{M}}$ values. The best-fitting $\mathrm{T}_{\mathrm{M}}$ values are $10 \mathrm{yrs}$ for Period a (Solution 3, Figure 5a) and 80 yrs for Period b (Solution 4, Figure $5 b$ ). We also define acceptable ranges of $T_{M}$ values, 1.8-40 yrs (horizontal error bar in Figure 5a) and 14-450 yrs (horizontal error bar in Figure 5b), for Periods a and b, respectively. However, Type 3 data do not provide a strong constraint for $\mathrm{H}_{\mathrm{e}}$ values (Figures 5a and $\mathrm{b}$ ). Figures $6 \mathrm{a}$ and $\mathrm{b}$ compare the best-fitting solutions with the monthly tidal records for Periods a and b, respectively.

The variations in the best-fitting $\mathrm{T}_{\mathrm{M}}$ values can be described by an empirical double exponential function: 


$$
\log \left[T_{M}(t) / 1 y r\right]=A\left[1-e^{(t-t o) / \tau}\right]
$$

where $t$ is the time since the 1960 earthquake. Regression analysis yields $\mathrm{A}=1.9, \mathrm{t}_{0}=2.0 \mathrm{yrs}$, and $\tau=10.5 \mathrm{yrs}$ (dashed line in Figure 7). Similar regression processes for the acceptable $\mathrm{T}_{\mathrm{M}}$ ranges yield $\mathrm{A}=2.7, \mathrm{t}_{0}=0.8 \mathrm{yrs}$, and $\tau=7.8 \mathrm{yrs}$ for the upper bound, and $\mathrm{A}=1.3, \mathrm{t}_{0}=5.9 \mathrm{yrs}$, and $\tau=14.8$ yrs for the lower bound (within in the gray region in Figure 7).

The four best-fitting $\mathrm{T}_{\mathrm{M}}$ values correspond to viscosities of $2 \times 10^{18}, 2 \times 10^{19}, 3 \times 10^{19}$, and $2 \times 10^{20} \mathrm{~Pa} \cdot \mathrm{s}$, assuming an asthenospheric shear modulus of $\mu_{a}=6.7 \times 10^{10} \mathrm{~Pa}$ (Table 1). The range of our best-fitting $\mathrm{T}_{\mathrm{M}}$ values between 5 and 70 yrs for the time period of 1965-1988 (dashed line in Figure 7) is consistent with the result of Piersanti [1999]. The lower bound of our acceptable range of $\mathrm{T}_{\mathrm{M}}$ values of 14 yrs for the time period of 1993-2005 (gray region in Figure 7) is similar to the result based on GPS observations [Hu et al., 2004] (Figure 7). The timedependent reduction in the $\mathrm{T}_{\mathrm{M}}$ and viscosity values might reflect either a non-linear stressdependent rheology [Freed and Burgmann, 2004; Freed et al., 2006] or a biviscous Burgers rheology of the asthenosphere [Pollitz, 2003; Hetland and Hager, 2006].

\section{Post-1960 Stress Transfer}

\subsection{Coulomb Stress Change}

For the viscosity structure that best explains the post-seismic deformation, we calculate the Coulomb stress changes on the 1960 and 2010 rupture planes caused by the viscoelastic process. The Coulomb stress change on a receiver fault is defined as:

$$
\Delta C F F=\Delta \tau+\mu \Delta \sigma
$$

where $\Delta \tau$ is the shear stress change resolved on the receiver fault (positive in the slip direction), $\Delta \sigma$ is the normal stress change on the receiver fault (positive when the fault is unclamped), and $\mu$ is the apparent friction coefficient after accounting for pore pressure, which is assumed to be 
0.4 [e.g. King et al., 1994]. We calculate the stress changes caused by viscoelastic relaxation using the VISCO1D code. We assume the strike, dip, and rake angles for the receiver fault of the 2010 earthquake to be $10^{\circ}, 20^{\circ}$, and $90^{\circ}$ [Lorito et al., 2011], and for the 1960 earthquake to be $7^{\circ}, 20^{\circ}$, and $105^{\circ}$ [Barrientos and Ward, 1992].

\subsection{Post-1960 Stress Transfer}

We first calculate the viscoelastic stress changes on the fault planes of the 1960 and 2010 earthquakes. Viscoelastic deformation and stress changes scale with $T_{M}$ [Hetland and Hager, 2006], so we calculate stress changes at various locations (i.e. Locations 1, 2, and 3 in Figure 8c) as a function of the scaled time, $t / T_{M}$, where $t$ is the time since the occurrence of the 1960 earthquake (Figure 9a). Since the effective $T_{M}$ increases with time (Figure 7), we define averaged $\mathrm{T}_{\mathrm{M}}$ values, $\tilde{T}_{M}(t)$, by solving the equation $t / \tilde{T}_{M}(t)=\int_{0}^{t} 1 / T_{M}(t) d t$, where $T_{M}(t)$ is given by Equation 1. Using $\tilde{T}_{M}(t)$ instead of $\mathrm{T}_{\mathrm{M}}$, we transform the stress evolution curves in Figure $9 \mathrm{a}$ to those in Figure $9 \mathrm{~b}$. The stress changes are calculated to increase rapidly at first and then level off toward constant values after less than 10 years. Because the stress evolution depends on temporal $\mathrm{T}_{\mathrm{M}}$ functions (Equation 1), we calculate the stress changes for the bestfitting (black line), as well as the upper and lower bound $\mathrm{T}_{\mathrm{M}}$ curves (gray region in Figure $9 \mathrm{~b}$ ).

On the rupture plane of the 1960 earthquake, the region of calculated viscoelastic stress increase is surrounded by areas of negative stress changes on the eastern and western margins (Figure 8d). Regions of greater viscoelastic stress increase are located at the depth of $20-50 \mathrm{~km}$, coinciding with the largest co-seismic stress drop of the 1960 earthquake (Figure 8b). For the best-fitting $T_{M}$ values and corresponding evolution curve (dashed line in Figure 7), the maximum stress increase is about 40 bars at the depth of $\sim 30 \mathrm{~km}$. The maximum stress increase corresponding to the lower and upper bounds of the temporal $\mathrm{T}_{\mathrm{M}}$ evolution curves (gray region in 
Figure 7) is calculated to be about 30 and 45 bars, respectively. Thus the viscoelastic stress changes tend to compensate for the co-seismic stress drop on the rupture plane of the 1960 earthquake. Meanwhile, the viscoelastic stress increase corresponding to the best-fitting $T_{M}$ curve (dashed line in Figure 7) is calculated to be 13.1 bars at the southern end of the 2010 rupture plane (Location 1 in Figure 8c), gradually decreasing to 0.1 bars at the northern end (Location 3). The hypocenter of the 2010 earthquake (Location 2) is calculated to have experienced a viscoelastic stress increase of 0.5 bars. We also calculate the stress increases on the 2010 rupture plane for the lower and upper bounds of the temporal $\mathrm{T}_{\mathrm{M}}$ evolution curves (gray region in Figure 7): Location 1 (9.2 and 16.4 bars), Location 2 ( 0.3 and 0.6 bars), and Location 3 (0.04 and 0.2 bars) (gray regions in Figure $9 b$ ).

We calculate the stress changes caused by the afterslip model of Barrientos and Ward [1990] using the Coulomb 3.3 software. The afterslip also loads both the 1960 and 2010 rupture planes (Figures 8e-f). On the 1960 rupture plane, the region of greater stress increase due to afterslip is at the depth of about $60 \mathrm{~km}$ (Figure 8f), which is deeper than that for the volumetric viscoelastic relaxation model (Figure 8d). On the 2010 rupture plane, the afterslip stress increase has a similar along-strike distribution (Figure 8e) as that of volumetric viscoelastic relaxation (Figure 8c), but with a smaller maximum stress increase (Location 1) of 3.2 bars, compared with 13.1 bars for the viscoelastic relaxation. At the hypocenter of the 2010 earthquake (Location 2), the stress increase caused by the afterslip and volumetric viscoelastic relaxation is similar: 0.4 bars (Figure 8e) and 0.5 bars (Figure 8c). In comparison, the calculated co-seismic stress increase at the hypocenter of the 2010 earthquake (Location 2) caused by the 1960 earthquake is about 0.3 bars [Lin and Stein, 2004] (Figure 8a), which is of the same order of magnitude as the postseismic viscoelastic and afterslip stress increase. 


\section{Discussion}

\subsection{Uncertainties in the Type 1 and 2 Post-seismic Deformation Data}

Barrientos and Ward [1990] and our study assume that Type 1 and 2 observations contain coseismic and post-seismic deformation signals. Type 1 and 2 observations may contain other information as well. For example, Linde and Silver [1989] suggested that these observations include pre- and co-seismic signals. Moreno et al. [2009] attributed all the deformation to coseismic slip by using a curved geometry rather than a plane fault. Despite alternative interpretations for the Type 1 and 2 observations, our study shows that the post-seismic deformation, which was previously interpreted as from the afterslip model of Barrientos and Ward [1990], could be equally well explained by the volumetric viscoelastic relaxation of the asthenosphere mantle.

\subsection{Viscoelastic Relaxation versus Afterslip}

Our results show that the volumetric viscoelastic relaxation and afterslip could equally explain the geodetic observations in the distance of about 70-370 $\mathrm{km}$ away from the Chile trench axis (Figure 4b). Data that could possibly distinguish the two post-seismic mechanisms include: (1) near-trench sea-floor observations [e.g. Newmann, 2011], (2) long-term geodetic observations, or (3) high-density horizontal deformation observations. Our calculations show that the predicted deformation between the volumetric viscoelastic and afterslip models is similar at the distance of more than $70 \mathrm{~km}$ from the trench axis, but is different near the Chile trench axis (Figure 4b). If future sea-floor deformation observations are collected, the afterslip and volumetric viscoelastic relaxation models could be distinguished from each other. Another method of distinction is to use long-term geodetic observations: Post-seismic viscoelastic relaxation usually continues within tens of years [Hetland and Hager, 2006], while afterslip occurs only within several years after a great earthquake [Helmstetter and Shaw, 2009]. Finally, 
Wang et al. [2007] argued that the opposing horizontal deformation directions observed at coastal and inland sites of high-density GPS surveys could be explained by post-seismic viscoelastic relaxation, but not afterslip.

\subsection{Stress Transfer versus Tectonic Loading}

The importance of stress transfer mechanisms to trigger an earthquake must be understood within the framework of the stress evolution in an entire earthquake cycle. The earthquake cycle of the 2010 M8.8 Maule, Chile earthquake could be considered to begin in 1835, when a M8.5 earthquake occurred in the same segment as the 2010 earthquake [Moreno et al., 2010]. During its earthquake cycle, the 2010 rupture plane is loaded by plate convergence due to the coupling between the subducting Nazca plate and the overriding South America plate. We estimate this secular tectonic stress using a GPS-inverted plate-coupling model with variable coupling coefficient [Moreno et al., 2010], assuming a plate convergence rate of $6.6 \mathrm{~cm} / \mathrm{yr}$ [Angermann et al., 1999]. Our calculations show that the tectonic stress increase and the 2010 co-seismic stress drop are of the similar "two-patch" spatial patterns (Figures 10a and b). The 2010 earthquake is calculated to have released a similar magnitude of stress as the stress accumulated by the secular tectonic loading in 1835-2010.

The above similarities also suggest that the 2010 rupture plane was close to failure before the occurrence of the 2010 Maule earthquake. Therefore, a relatively small amount of additional stress increase, such as that due to co- and post-seismic processes caused by the nearby 1960 earthquake, could contribute to the triggering of the 2010 earthquake.

We also estimate the residual stress after the occurrence of the 2010 earthquake by adding the $1835-2010$ tectonic and 2010 co-seismic stresses. The post-1835 tectonic stress accumulated on the slip patch to the north of the 2010 hypocenter seems to be fully released, while the 
southern patch is still associated with a certain amount of residual stresses (Figure 10c), similar to the interpretations of Moreno et al. [2010] based on slip deficit calculation.

\section{Conclusions}

Our investigation of the post-seismic deformation of the 1960 M9.5 Valdivia, Chile earthquake and the associated stress transfer yields the following results:

1. Three types of post-1960 geodetic observations during four time periods could be explained by a volumetric viscoelastic relaxation model equally well as the previous afterslip models. The observations in four sequential time periods could be explained by a consistent elastic lithosphere thickness of about $65 \mathrm{~km}$, but require a significant increase in the effective Maxwell decay times of the asthenospheric mantle.

2. The inverted effective Maxwell decay times of the asthenosphere mantle are 0.7, 6, 10, and 80 yrs to best explain the observations during the time periods of 1960-1964, 1960-1968, 19651973, and 1980-2010, respectively.

3. The rupture plane of the 2010 Maule, Chile earthquake is calculated to have experienced stress increase of 0.1-13.1 bars due to post-1960 viscoelastic relaxation, in comparison to 0.1-3.2 bars due to afterslip. These post-1960 stress increases might have contributed to the triggering of the 2010 earthquake.

Acknowledgements. We are grateful to Andrés Tassara of the University of Concepcion for help accessing the PSMSL tidal gauge data in Chile. We thank Fred Pollitz of USGS for providing the VISCO1D code and technical consultation on using the code. This study also benefitted from discussion with Mark Behn, Ikudo Wada, Nathaniel Miller, Matt Wei, Shane McGary, and the Marine Tectonics Group of WHOI, Andrew Freed of Purdue University, Sergio Barrientos of the University of Chile, and Ross Stein of USGS. This work was supported by a MIT/WHOI Joint Program Student Fellowship and a Graduate Student Fellowship from the WHOI Deep Ocean Exploration Institute (M. D.), as well as NSF Grant OCE-1141785 and a Deerbrook Foundation Award (J. L.). 


\section{References}

Angermann, D., J. Klotz, and C. Reigber (1999), Space-geodetic estimation of the NazcaSouth America Euler vector, Earth Planet. Sci. Lett., 171, 329-334, doi:10.1016/S0012821X(99)00173-9.

Barrientos, S. E., G. Plafker, and E. Lorca (1992), Postseismic coastal uplift in southern Chile, Geophys. Res. Lett., 19, 701-704, doi:10.1029/92GL00210.

Barrientos, S. E. and S. N. Ward (1990), The 1960 Chile earthquake: Inversion for slip distribution from surface deformation, Geophys. J. Int., 103, 589-598.

Beck, S., S. Barrientos, E. Kausel, and M. Reyes (1998), Source characteristics of historic earthquakes along the central Chile subduction zone, J. S. Am. Earth Sci., 11, 115-129, doi:10.1016/S0895-9811(98)00005-4.

Dziewonski, A. M., and D. L. Anderson (1981), Preliminary reference Earth model, Phys. Earth Plan. Int., 25, 297-356.

Freed, A. M. (2005), Earthquake triggering by static, dynamic, and postseismic stress transfer, Annu. Rev. Earth Plan. Sci., 33, 335-67, doi: 10.1146/annurev.earth.33.092203.122505.

Freed, A. M., and R. Bürgmann (2004), Evidence of power-law flow in the Mojave desert mantle, Nature, 430, 548-551, doi:10.1038/nature02784.

Freed, A. M., R. Bürgmann, E. Calais, and J. Freymueller (2006), Stress-dependent powerlaw flow in the upper mantle following the 2002 Denali, Alaska, earthquake, Earth Plan. Science Lett., 252, 481-489, doi:10.1016/j.eps1.2006.10.011.

Helmstetter, A., and B. E. Shaw (2007), Afterslip and aftershocks in the rate-and-state friction law, J. Geophys. Res., 114, doi: 10.1029/2007JB005077.

Hetland, E. A., and B. H. Hager (2006), The effects of rheological layering on post-seismic deformation, Geophys. J. Int., 166, 277-292, doi: 10.1111/j.1365-246X.2006.02974.x.

Hu, Y., K. Wang, J. He, J. Klotz, and G. Khazaradze (2004), Three-dimensional viscoelastic finite element model for postseismic deformation of the great 1960 Chile earthquake, J. Geophys. Res., 109, doi:10.1029/2004JB003163.

King, G. C. P., R. S. Stein, and J. Lin (1994), Static stress changes and the triggering of earthquakes, Bull. Seismol. Soc. Am., 84, 935-953.

Linde, A. T. and P. G. Silver (1989), Elevation changes and the great 1960 Chilean earthquake: Support for aseismic slip, Geophys. Res. Lett., 16, 1305-1308.

Lin, J. and R. S. Stein (2004), Stress triggering in thrust and subduction earthquakes and stress interaction between the southern San Andreas and nearby thrust and strike-slip faults, J. Geophys. Res., 109, doi:10.1029/2003JB002607. 
Lorito, S., F. Romano, S. Atzori, X. Tong, A. Avallone, J. McCloskey, M. Cocco, E. Boschi, and A. Piatanesi (2011), Limited overlap between the seismic gap and coseismic slip of the great 2010 Chile earthquake, Nature Geosci., 4, 173-177, doi:10.1038/ngeo1073.

Moreno, M., M. Rosenau, and O. Oncken (2010), 2010 Maule earthquake slip correlates with pre-seismic locking of Andean subduction zone, Nature, 467, 198-202, doi:10.1038/nature09349.

Moreno, M. S., J. Bolte, J. Klotz, and D. Melnick (2009), Impact of megathrust geometry on inversion of coseismic slip from geodetic data: Application to the 1960 Chile earthquake, Geophys. Res. Lett., 36, doi: 10.1029/2009GL039276.

Newman, A. V. (2011), Hidden depths, Nature, 474, 441-443, doi:10.1038/474441a.

Piersanti, A. (1999), Postseismic deformation in Chile: Constraints on the asthenospheric viscosity, Geophys. Res. Lett., 26, 3157-3160, doi:10.1029/1999GL005375.

Plafker, G., and J. C. Savage (1970), Mechanism of the Chilean Earthquakes of May 21 and 22, 1960, Geol. Soc. Am. Bull., 81, 1001-1030, doi:10.1130/0016-7606(1970)81.

Pollitz, F. F. (1992), Postseismic relaxation theory on the spherical earth, Bull. Seismol. Soc. Am., 82, 422 -453.

Pollitz, F. F. (2003), Transient rheology of the uppermost mantle beneath the Mojave Desert, California, Earth Planet. Sci. Lett., 215, 89-104, doi:10.1016/S0012-821X(03)00432-1.

Tichelaar, B. W., and L. J. Ruff (1991), Seismic coupling along the Chilean Subduction Zone, J. Geophys. Res., 96, 11997-12022, doi:10.1029/91JB00200.

Toda, S., R. S. Stein, K. Richards-Dinger, and S. Bozkurt (2005), Forecasting the evolution of seismicity in southern California: Animations built on earthquake stress transfer, J. Geophys. Res., 110, doi:10.1029/2004JB003415.

Wang, K. (2007). Elastic and viscoelastic models of crustal deformation in subduction earthquake cycles, in The Seismogenic Zone of Subduction Thrust Faults, eds Dixon, T. \& Moore, J. C., Columbia Univ. Press, NY.

Wang, K., Y. Hu, and J. He (2012), Deformation cycles of subduction earthquakes in a viscoelastic Earth, Nature, 484, 327-332, doi:10.1038/nature11032.

Wang, K., Y. Hu, M. Bevis, E. Kendrick, R. Smalley, R. B. Vargas, and E. Lauría (2007), Crustal motion in the zone of the 1960 Chile earthquake: Detangling earthquake-cycle deformation and forearc-sliver translation, Geochem. Geophys. Geosyst., 8, doi:10.1029/2007GC001721. 


\section{Tables}

Table 1. Parameters for Post-1960 Viscoelastic Relaxation Models

\begin{tabular}{|c|c|c|}
\hline Parameters & Description & Value \\
\hline $\mathrm{H}_{\mathrm{e}}$ & Thickness of the elastic lithosphere, $\mathrm{km}$ & $50-80$ \\
\hline$\rho_{e}$ & Range of the density of the elastic lithosphere, $\mathrm{kg} / \mathrm{m} 3$ & $2.6-3.38 \times 10^{3}$ \\
\hline$\lambda_{e}$ & Range of the Lamé's first parameter of the elastic lithosphere, Pa & $2.93-7.86 \times 10^{10}$ \\
\hline$\mu_{e}$ & Range of the shear modulus of the elastic lithosphere, $\mathrm{Pa}$ & $2.49-6.82 \times 10^{10}$ \\
\hline$\eta_{e}$ & Viscosity of the elastic lithosphere, $\mathrm{Pa} \cdot \mathrm{s}$ & $1 \times 10^{29}$ \\
\hline $\mathrm{H}_{\mathrm{a}}$ & Thickness of the asthenosphere mantle, $\mathrm{km}$ & 100 \\
\hline$\rho_{a}$ & Range of the density of the asthenosphere mantle, $\mathrm{kg} / \mathrm{m} 3$ & $3.38-3.44 \times 10^{3}$ \\
\hline$\lambda_{a}$ & Lamé's first parameter of the asthenosphere mantle, $\mathrm{Pa}$ & $7.86 \times 10^{10}$ \\
\hline$\mu_{a}$ & Shear modulus of the asthenosphere mantle, $\mathrm{Pa}$ & $6.70 \times 10^{10}$ \\
\hline$\eta_{a}$ & Viscosity of the asthenosphere mantle, $\mathrm{Pa} \cdot \mathrm{s}$ & $1 \times 10^{18}-2 \times 10^{21}$ \\
\hline $\mathrm{T}_{\mathrm{M}}$ & $\begin{array}{l}\text { Effective Maxwell decay time of the asthenosphere mantle defined as } \\
\qquad 2 \eta_{a} / \mu_{a}, \mathrm{yr}\end{array}$ & $0.31-640$ \\
\hline$\eta_{\text {lower }}$ & Viscosity of the lower mantle, $\mathrm{Pa} \cdot \mathrm{s}$ & $1 \times 10^{22}$ \\
\hline $\mathrm{s}$ & Co-seismic slip of the 1960 rupture, $\mathrm{m}$ & $0-40 \mathrm{~m}$ \\
\hline$\theta$ & Strike of the 1960 fault plane & $7^{\circ}$ \\
\hline$\delta$ & Dip of the 1960 slip model & $20^{\circ}$ \\
\hline$\lambda$ & Rake of the 1960 slip model & $105^{\circ}$ \\
\hline $\mathrm{H}_{\mathrm{s}}$ & Maximum depth of the co-seismic slip plane, $\mathrm{km}$ & 60 \\
\hline
\end{tabular}




\section{Figures}

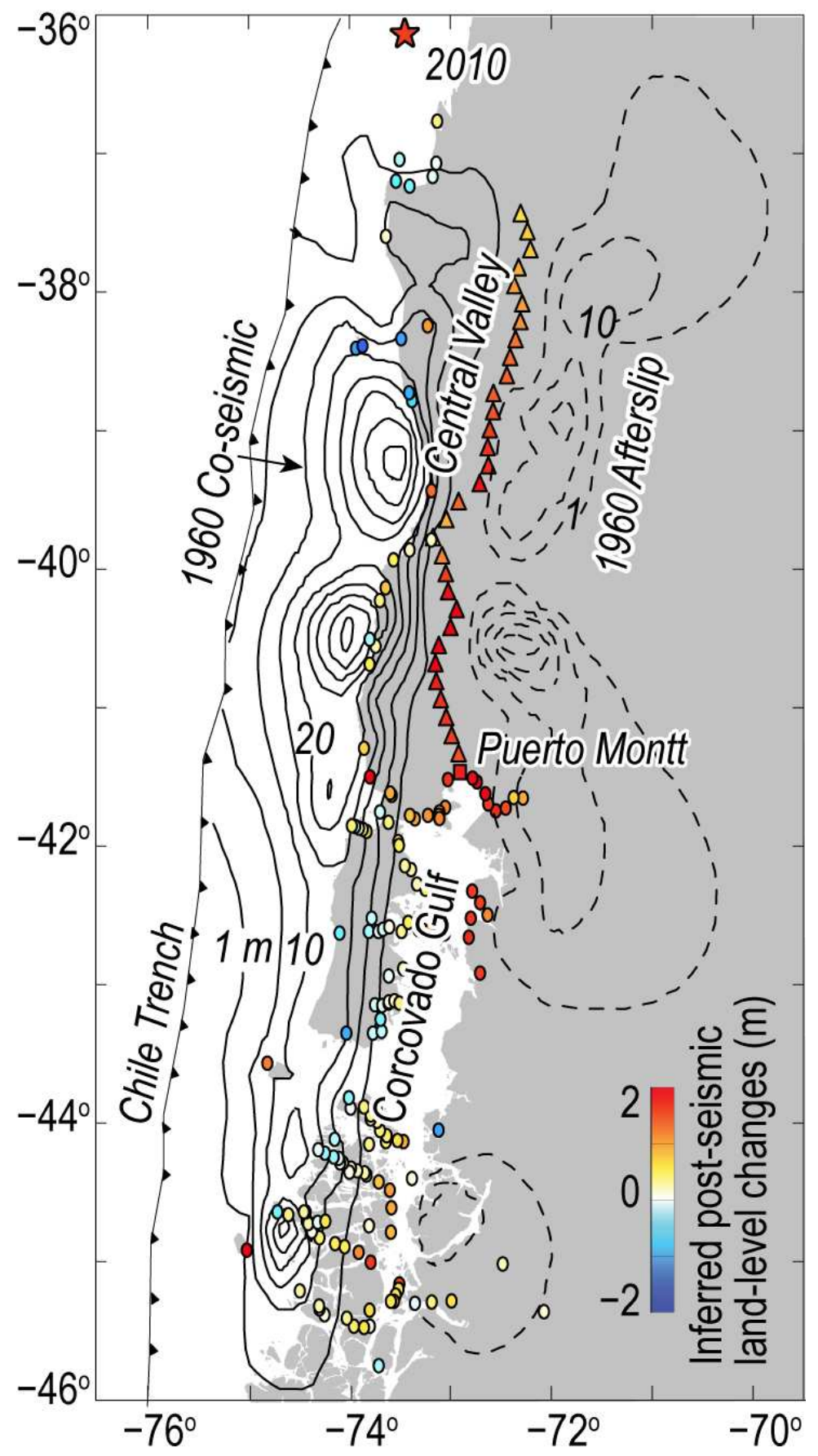

Figure 1. Locations of three types of post-1960 observations: Circles-Type 1; Triangles-Type 2; and Square-Type 3 data. Also shown are co-seismic (solid contours) and post-seismic afterslip (dashed contours) models of the 1960 Valdivia, Chile earthquake [Barrientos and Ward, 1990]. The epicenter of the 2010 Maule, Chile earthquake is marked by a red star. The colors of Types 1 and 2 sites indicate the values of inferred post-seismic land-level changes within the corresponding observation time periods. 


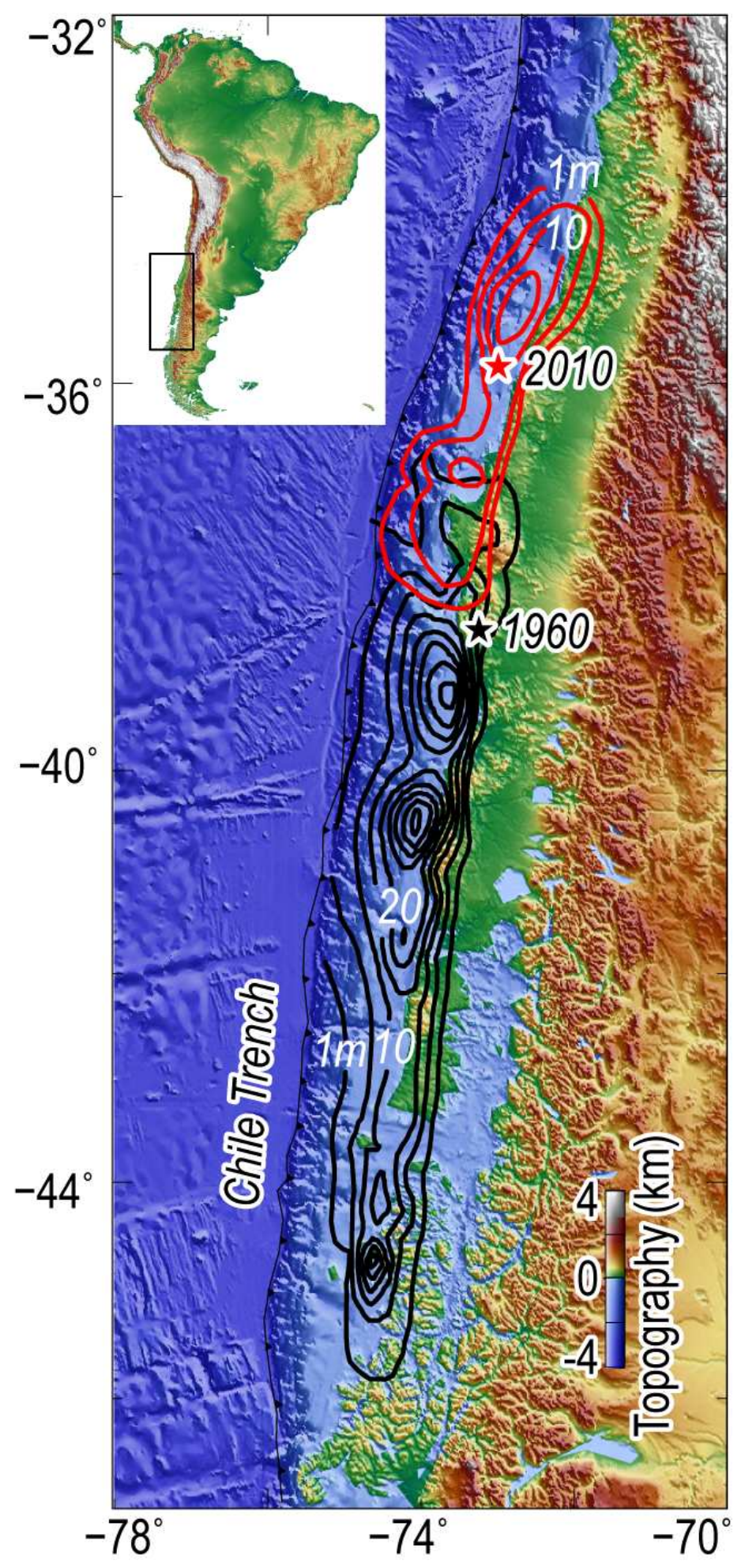

Figure 2. Map-view contours showing slip distributions of the 1960 (black) and 2010 (red) earthquakes, as well as epicenters (stars). Background is land topography and seafloor bathymetry. 

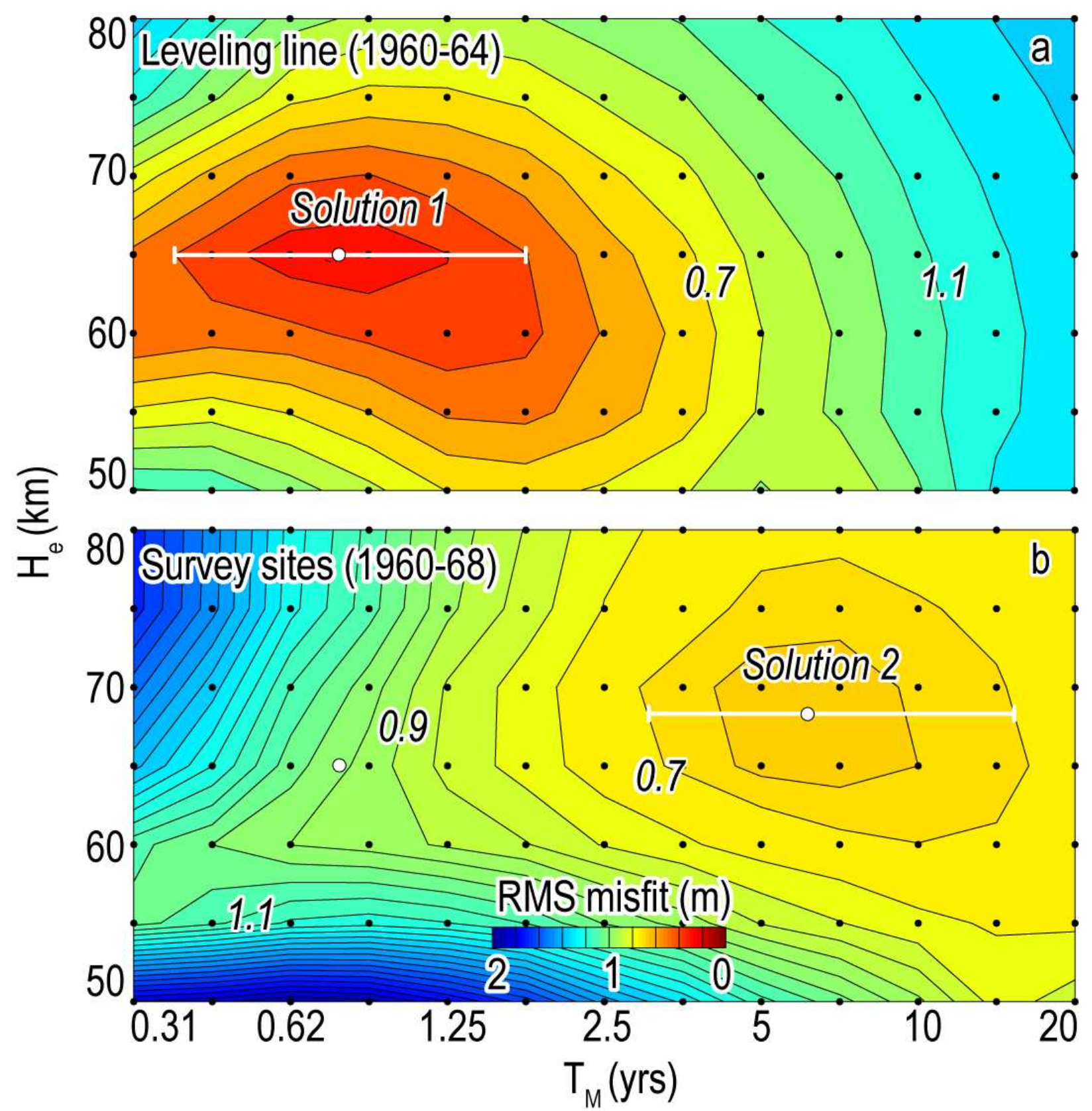

Figure 3. RMS misfits between (a) Type 1 and (b) Type 2 post-seismic observations and volumetric viscoelastic relaxation models. Horizontal axis $\left(\mathrm{T}_{\mathrm{M}}\right)$ is on a logarithmic scale. Bestfitting solutions are indicated by large black circles: (a) Solution $1\left(\mathrm{H}_{\mathrm{e}}=65 \mathrm{~km}, \mathrm{~T}_{\mathrm{M}}=0.7 \mathrm{yrs}\right)$; (b) Solution $2\left(\mathrm{H}_{\mathrm{e}}=67 \mathrm{~km}, \mathrm{~T}_{\mathrm{M}}=6 \mathrm{yrs}\right)$. White horizontal error bars indicate $\mathrm{T}_{\mathrm{M}}$ ranges that yield acceptable RMS misfits. 

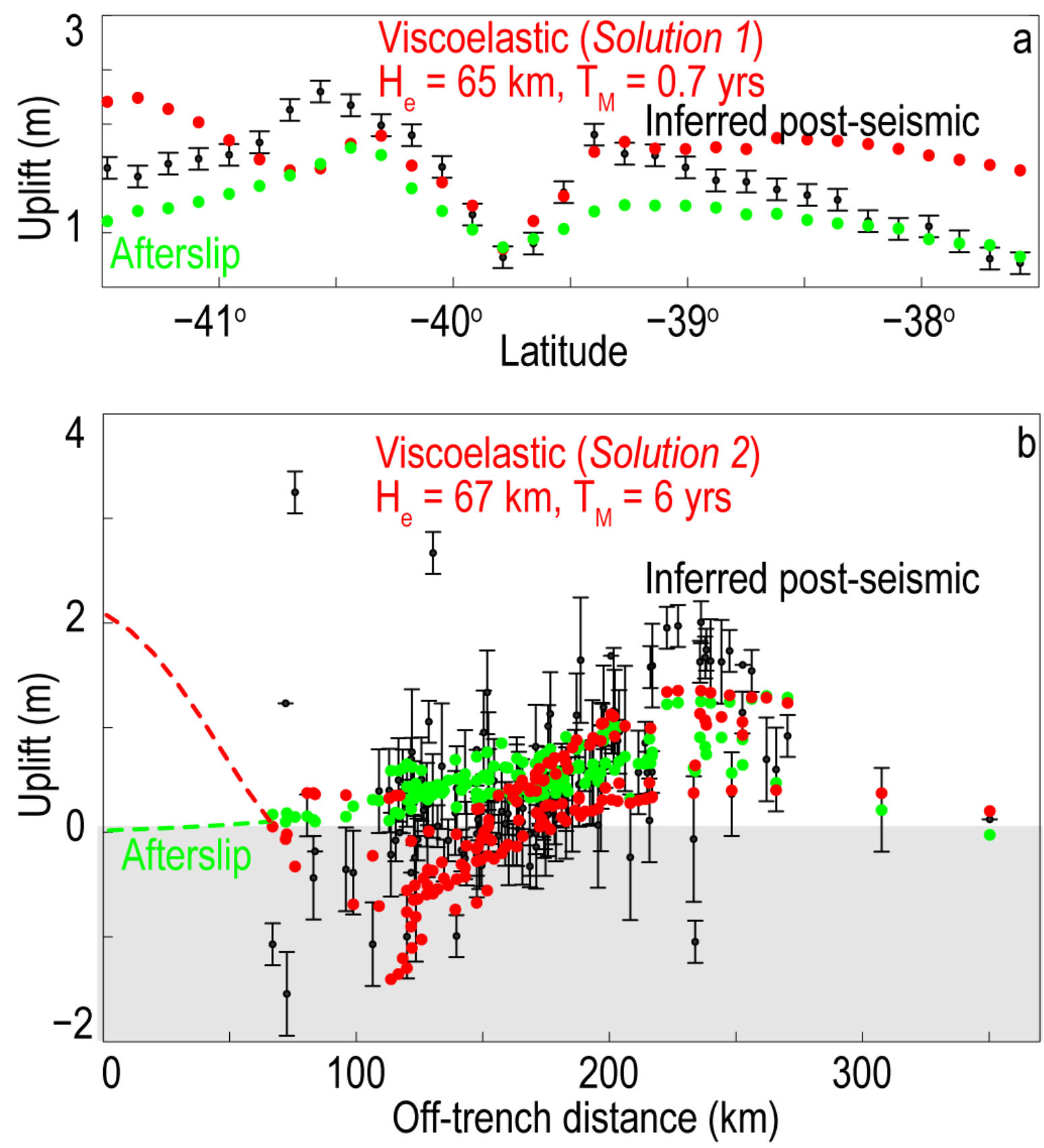

Figure 4. Comparison between observations (black dots and error bars) and best-fitting solutions (red dots): (a) Solution 1 for Type 1 post-seismic deformation and (b) Solution 2 for Type 2 deformation. The error bars indicate observation errors in the geodetic survey [Plafker and Savage, 1970]. Green dots are the corresponding deformation calculated for the afterslip model of Barrientos and Ward [1990]. Red and green dashed lines in (b) show our modeling results near the trench axis for the best-fitting viscoelastic and the afterslip models, respectively. 


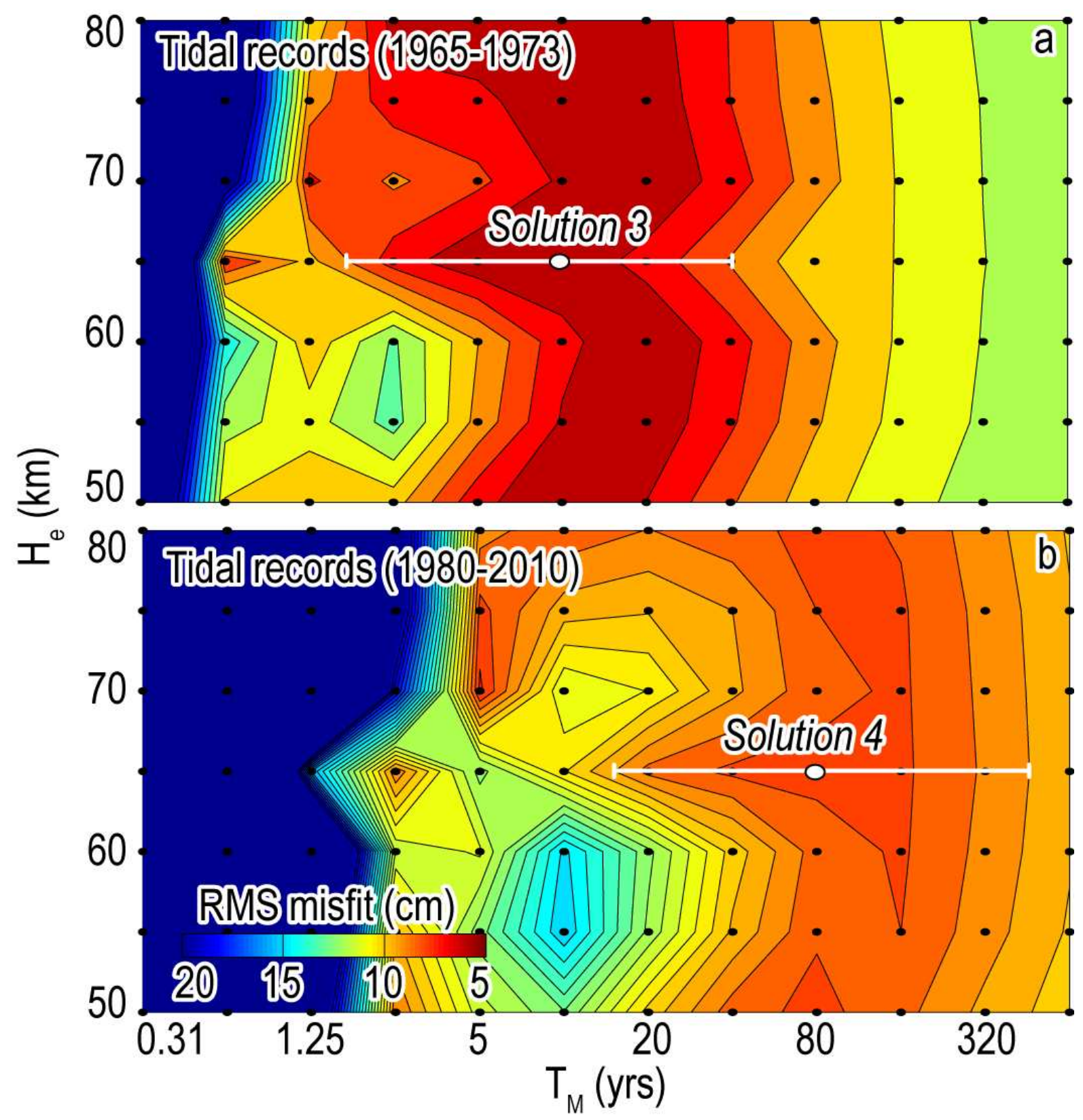

Figure 5. RMS misfits between Type 3 tidal data and viscoelastic models: (a) Solution 3 for 1965-1973 (Period a); (b) Solution 4 for 1980-2010 (Period b). Horizontal axis $\left(\mathrm{T}_{\mathrm{M}}\right.$ ) is on a logarithmic scale. The tidal data do not provide a strong constraint for $\mathrm{H}_{\mathrm{e}}$ values. Assuming $\mathrm{H}_{\mathrm{e}}=$ $65 \mathrm{~km}$, we invert for the best-fitting $\mathrm{T}_{\mathrm{M}}$ solutions: (a) Solutions 3 ( $\mathrm{T}_{\mathrm{M}}=10 \mathrm{yrs}$ ); (b) Solution 4 $\left(\mathrm{T}_{\mathrm{M}}=80 \mathrm{yrs}\right)$. White horizontal error bars indicate $\mathrm{T}_{\mathrm{M}}$ ranges that yield acceptable RMS misfits. 


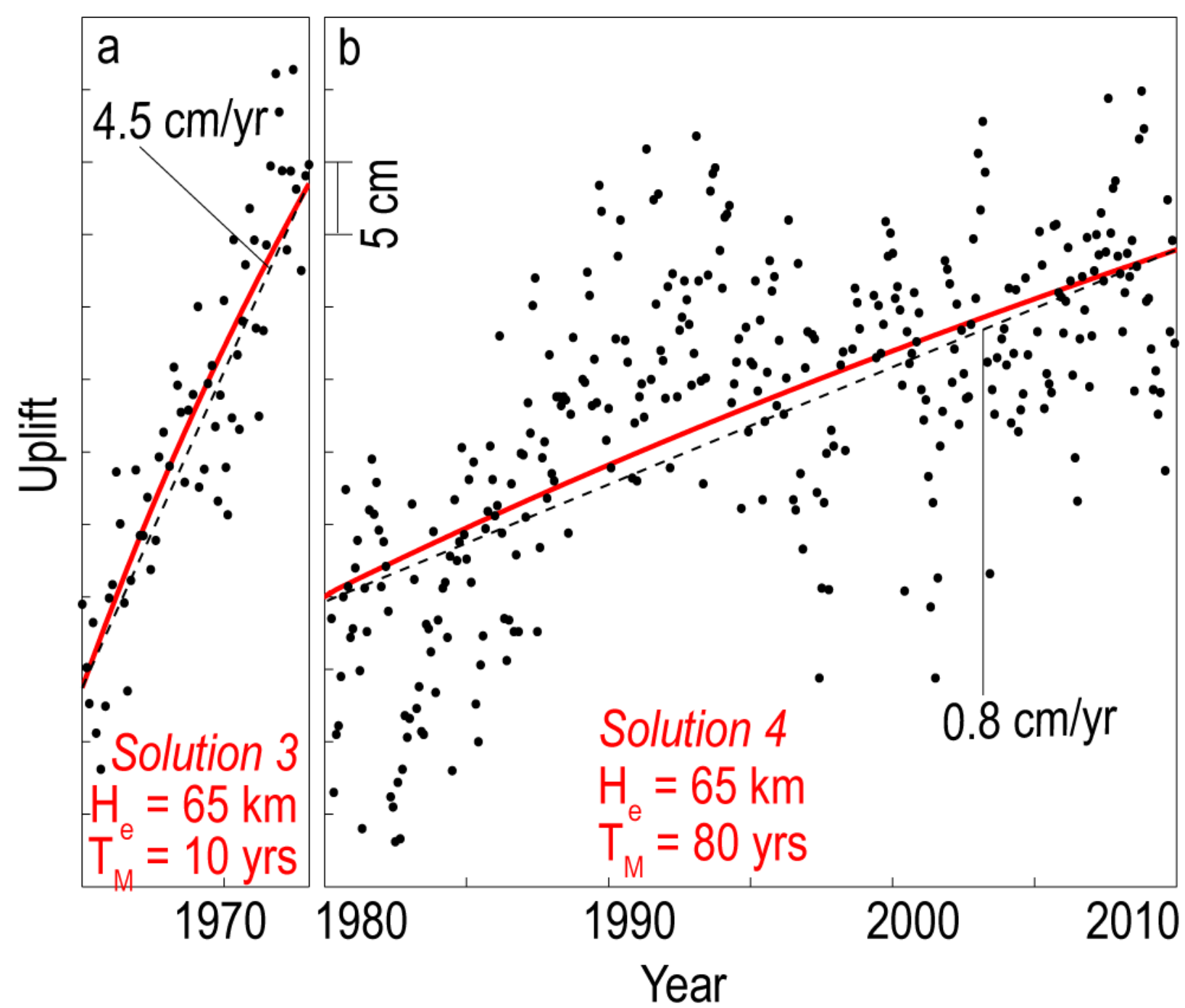

Figure 6. Comparison between Type 3 monthly tidal records (black dots) and best-fitting viscoelastic models (red lines) of (a) Solutions 3 and (b) Solution 4. Dashed black lines indicate lincear regression lines with uplift rates of $4.5 \mathrm{~cm} / \mathrm{yr}$ (a, in Period a) and $0.8 \mathrm{~cm} / \mathrm{yr}$ (b, in Period b). 


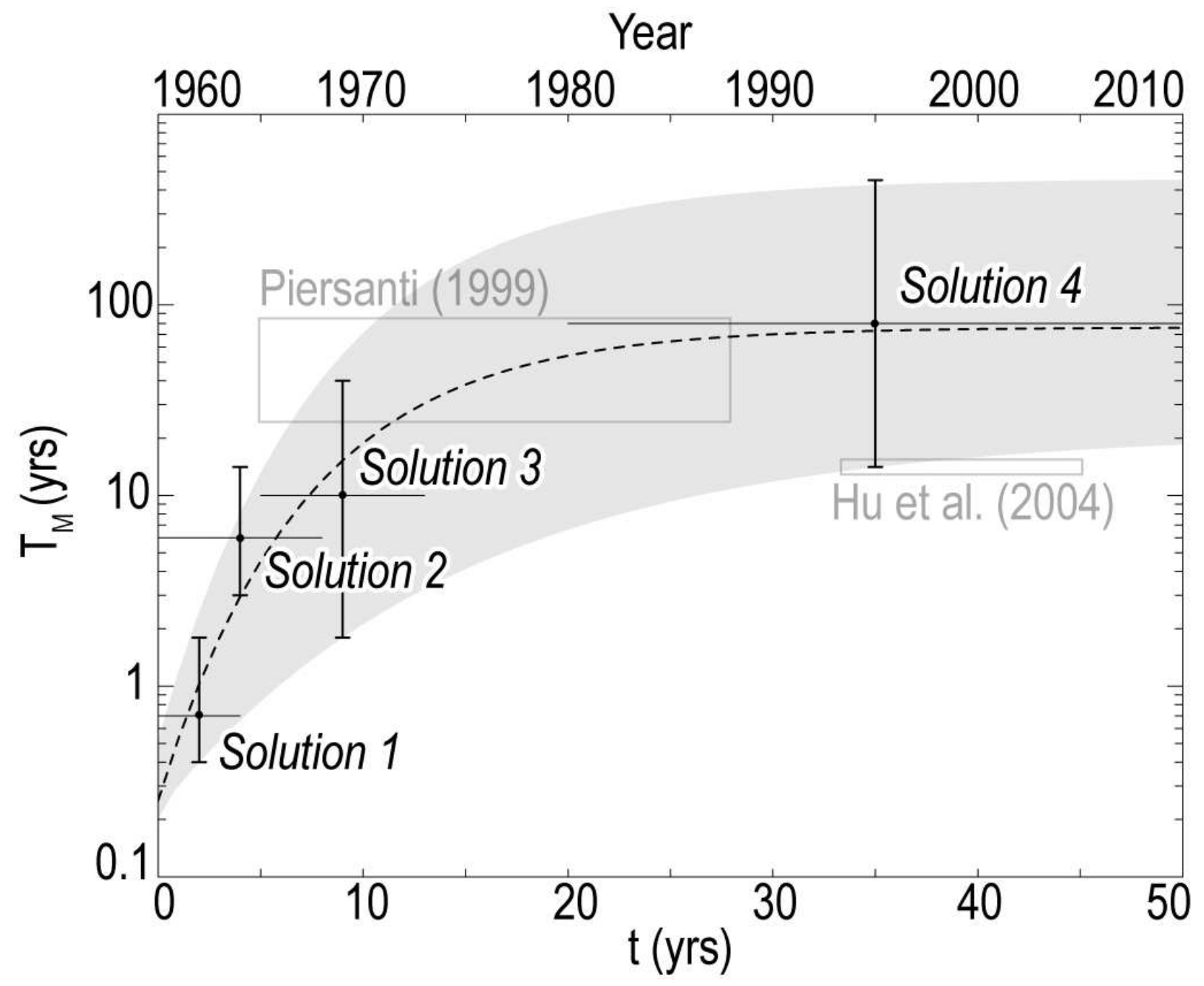

Figure 7. Effective Maxwell decay times, $\mathrm{T}_{\mathrm{M}}$, of Solutions 1-4, and a regression curve in the form of Equation 1 (dashed line). $T_{M}$ values of Solutions 1-4 and their corresponding acceptable ranges are indicated by dots and error bars for the observation time periods of 1960-1964 (for Type 1 data), 1960-1968 (for Type 2 data), 1965-1973 (for Type 3-Period a data), and 1980-2010 (for Type 3-Period b data), respectively. Gray region is constrained by regression curves for the upper and lower bounds of acceptable $\mathrm{T}_{\mathrm{M}}$ values. Gray-line boxes indicate results from Piersanti [1999] and Hu et al. [2004]. 

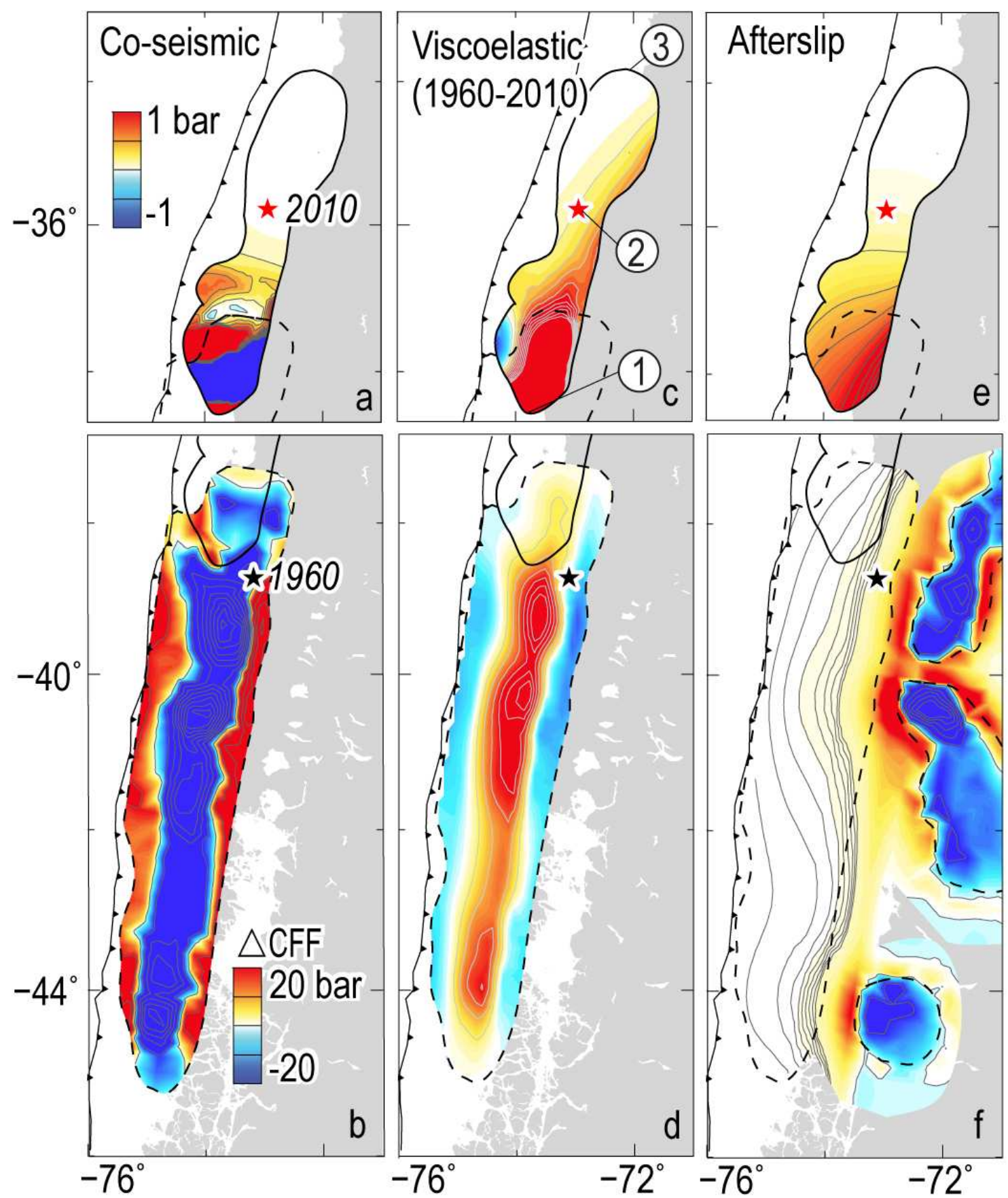

Figure 8. Coulomb stress changes on the rupture plane of the 1960 Valdivia (b, c, d) and 2010 Maule (a, c, e) earthquakes. Red color indicates positive Coulomb stress change. (a-b) Coseismic stress changes caused by the 1960 co-seismic slip model of Barrientos and Ward [1990]. (c-d) Post-seismic Coulomb stress changes corresponding to our best-fitting volumetric viscoelastic relaxation model with $\mathrm{T}_{\mathrm{M}}$ values increasing with time (i.e. dashed curve in Figure 7). (e-f) Post-seismic Coulomb stress changes due to the afterslip model of Barrientos and Ward [1990] (black dashed contours on the right side of Panel f). 

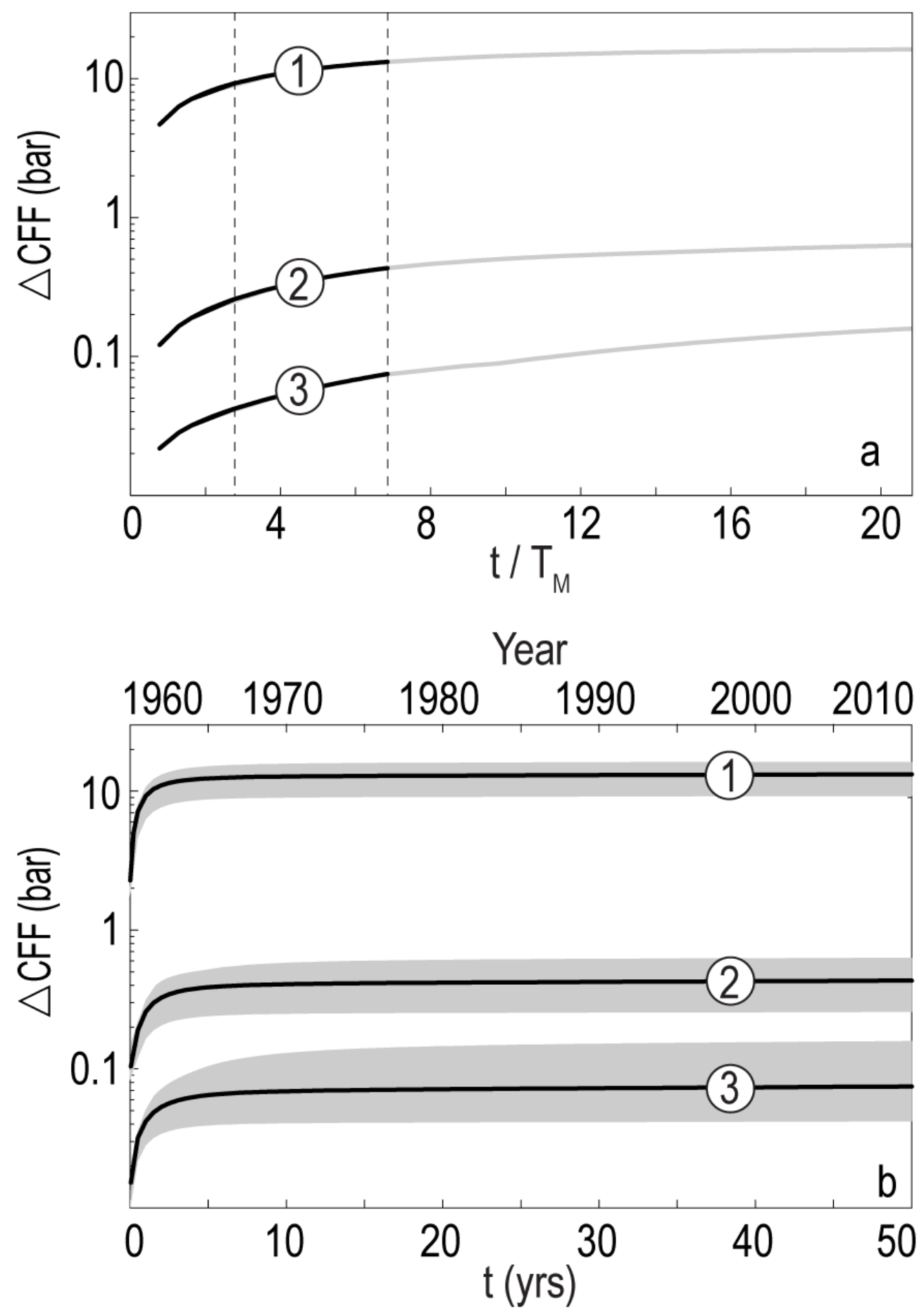

Figure 9. Coulomb stress evolution at Locations 1-3 (Figure 8c) on the rupture plane of the 2010 Maule earthquake. (a) Stress changes at differrent scaled times, $t / \mathrm{T}_{\mathrm{M}}$. (b) Corresponding stress changes within 50 years since 1960, assuming that the $\mathrm{T}_{\mathrm{M}}$ value increases with time in the form of Equation 1. Black solid curves corresponds to the regression curve for the best-fitting $T_{M}$ values (dashed curve in Figure 7), while the gray regions correspond to the lower and upper bound curves of the acceptable $\mathrm{T}_{\mathrm{M}}$ ranges (gray region in Figure 7). 

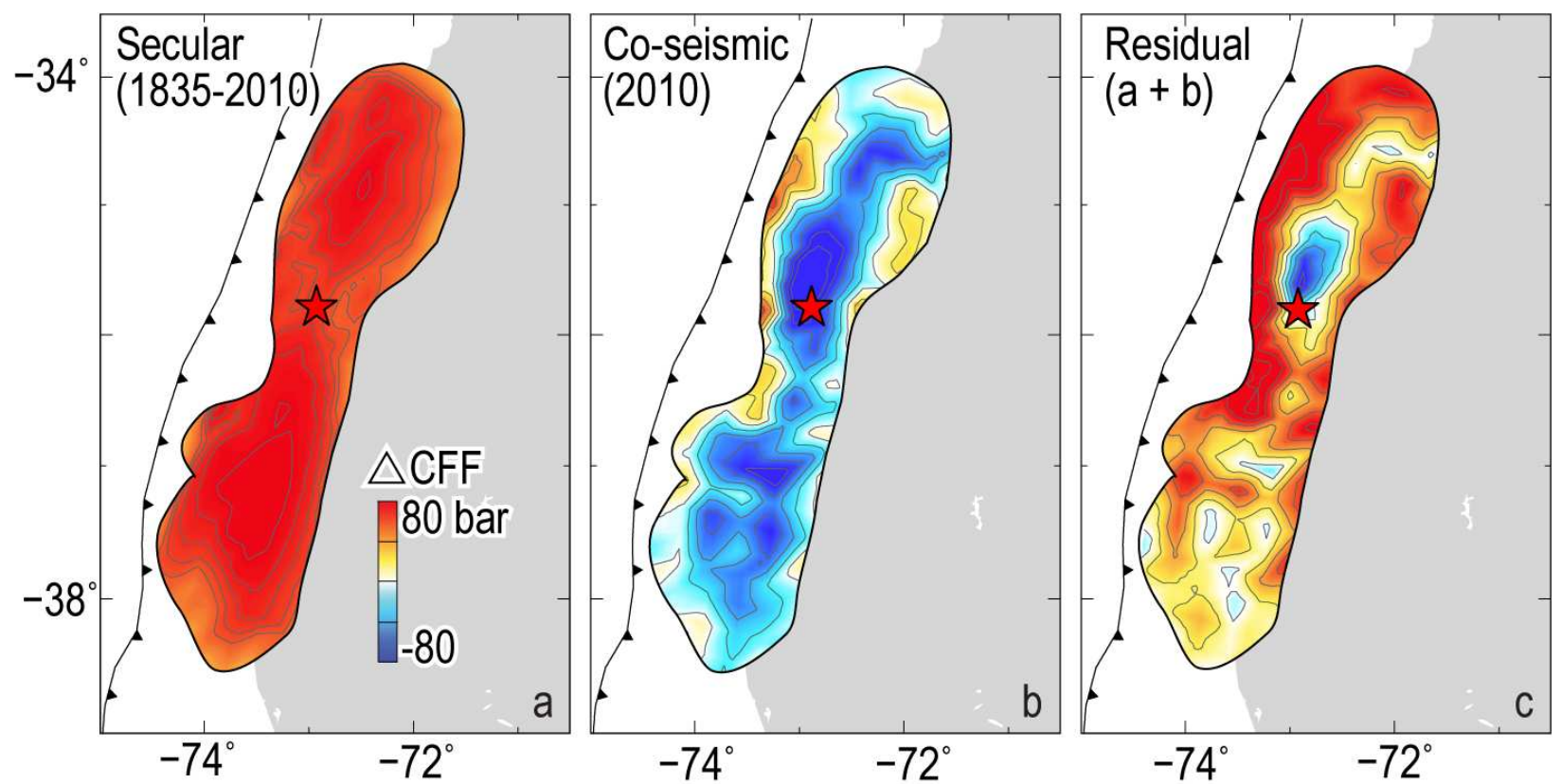

Figure 10. (a) Accumulated Coulomb stress increase within the earthquake cycle of 1835-2010 using a model of variable plate-coupling coefficient inverted from 1996-2008 GPS observations [Moreno et al., 2010]. (b) Co-seismic stress drop of the 2010 Maule earthquake, using the Lorito et al. [2011] slip model based on tsunami and geodetic observations. (c) Calculated residual stress after the occurrence of the 2010 earthquake by adding (a) and (b). 


\section{Appendix A: Model Sensitivity of Viscoelastic Deformation}

The calculated post-seismic viscoelastic deformation depends on two key variables: the thickness of elastic lithosphere, $\mathrm{H}_{\mathrm{e}}$, and the effective Maxwell decay time of the asthenosphere mantle, $\mathrm{T}_{\mathrm{M}}$. We assume a 100-km-thick asthenosphere mantle.

\subsection{Types 1 and 2 Observations}

With decreasing $\mathrm{H}_{\mathrm{e}}$ values, the calculated Type 1 deformation becomes more positive (Figure A1a). Meanwhile, the distance of the region of the calculated maximum uplift from the trench axis decreases for Type 2 data (Figure A1b). For both Type 1 (Figure A2a) and Type 2 (Figure A2b) data, a reduction in $\mathrm{T}_{\mathrm{M}}$ leads to more positive calculated deformation.

\subsection{Type 3 Observations}

The calculated post-1960 deformation at the Puerto Montt station increases exponentially with time (Figure A3). For both Period a (1965-1973, Figure A3a) and Period b (1980-2010, Figure A3b), all the $\mathrm{H}_{\mathrm{e}}$ values in the range of 50-80 km explain the observations well, assuming a constant $\mathrm{T}_{\mathrm{M}}$. Thus Type 3 observations do not provide a strong constraint for $\mathrm{H}_{\mathrm{e}}$ values. For both Period a (Figure A3c) and Period b (Figure A3d), a reduction in $\mathrm{T}_{\mathrm{M}}$ leads to an increase in the calculated rate of deformation, assuming a constant $\mathrm{H}_{\mathrm{e}}$. 
Figures
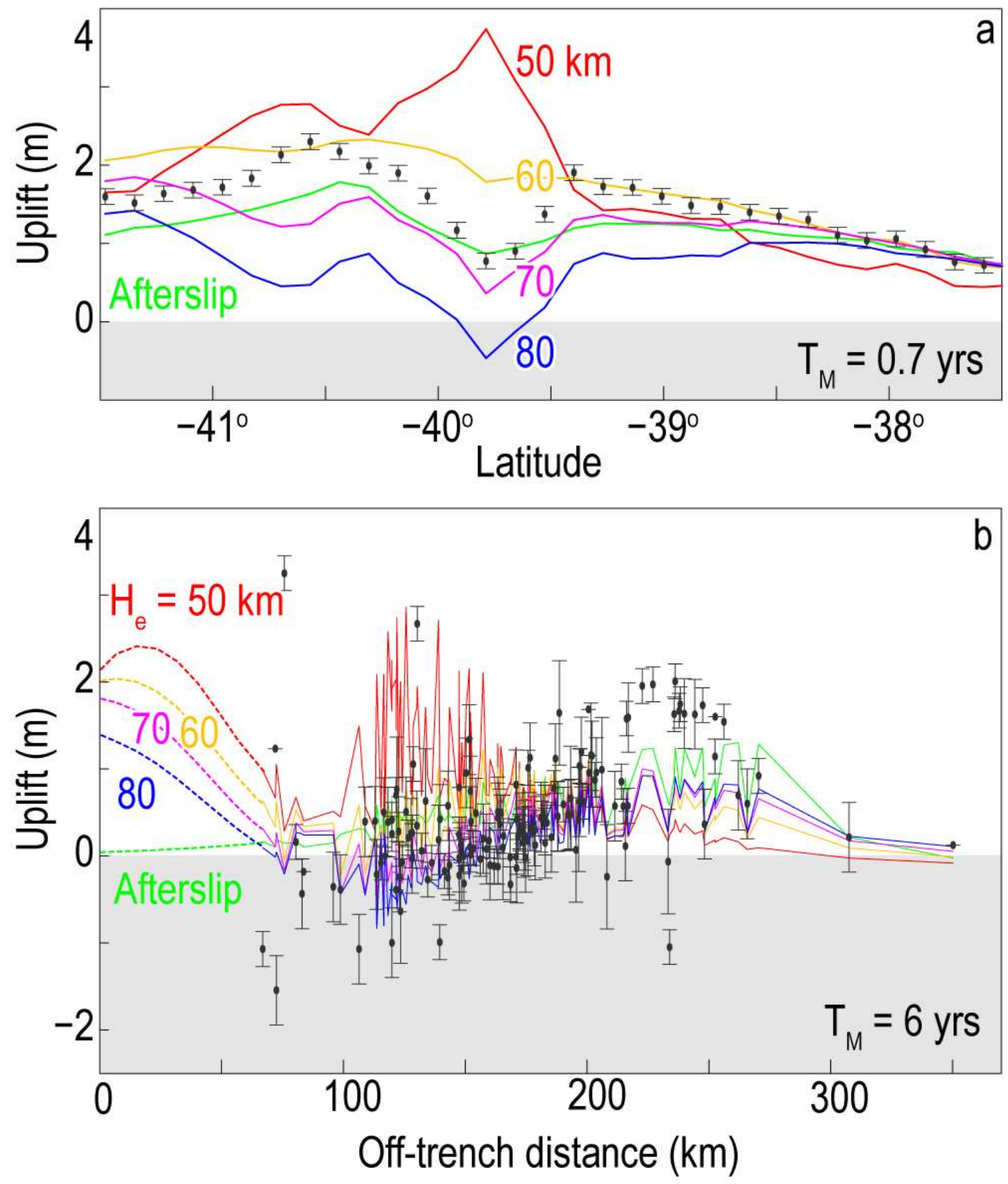

Figure A1. Calculated deformation for (a) Type 1 and (b) Type 2 observations assuming different lithospheric thickness: $\mathrm{H}_{\mathrm{e}}=50 \mathrm{~km}$ (red), $60 \mathrm{~km}$ (orange), $70 \mathrm{~km}$ (magenta), $80 \mathrm{~km}$ (blue). Green curves correspond to the afterslip model [Barrientos and Ward, 1990]. Black dots with error bars indicate the corresponding post-1960 land-level changes. Viscoelastic models assume constant $\mathrm{T}_{\mathrm{M}}$ values of $0.7 \mathrm{yrs}$ (Solution 1) in (a) and 6 yrs (Solution 2) in (b). 

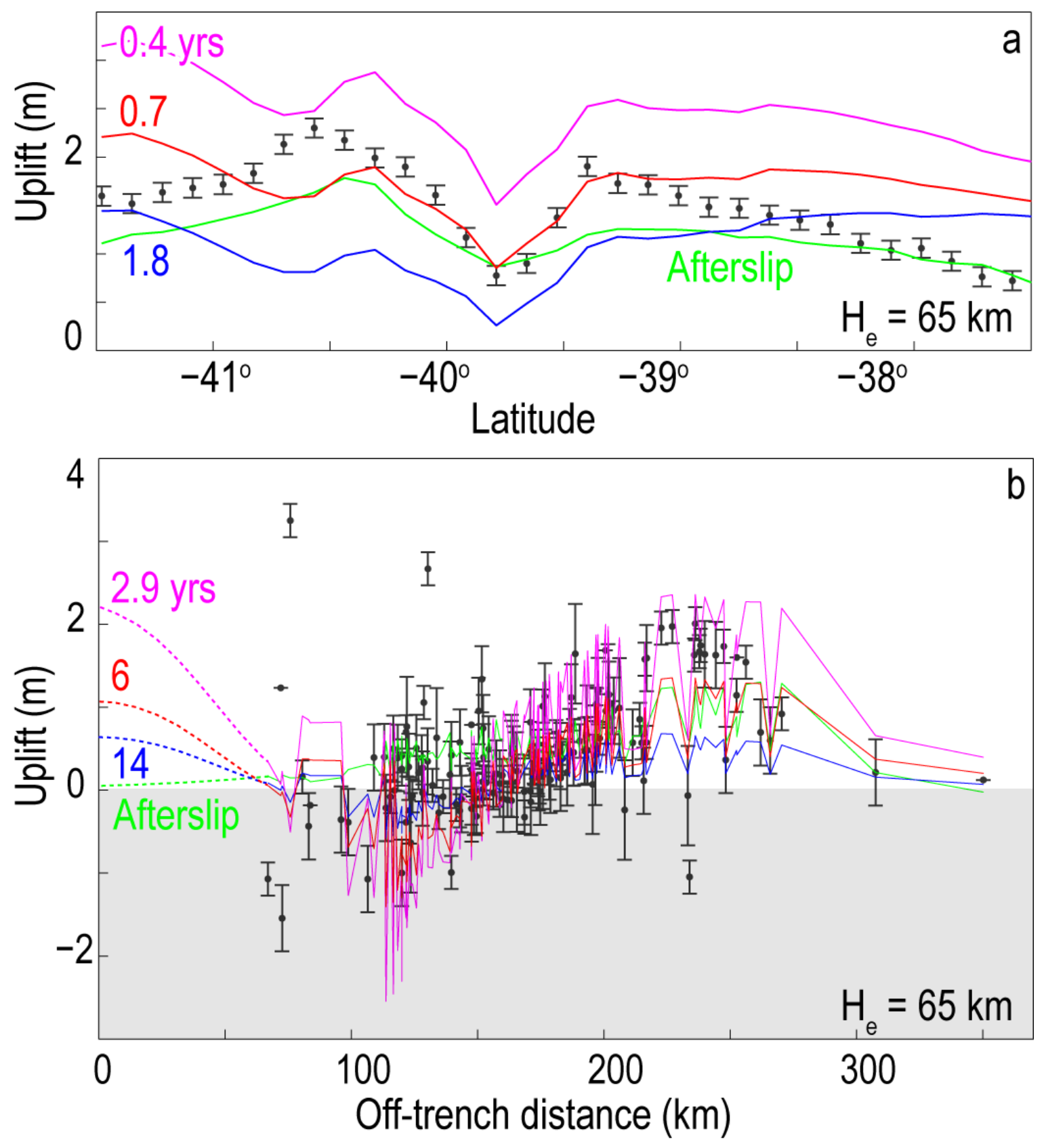

Figure A2. Calculated Type 1 and 2 deformation for viscoelastic models with different $\mathrm{T}_{\mathrm{M}}$ values: best-fitting $\mathrm{T}_{\mathrm{M}}$ (red), as well as lower (blue) and upper (purple) bounds of the acceptable $\mathrm{T}_{\mathrm{M}}$ ranges. Viscoelastic models assume a constant $\mathrm{H}_{\mathrm{e}}$ value of $65 \mathrm{~km}$. Green curves correspond to the afterslip model [Barrientos and Ward, 1990]. Black dots with error bars indicate the corresponding post-1960 land-level changes. (a) For Type 1 observations. (b) For Type 2 observations. 

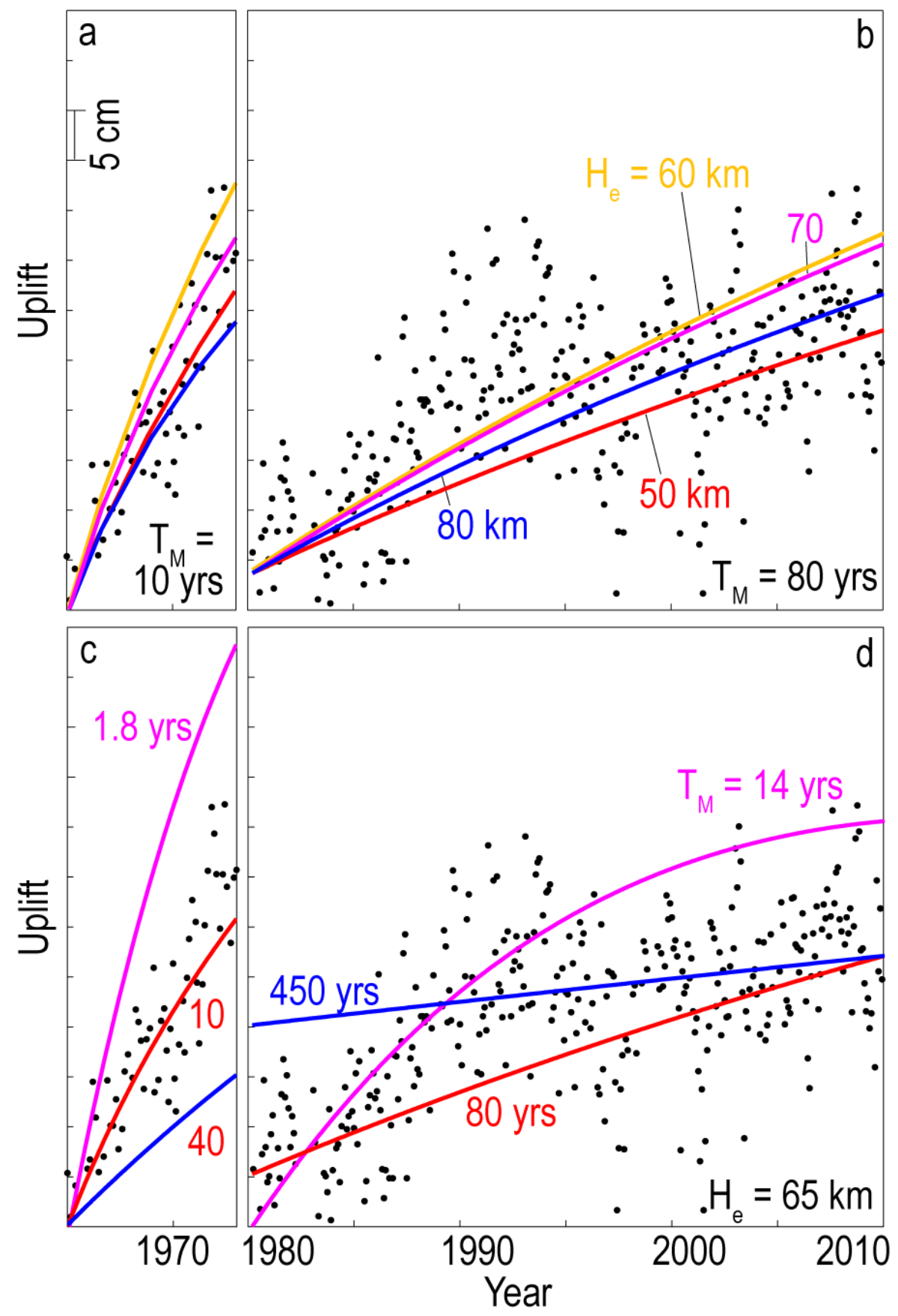

Figure A3. Calculated deformation at the tidal station Puerto Montt for two time intervals: (a, c) Period a of 1965-1973 and (b, d) Period b of 1980-2010. Black dots are the observed monthly time series. Post-seismic viscoelastic models with different $\mathrm{H}_{e}$ and $\mathrm{T}_{M}$ values are shown by different colors. (a-b) Modeling results for different $\mathrm{H}_{\mathrm{e}}$ values, 50, 60, 70, and $80 \mathrm{~km}$, assuming $\mathrm{T}_{\mathrm{M}}$ to be $10 \mathrm{yrs}$ in (a) and $80 \mathrm{yrs}$ in (b). (c-d) Modeling results for different $\mathrm{T}_{\mathrm{M}}$ values: bestfitting $\mathrm{T}_{\mathrm{M}}$ (red), as well as lower (blue) and upper (purple) bounds of the acceptable $\mathrm{T}_{\mathrm{M}}$ ranges, assuming $\mathrm{H}_{\mathrm{e}}=65 \mathrm{~km}$. 


\section{Appendix B: Layered Earth Viscosity Model}

We assume a three-layered Earth viscosity model that includes a low-viscosity asthenosphere mantle layer with a Maxwell rheology. The asthenospheric mantle layer is sandwiched between overlying elastic lithosphere and underlying lower mantle, both of which are of high viscosities (Table 1, Figure B1). The shear modulus and densities of the lithosphere and asthenosphere are based on the Preliminary Reference Earth Model (PREM) [Dziewonshi and Anderson, 1981], increasing with depth from $2.49 \times 10^{10}$ to $6.82 \times 10^{10} \mathrm{~Pa}$ for shear modulus and from $2.6 \times 10^{3}$ to $3.44 \times 10^{3} \mathrm{~kg} / \mathrm{m}^{3}$ for density, respectively. In Figure B1, we show an example of layered viscosity model including a lithospheric layer with thickness $\mathrm{H}_{\mathrm{e}}=50 \mathrm{~km}$, an asthenospheric layer with thickness $\mathrm{H}_{\mathrm{a}}=100 \mathrm{~km}$, and an underlying lower mantle layer. We assume the viscosity of the asthenosphere $\eta_{\boldsymbol{a}}=3 \times 10^{18} \mathrm{~Pa}$. . The co-seismic rupture occurs within the lithosphere and drives the subsequent viscoelastic relaxation of the underlying asthenosphere.

The Earth viscosity model used in this study is laterally homogeneous, while a real subduction zone includes 3-D laterally inhomogeneous structure. In subduction zones, an elastic oceanic plate with high viscosity subducts beneath the continental plate. Between the subducting plate and the overriding continental plate, the triangle-shaped mantle block with low viscosity is called mantle wedge. In the process of post-seismic viscoelastic relaxation, the presence of such low-viscosity mantle wedge would cause the focusing of asthenospheric relaxation and surface deformation to be skewed towards the landward side of the subduction zone. Furthermore, the magnitude of the surface vertical deformation could be greater for a model with a low-viscosity mantle wedge than that calculated for the flat Earth viscosity model of this study. 


\section{Figures}

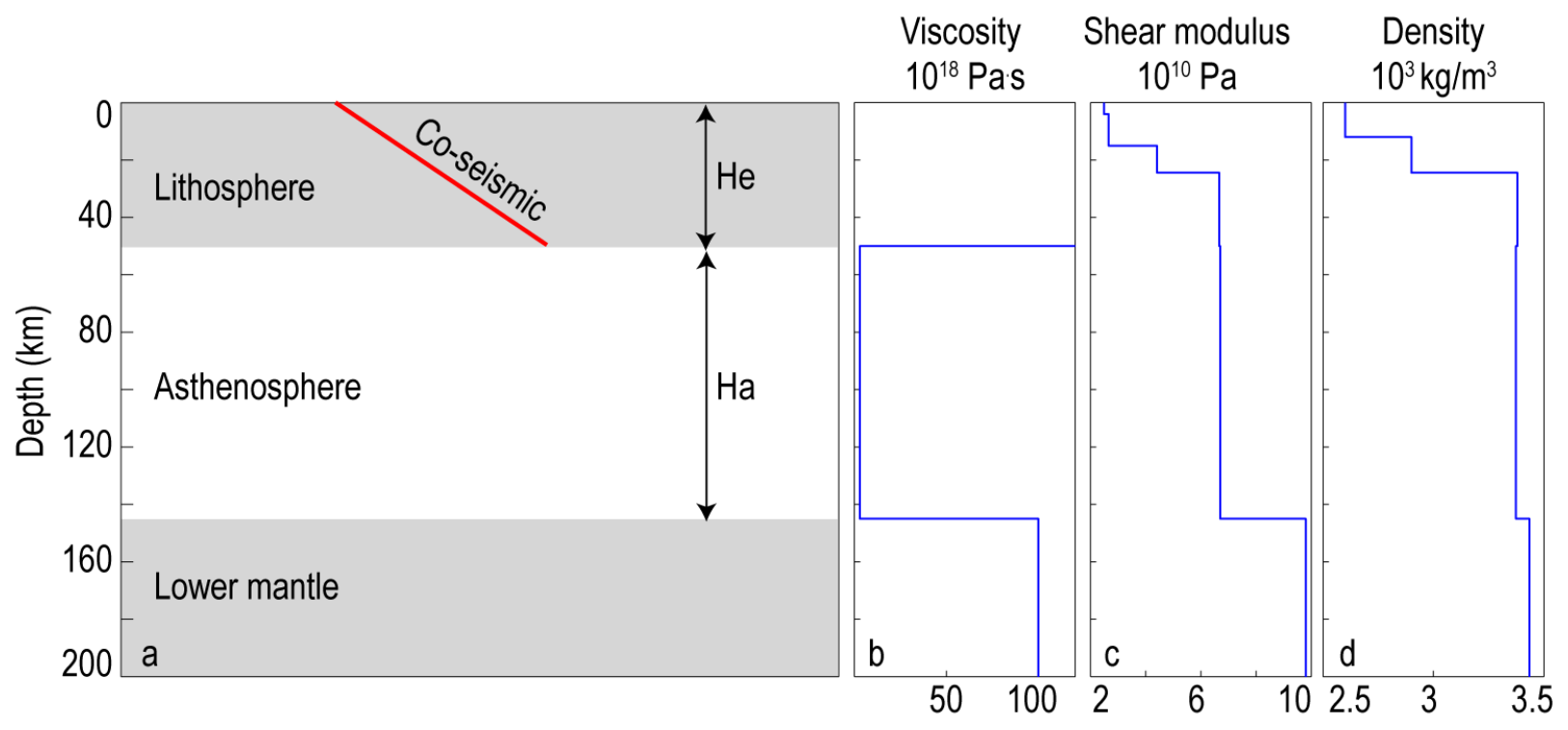

Figure B1. (a) A layered viscosity model assuming a lithospheric layer with thickness $\mathrm{H}_{\mathrm{e}}=50$ $\mathrm{km}$, an asthenospheric layer of $100 \mathrm{~km}$ thick, and an underlying lower mantle layer. (b) We assume large viscosities for the lithospheric and lower mantle layers, and small viscosity $\left(3 \times 10^{18}\right.$ Pas in this model) for the asthenosphere layer. (c) Assumed shear modulus as a function of depth. (d) Assumed depth-dependent density. 


\title{
Chapter 3: Elastoplastic Deformation and Faulting in the Overriding Plate Caused By a Subducted Seamount ${ }^{2}$
}

\begin{abstract}
We simulate elastoplastic deformation and faulting in a wedge-shaped overriding plate caused by a subducted seamount. The modeling results reveal surface subsidence on the seaward side of the seamount and uplift on the landward side of the seamount. A pair of conjugate normal faults would first appear in the thinner part of the plate, seaward of the seamount. Subsequently, a second pair of conjugate thrust faults would form in the thicker part of the plate, landward of the seamount. As the seamount buried depth increases, the seamount displacement required for both the normal and thrust faults to cut through the entire plate increases. The dipping angles of the faults are controlled by the internal friction angle of the overriding plate. Results of analysis also reveal that a shear zone could develop at the interface between the seamount and overriding plate, releasing the basal normal stress caused by the seamount movement. These analyses provide a quantitative framework to investigate the fault formation and surface deformation processes during seamount subduction.
\end{abstract}

\footnotetext{
${ }^{2}$ Ding, M., and J. Lin, Elastoplastic deformation and faulting in the overriding plate caused by a subducted seamount, manuscript for submission to Geophys. Res. Lett.
} 


\section{Introduction}

Seamounts are ubiquitous topographic features of ocean basins. The total number of seamounts have been estimated to be over 100,000 [Wessel et al., 2010], indicating on average at least one seamount within a seafloor area of $3,600 \mathrm{~km}^{2}$. Seamounts are carried to the subduction zones by plate motion and finally subducted beneath the overriding plate in subduction zones. There are many examples of seamounts that are in the process of being subducted. Seismic reflection and tomography, for example, clearly show subducted seamounts in the Hikurangi subduction margin off New Zealand [Bell et al., 2010], Gulf of Nicoya off Costa Rica [Husen et al, 2002], and Nankai Trough off Japan [Kodaira et al., 2000]. Magnetic and gravity anomalies have also been used to interpret subducted seamounts in the Cascadia subduction zone off Oregon [Trehu et al., 2012].

Subducted seamounts could profoundly influence the morphology and stress state of the overriding plate. Subducted seamounts generally produce indentation at the front of the overriding plates, followed by complex pattern of uplift and subsidence at different stages [Dominguez et al., 1998]. Meanwhile, the seamount may generate a complex fracture network in the overriding plate [Wang and Bilek, 2011]. The presence of the complex fault system could influence the occurrence of megathrust earthquakes. Previous studies suggest that subducted seamount could either trigger [Scholtz and Small, 1997; Cloos, 1992; Yang et al., 2013] or arrest megaearthquakes [Mochizuki et al., 2008; Kodaira et al., 2000; Yang et al., 2012]. However, those studies ignore the fault system caused by seamount subduction, and simply presume a normal stress increase at the location of seamount.

The goal of this investigation is to test this conceptual hypothesis of a fracture network caused by seamounts. Using the finite element modeling software COMSOL Multiphysics 4.4, 
we simulate the evolution of the fault-like shear zones (referred to as faults) due to the kinematic movement of the seamount. We explore how the key parameters, including the seamount burial depth $(H)$, the subduction dipping angle $(\theta)$, and the internal friction angle of the overriding plate $(\phi)$, influence the formation and geometry of the fault system. Our study could provide more realistic stress conditions along the seamount interface for better understanding the influence of seamounts on megathrust earthquakes.

\section{Model Set-up}

We calculate elastoplastic deformation of the overriding plate caused by the kinematic movement of a subducted seamount using COMSOL Multiphysics 4.4. The influence of seamount movement is modeled as a boundary of increasing displacement on the subduction interface. We assume the physical properties of the overriding plate to be constant, including its Young's modulus, Poisson's ratio, crustal density, and cohesion (Table 1). The key variables include the seamount buried depth $(H)$, the subduction dipping angle $(\theta)$, and the internal friction angle of the overriding plate $(\phi)$ (Figures 2a-b).

\subsection{Elastoplastic Material}

The mechanical failure of the overriding plate is modeled by the Mohr-Coulomb failure criteria. In Mohr-Coulomb criteria, the shear strength of the material is given by:

$$
\tau_{F}=\tan (\phi) \sigma_{n}+C
$$

where $\sigma_{n}$ is the normal stress. $\phi$ and $C$ are the internal friction angle and cohesion, respectively. When $\phi=0^{\circ}$, the Mohr-Coulomb failure criterion reduces to Von Mises criterion. Material begins to fail mechanically when the resultant shear stress on a plane at a given point reaches the shear strength, $\tau_{F}$, i.e., the Mohr circle transacts with the yield line in Figure 2a. We assume that the material behaves as a perfect plastic body afterward and the shear stress would 
always be equal to the shear strength on at least one plane. In COMSOL Multiphysics software, the Mohr-Coulomb failure is determined by the yield function, $F$ :

$$
F=\frac{\tan \phi}{\sqrt{9+12 \tan ^{2} \phi}} \sigma_{i i}+\sqrt{\frac{1}{2} s_{i j} s_{i j}}
$$

where $\sigma_{i j}$ is the stress tensor, $s_{i j}$ is the deviatoric stress tensor, and $\sqrt{\frac{1}{2} s_{i j} s_{i j}}$ is the equivalent deviatoric stress. $F$ equals the maximum value of $\tau-\tan (\phi) \sigma_{n}$. When $F$ reaches the cohesion, $C$, material begins to fail. $F$ will stay equal to $C$ for perfect-plastic deformation afterward:

$$
F=C
$$

The nonlinear plastic strain tensor, $\varepsilon_{i j}^{p}$, is then determined by solving the equations of plastic flow law in combination Hook's law and stress equilibrium conditions. The plastic flow law is expressed as:

$$
\begin{gathered}
\frac{\delta \varepsilon_{i j}^{p}}{\delta t}=d \lambda \frac{\partial F}{\partial \sigma_{i j}}, \\
\varepsilon_{i j}^{p}=\int \frac{\delta \varepsilon_{i j}^{p}}{\delta t} \delta t,
\end{gathered}
$$

where $\frac{\delta}{\delta t}$ stands for differentiation with respect to pseudo-time. The plastic multiplier $d \lambda$ is zero in the elastic domain. Once the material deforms plastically, $d \lambda$ will be determined by solving Equations 3 and 4 implicitly.

The elastic stress-strain relationship, i.e., the Hooke's law, and the decomposition of elastic and plastic strain are described by the following equations:

$$
\begin{gathered}
\sigma_{i j}=C_{i j k l}\left(\varepsilon_{k l}-\varepsilon_{k l}^{p}\right), \\
C_{i j k l}=\lambda \delta_{i j} \delta_{k l}+\mu\left(\delta_{i k} \delta_{j l}+\delta_{i l} \delta_{j k}\right),
\end{gathered}
$$


where $C_{i j k l}$ is the stiffness tensor, $\varepsilon_{k l}^{p}$ is the plastic strain tensor, $\varepsilon_{k l}-\varepsilon_{k l}^{p}$ is the elastic strain tensor, $\lambda=E v /(1-v) /(1-2 v)$ and $\mu=E / 2(1+v)$ are elastic moduli, and $\delta_{i j}$ is the Kronecker delta. We assume Poisson's ratio, $v=0.25$, and Young's modulus, $E=8 \times 10^{10} \mathrm{~Pa}$. Finally, the material is assumed to be in stress equilibrium:

$$
\sigma_{i j, j}=0, \sigma_{i j}=\sigma_{i j} .
$$

Hooke's law (Equation 6) and the mechanical equilibrium equations (Equation 8) are two equations required for describing elastic behavior. Once the accumulated stress reaches the yield criterion (Equation 3), the plastic strain, $\varepsilon_{i j}^{p}$, starts to grow. The following plastic strain is determined by two equations: the yield criterion (Equation 3) and the plastic flow law (Equation 4).

\subsection{Model Geometry and Boundary Condition}

The modeling domain corresponds to a cross section of the overriding plate, with an upwardpointed triangular notch to represent the seamount (Figure 2b). The seamount is assumed to be $30 \mathrm{~km}$ wide and $3 \mathrm{~km}$ high, similar to the Takuyo-Daiichi seamount (Figure 1b) [Dominguez et al., 1998]. We also modeled a flat-topped seamount, similar to the Erimo seamount; the results are found to be similar, in large part to that for a conical seamount. The geometry of the modeling domain is controlled by two key parameters: the plate/subduction dipping angle $(\theta)$ and the seamount buried depth $(H)$.

The seamount movement is modeled as increasing displacements on the seamount-overrding plate boundary $(u)$, paralleling to the plate dipping direction (Figure $2 \mathrm{~b}$ ). The remaining part of the subduction interface is fixed. The top boundary of the model is assumed to be stress free, while the right hand side (landward) is assumed to a free-slip boundary with zero horizontal displacement but stress free in vertical direction. We adopt a triangular meshing scheme with a 
maximum grid size of $1 \mathrm{~km}$ (Figure 2c). The quasi-static deformation of the overriding plate is calculated using a stationary solver with the seamount displacement on the seamount-overrding plate interface $(u)$ sweeping from 0 to $2 \mathrm{~km}$, large enough for the formation of a faulting system in the overriding plate.

\section{Results}

We test a series of models with various $\theta, \phi$, and $H$ values. The three parameters influence the formation of the four sets of seamount-induced faults (Figure 3a2): Landward-dipping normal fault (NF-L), with the dipping angle $\alpha_{N F-L}$; seaward-dipping normal fault (NF-S), with $\alpha_{N F-S}$; landward-dipping thrust fault (TF-L), with $\alpha_{T F-L}$; and seaward-dipping thrust fault (TFS), with $\alpha_{T F-S}$. Our models predict the seamount displacements $(D)$ that are required for the four sets of faults to cut through the entire plate (Figure 4). We show stress condition on the subduction interface and surface displacement for a typical model (Figure 6).

\subsection{Formation of Fault Systems}

The modeling results illustrate the formation of two distinctive groups of faults caused by the seamount movement: A group of conjugate normal faults (NF-L and NF-S in Figures 3a1) first appears on the seaward side of the seamount in the thinner part of the plate. Subsequently, two conjugate thrust faults (TF-L and TF-S in Figure 3a2), or a single left-dipping thrust fault (TF-S in Figure 3b2) would appear on the landward side of the seamount in the thicker part of the plate. In addition to the normal and thrust faults, a shear zone develops along the interface between the seamount and overriding plate (SZ in Figure 3b2).

The evolution of the fault system is controlled by $\theta, H$, and $\phi$. When $\theta, H$, and $\phi$ are large enough, the faults NF-S, TF-L, and TF-L can not cut through the entire plate (Figure 4b-d, f-h). For the cases of cutting through faults, as $H$ increases, the required seamount displacements $(D)$ 
for faults to cut through the entire plate increase. For example, when $\phi=0^{\circ}$ and $\theta=0^{\circ}$, as $H$ increases from 4 to $14 \mathrm{~km}, D_{N F-L}$ increases from 40 to $140 \mathrm{~km}$ (Figure 4a), $D_{N F-S}$ increases from 40 to $800 \mathrm{~km}$ (Figure $4 \mathrm{~b}$ ), $D_{T F-L}$ increases from 40 to $800 \mathrm{~km}$ (Figure 4c), and $D_{T F-S}$ increases from 40 to $240 \mathrm{~km}$ (Figure $4 \mathrm{~d}$ ). In contrast, as $\theta$ or $\phi$ increases, $D_{N F-L}$ (Figures $4 \mathrm{a}$ and e) and $D_{N F-S}$ (Figures $4 \mathrm{~b}$ and f) decreases, while $D_{T F-L}$ (Figures $4 \mathrm{c}$ and g) and $D_{T F-S}$ (Figures $4 \mathrm{~d}$ and h) increases for most of the tested models.

The predicted dipping angles $(\alpha)$ of the resultant faults are controlled by $\phi$. Results are slightly different for various $\theta$ values (lines in Figure 5), but are insensitive to $H$. Figure 5 shows results for $H=10 \mathrm{~km}$. As $\phi$ increases from 0 to $40^{\circ}, \alpha_{N F-L}$ increases from $49-51^{\circ}$ to 62 $67^{\circ}$ (Figure 5a), and $\alpha_{N F-S}$ increases from $49-59^{\circ}$ to $64-65^{\circ}$ (Figure 5b). In contrast, $\alpha_{T F-L}$ decreases from $60^{\circ}$ to $50^{\circ}\left(\theta=0^{\circ}\right.$, Figure $5 \mathrm{c}$ ), and $\alpha_{T F-S}$ decreases from $55-58^{\circ}$ to $48^{\circ}$ (Figure 5d). The slopes of those curves are consistent with the expected dipping angles for horizontal extension, $45^{\circ}+0.5 \phi$, or for horizontal compression, $45^{\circ}-0.5 \phi$.

\subsection{Surface Deformation and Basal Stress}

We show the normal and shear stress on the basal subduction interface for the model with $\theta$ $=10^{\circ}, H=10 \mathrm{~km}$, and $\phi=0^{\circ}$ (Figure 6). The maximum surface uplift is approximately over the landward base of the seamount, with the maximum uplift being $\sim 15 \%$ of the corresponding seamount displacement (Figure 6a). In contrast, the maximum surface subsidence is approximately over the landward base of the seamount, with the maximum subsidence being $\sim 30 \%$ of the corresponding seamount displacement.

The basal stress state is also estimated. While the shear stress only changes slightly (Figure 6c), the normal stress evolves significantly as the seamount moves and the shear zone (SZ in 
Figure 3b2) develops. At the first stage, the normal stress increases on the landward flank of the seamount, but decreases on the seaward flank; this is illustrated by comparing blue curve (after seamount movement) with dashed back curve (before seamount movement) in Figure 6b. Once the shear zone (SZ) surrounding the seamount starts to develop, it releases the normal stress changes. The normal stress will finally be decreased on the landward flank, and increased on the seaward flank (compare red curves with dashed curve in Figure 6b). The basal normal stress increases on the landward side and decreases on the seaward side within a distance of $5 \mathrm{~km}$ away from the seamount (Figure 6b).

\section{Discussions}

Our study provides a quantitative analysis of the time-dependent lithospheric deformation and fault formation during seamount subduction. The models have broad implications for the observable surface displacement and earthquake characteristics.

\subsection{Evolution of the Fault Systems}

When a seamount subducts from the trench axis to a deeper location, a series of normal and thrust faults would develop at different stage of seamount subduction, as suggested by both our numerical experiments and the sandbox experiment of Dominguez et al. [1998]. When the seamout is at a certain burial depth $(H)$, the faults far from the seamount do not develop further and new faults form. As $H$ increases, new NF-L and TF-S are preferred, while new NF-S and TF-L might not yet be able to cut through the overriding plate (Figure 4). At extremely large $H$, all of the four sets of faults might not be able to cut through the overriding plate. TF-S has been observed in Costo Rica margin [Dominguez et al., 1998]. Other tectonic features suggested by the sandbox experiment and topographic observation, including indentation at the front of the 
overriding plate and a surface strike-slip network, could not be addressed in our 2D numerical experiment.

\subsection{Effect of Fluids}

The subduction process brings a large quantity of sediments and fluids to great depth [Peacock, 1990]. This process might be enhanced by seamounts, which trap the sediment with high fluid content. The presence of fluids could influence our models of fault formation in three aspects: (1) Fluids could decrease the effective normal stress of the overriding plate, promoting faults at greater depths. (2) Fluids could decrease the basal friction of the subduction interface, making faulting in the overriding plate less preferable. (3) If sediments and fluids trapped by a seamount decrease the basal friction only on the flanks of the seamount, the friction contrast could make faults easier to develop. We suggest that the above processes (1) and (3) might play a significant role in promoting faults.

\subsection{Comparison with Compressional Wedge Model}

Our models predict horizontal extension on the seaward side of the seamount and compression on the landward side. Such models differ from the compression wedge model where the entire overriding plate is under horizontal compression [Buiter, 2012]. In Figure 7, we consider a compression wedge with the seamount as a geometric boundary. We assume that the subducting slab moves downward along the subduction interface, which pulls the entire overriding plate by friction (Figure 7a). The basal friction coefficient between the subducting slab and the overriding plate is assumed to be 0.1 . Results show that the entire overriding plate is under horizontal compression, similar to the compressional wedge model. A conjugate thrust faults (TF-L and TF-S1) first appear in the thicker part of the plate (Figure 7b), followed by a seaward-dipping thrust fault (TF-S2) in the thinner part of the plate (Figure 7c). Thus the major difference in a compressional wedge model is horizontal compression even on the seaward side 
of the seamount. Compared with our kinematic seamount movement models, the stress condition of the compressional wedge would strengthen the formation of thrust faults on the seaward side of the seamount (TF-L and TF-S) but weaken the formation of normal faults on the landward side of the seamount (NF-L and NF-S).

\subsection{Interaction with Pre-existing Splay Faults}

Seismic reflection data show that a series of splay thrust faults exist in the overriding plate of some subduction systems [e.g., Moore et al., 2014; Bell et al., 2010]. Those splay thrust faults are similar to our modeled landward-dipping thrust faults (TF-L in Figures $3 \mathrm{a} 2$ and $7 \mathrm{~b}$ ). The seamount-induced stressing and faulting might interact with pre-existing splay faults in three ways: (1) Splay faults on the seaward side of the seamount could be deactivated, or even converted to normal faults similar to NF-L (Figure 3a2); (2) Splay faults on the landward side of the seamount could be strengthened or re-activated by the influence of TF-L; (3) Seamountinduced faults and shear zone might be weaker than in our model due to the stress release by preexisting splay faults.

\subsection{Influence on Megathrust Earthquakes}

The stress condition on the subduction interface might greatly influence the occurrence of megathrust earthquakes [Wang and Bilek, 2011]. Our models suggest that the seaward and landward sides of the seamount are associated with different normal stress conditions. On the landward flank of the seamount, normal stress is increased at the initial stage, and will be decreased once the surrounding shear zone starts to develop. Therefore, the stress condition on the seamount flank varies at different stages of seamount movement, which could contribute to the observed complexity of seamounts acting as asperities or barriers to megathrust earthquakes. 


\subsection{Future Directions}

Now that we have numerically simulated seamount-induced faults, we are ready to compare models with observations including: (1) Surface faults observable in multibeam bathymetry data of different tectonic settings and (2) Buried faults detectable in seismic reflection profiles [e.g., Ten Brink, 2005; Barnes et al., 2010; Bell et al., 2010]. The comparison with observations will help to tell whether the displacement or frictional boundary condition model might be more suitable for describing the influence of seamounts. Furthermore, when modeling a specific subduction zone system, we must consider the tectonic conditions unique for that system, such as subduction accretion or erosion, pre-existing splay faults, and the layered structure of the overriding plate. It has also been suggested that fluid flow in the accretionary wedge and sediment trapped by the seamounts could influence the stress condition and fault evolution of the overriding plate [e.g., Ellis et al., 2014], which requires further consideration.

It has been proposed that a subducted seamount might act as either barrier [Scholtz and Small, 1997; Cloos, 1992; Yang et al., 2013] or asperity [Mochizuki et al., 2008; Kodaira et al., 2000; Yang et al., 2012] for megathrust earthquakes. This study reveals significant increase and decrease of normal stress on the seamount-overriding plate interface that could have a profound influence on the dynamics of magathrust earthquakes. However, the relationship between the long-term interface normal stress, complex fault system, plate coupling, and short-term megathrust earthquakes requires further detailed numerical analysis. Finally, other subducted topographic roughness features, including subducted oceanic plateaus, mid-ocean ridges, and fracture zones, could have similar influence as the seamounts. Those roughness features require furture analysis. 


\section{Conclusions}

Our models illustrate the plastic deformation and resultant fault formation in the overriding plate caused by seamount movement, yielding the following results:

1. A region of horizontal extension develops on the seaward side of the seamount, while a region of horizontal compression develops on the landward side of the seamount. Accordingly, a pair of conjugate normal faults could first form on the seaward side of the seamount in the thinner part of the plate, followed by a second pair of conjugate thrust faults on the landward side of the seamount in the thicker part of the plate.

2. The required seamount displacement for the normal faults to cut through the overriding plate is larger for deeper seamount, smaller subduction dipping angle, and smaller internal friction angle of the plate material. The required seamount displacement for the thrust faults to cut through the plate is larger for deeper seamount, larger subduction dipping angle, and larger internal friction angle of the plate material.

3. As seamount movement increases, a shear zone could form along the interface between the seamount and overriding plate. Before the formation of the shear zone, the basal normal stress is calculated to decrease on the seaward flank of the seamount but increase on landward flank. However, these normal stresses are significantly reduced after the formation of the shear zone.

Acknowledgements. Our study benefitted from discussion with Mark Behn, Jean-Arthur Olive, Hongfeng Yang, Jeff McGuire, and Brian Tucholke of the Woods Hole Oceanographic Institution, as well as with Charles Williams of the GNS Science Institution, New Zealand. We thank COMSOL Help Group and Srikanth Vaidianathan at the COMSOL Inc. for technical support. This work is supported by NSF Grant OCE-1141785 (J. L.) and WHOI DOEI Graduate Student Fellowship (M. D.). 


\section{References}

Barnes, P. M., G. Lamarche, J. Bialas, S. Henrys, I. Pecher, G. L. Netzeband, J. Greinert, J. J. Mountjoy, K. Pedley, and G. Crutchley (2010), Tectonic and geological framework for gas hydrates and cold seeps on the Hikurangi subduction margin, New Zealand, Marine Geology, 272, 26-48, doi:10.1016/j.margeo.2009.03.012.

Bell, R., R. Sutherland, D. H. N. Barker, S. Henrys, S. Bannister, L. Wallace, and J. Beavan (2010), Seismic reflection character of the Hikurangi subduction interface, New Zealand, in the region of repeated Gisborne slow slip events, Geophys. J. Int., 180, 34-48, doi:10.1111/j.1365246X.2009.04401.x.

Buiter, S. J. H. (2012), A review of brittle compressional wedge models, Tectonophy., 530531, 1-17, doi:10.1016/j.tecto.2011.12.018.

Cloos, M. (1992), Thrust-type subduction-zone earthquakes and seamount asperities: A physical model for seismic rupture, Geology, 20, 601-604, doi:10.1130/0091-7613.

Dominguez, S., S. Lallemand, J. Malavieille, and R. von Huene (1998), Upper plate deformation associated with seamount subduction, Tectonophy., 293, 207-224, doi:10.1016/S0040-1951(98)00086-9.

Ellis, S., F. Ghisetti, P. Barnes, A. Reyes, A. Fagereng, F. Henrys, D. Barker, and S. Henrys (2014), Numerical experiments into the style of accretion and megathrust behavior along the Hikurangi margin, New Zealand, Abstract T51A-4596 presented at 2014 Fall Meeting, AGU, San Francisco, Calif., 15-19 Dec.

Husen, S., E. Kissling, and R. Quintero (2002), Tomographic evidence for a subducted seamount beneath the Gulf of Nicoya, Costa Rica: The cause of the $1990 \mathrm{Mw}=7.0 \mathrm{Gulf}$ of Nicoya earthquake, Geophys. Res. Lett., 29, doi:10.1029/2001GL014045.

Kodaira, S., N. Takahashi, A. Nakanishi, S. Miura, and Y. Kaneda (2000), Subducted seamount imaged in the rupture zone of the 1946 Nankaido earthquake, Science, 289, 104-106, doi:10.1126/science.289.5476.104.

Mochizuki, K., T. Yamada, M. Shinohara, Y. Yamanaka, and T. Kanazawa (2008), Weak interplate coupling by seamounts and repeating $\mathrm{M} \sim 7$ earthquakes, Science, 321, 1194-1197, doi:10.1126/science.1160250.

Moore, G. F., N. L. Bangs, A. Taira, S. Kuramoto, E. Pangborn, and H. J. Tobin (2007), Three-dimensional splay fault geometry and implications for tsunami generation, Science, 318, 1128-1131, doi:10.1126/science.1147195.

Peacock, S. A. (1990), Fluid processes in subduction zones, Science, 248, 329-337.

Scholz, C. H., and C. Small (1997), The effect of seamount subduction on seismic coupling, Geology, 25, 487-490, doi:10.1130/0091-7613.

Ten Brink, U. (2005), Vertical motions of the Puerto Rico Trench and Puerto Rico and their cause, J. Geophys. Res., 110, doi:10.1029/2004JB003459. 
Tréhu, A. M., R. J. Blakely, and M. C. Williams (2012), Subducted seamounts and recent earthquakes beneath the central Cascadia forearc, Geology, 40, 103-106, doi:10.1130/G32460.1.

Wang, K., and S. L. Bilek (2011), Do subducting seamounts generate or stop large earthquakes?, Geology, 39, 819 -822, doi:10.1130/G31856.1.

Wessel, P., D. T. Sandwell, and S.-S. Kim (2010), The global seamount census, Oceanogra., $23,24$.

Yang, H., Y. Liu, and J. Lin (2012), Effects of subducted seamounts on megathrust earthquake nucleation and rupture propagation, Geophys. Res. Lett., 39, L24302, doi:10.1029/2012GL053892.

Yang, H., Y. Liu, and J. Lin (2013), Geometrical effects of a subducted seamount on stopping megathrust ruptures, Geophys. Res. Lett., 40, 1-6, doi:10.1002/grl.50509. 


\section{Table}

Table 1. Model Parameters

\begin{tabular}{lll}
\hline Parameter & Description & Value \\
\hline$E$ & Young's modulus $(\mathrm{Pa})$ & $8 \times 10^{8}$ \\
$v$ & Poisson's ratio & 0.25 \\
$C$ & Cohesion $(\mathrm{Pa})$ & $1 \times 10^{8}$ \\
$\rho$ & Crustal density $\left(\mathrm{kg} / \mathrm{m}^{3}\right)$ & 2700 \\
$\theta$ & Subduction dipping angle $\left(^{\circ}\right)$ & $0,5,10,15,20$ \\
$\mathrm{H}$ & Seamount buried depth from the seaward base to surface $(\mathrm{km})$ & $4,6,8,10,12,14$ \\
$\phi$ & Angle of internal friction $\left(^{\circ}\right)$ & $0,10,20,30$ \\
\hline
\end{tabular}




\section{Figures}
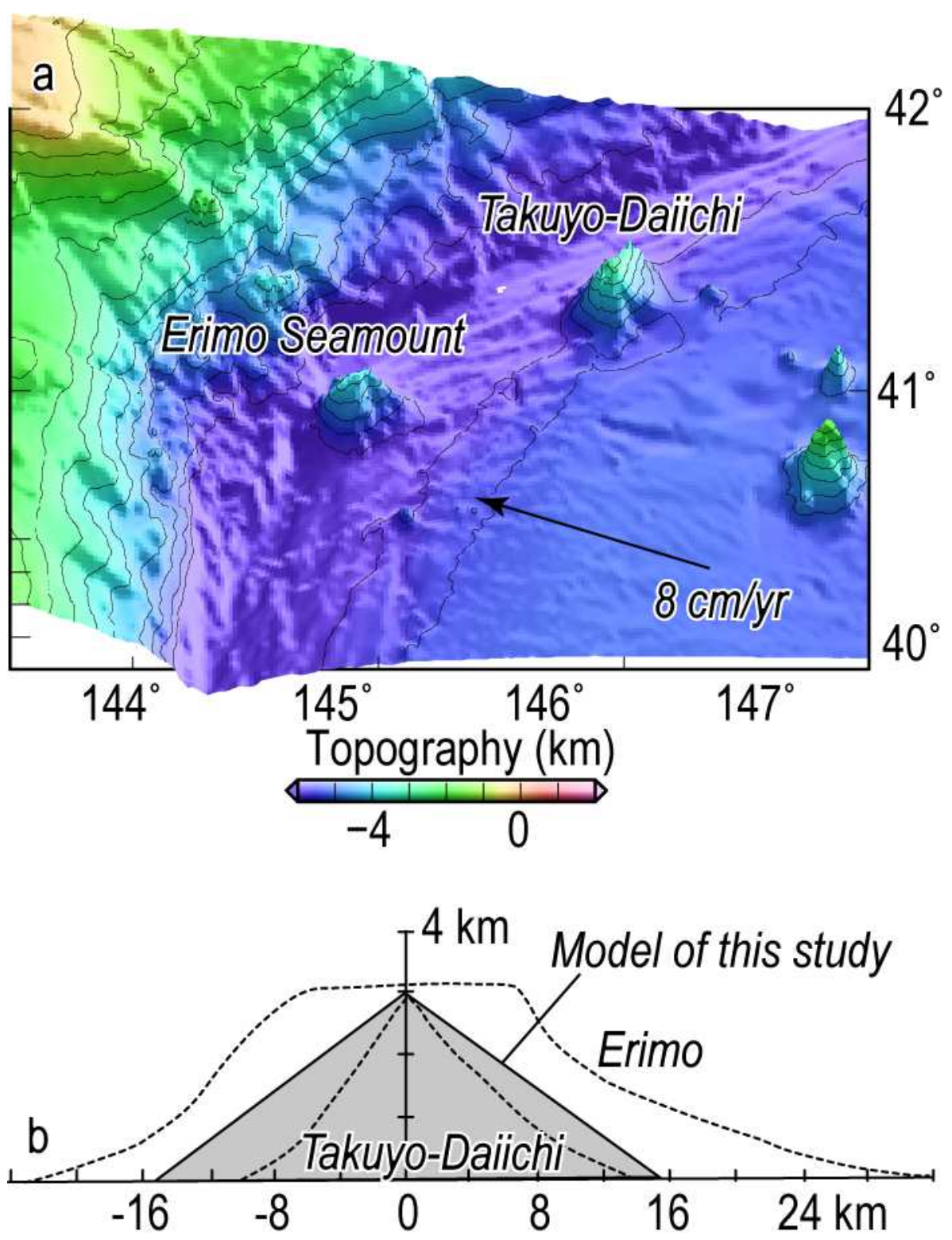

Figure 1. (a) 3D perspective of surface topography of the flat-topped Erimo and conical TakuyoDaiichi seamounts near the Japan Trench. (b) Cross-sections of Erimo and Takuyo-Daiichi seamounts, modified after Dominguez et al. [1998]. Seamount model used in this study is $30 \mathrm{~km}$ wide at the base and $3 \mathrm{~km}$ high. 

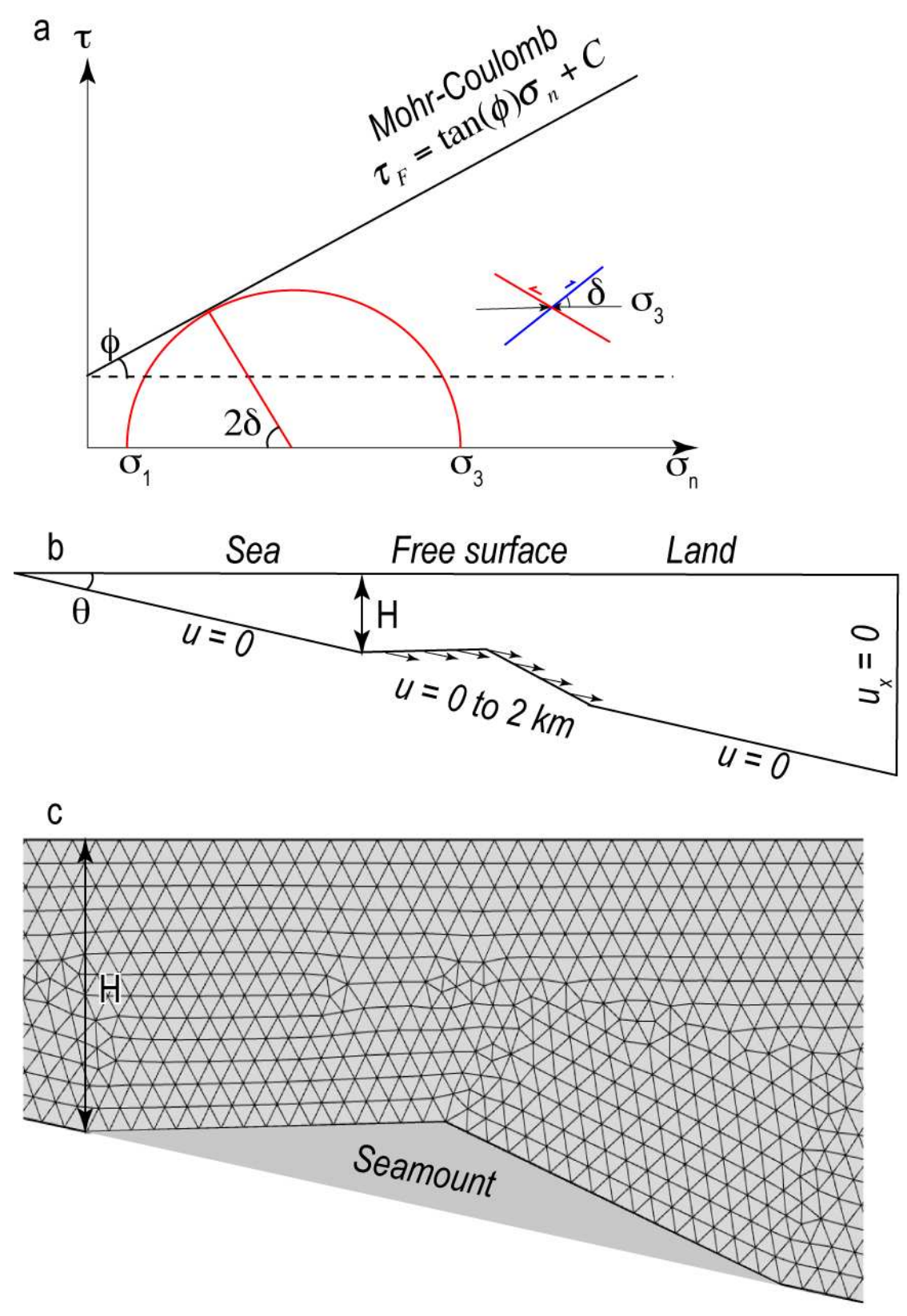

Figure 2. (a) Failure criterion and Mohr's circle. Black line represents for Mohr-Coulomb with an internal friction angle, $\phi$. Red semi-circle is the Mohr's circle representing the stress state. $\sigma_{3}$ and $\sigma_{1}$ are the maximum and minimum compressional principal stresses, respectively. Compression stress is positive. When the Mohr's circle interacts with yield envelope, failure is expected to form with an angle of $\delta=45^{\circ}-\phi / 2$ to the direction of $\sigma_{3}$. (b) Model set-up. (c) Finite element meshes for the modeling domain, with a maximum mesh size of $1 \mathrm{~km}$. 


\section{NF-L NF-S}

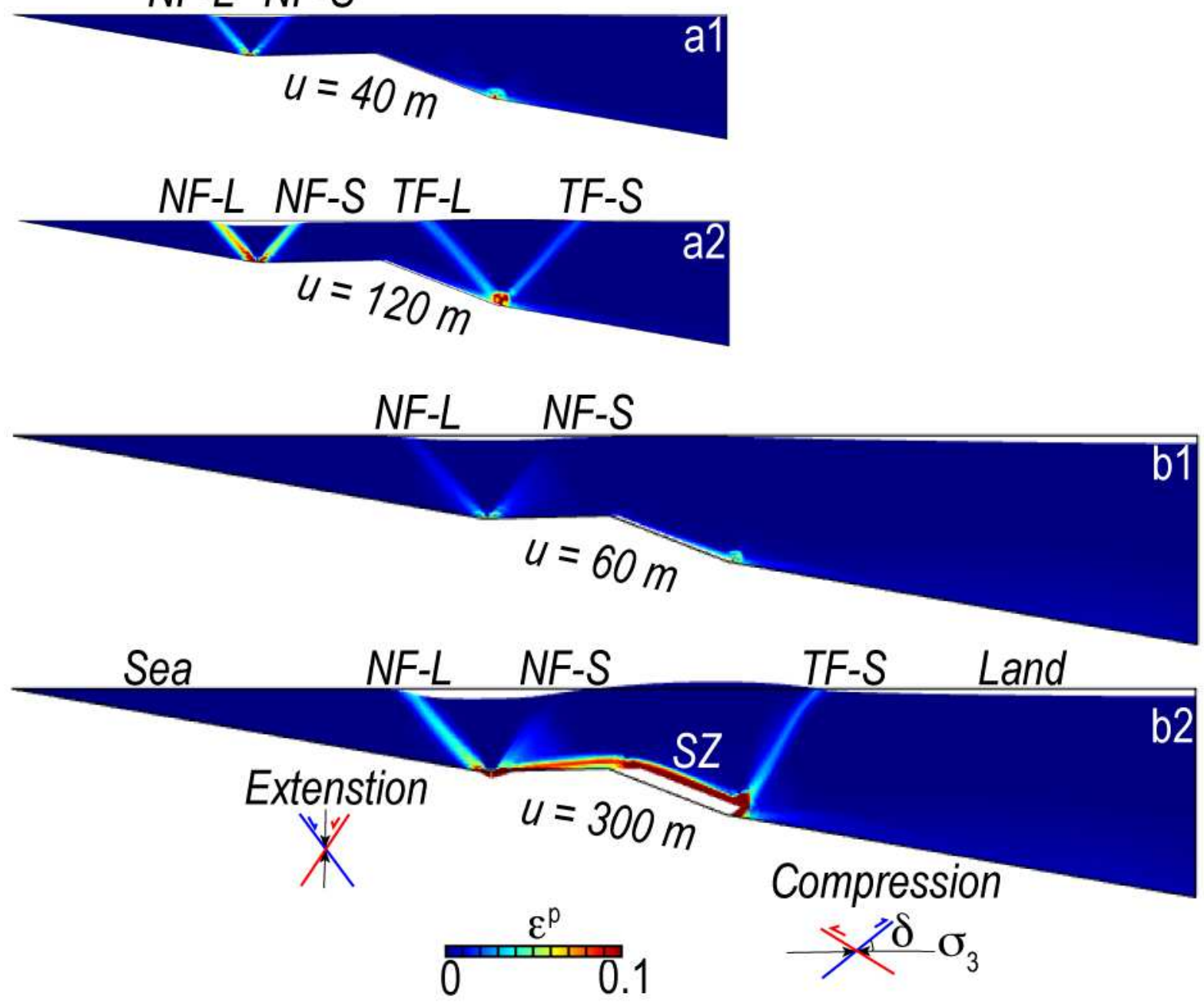

Figure 3. Snapshots showing a sequence of faults cutting though the entire plates for different seamount buried depths: (a1, a2) $H=5 \mathrm{~km}$; (b1, b2) $H=10 \mathrm{~km}$. $\theta$ and $\phi$ are assumed to be $10^{\circ}$ and $0^{\circ}$, respectively. $u$ indicates the seamount displacement for each snapshot. NF-L and NF-S are landward- and seaward-dipping normal faults caused by horizontal extension, while TF-L and TF-S are landward- and seaward-dipping thrust faults caused by horizontal compression. SZ is the shear zone following the top contour of the seamount. $\varepsilon_{\mathrm{p}}$ is the effective plastic strain, i.e., the second invariant of the plastic strain tensor, with dark blue color indicating elastic regions. Deformation of the model domain is exaggerated by a factor of 5 . 


\section{Seamount disp. required for cutting through fault, $D(m)$}
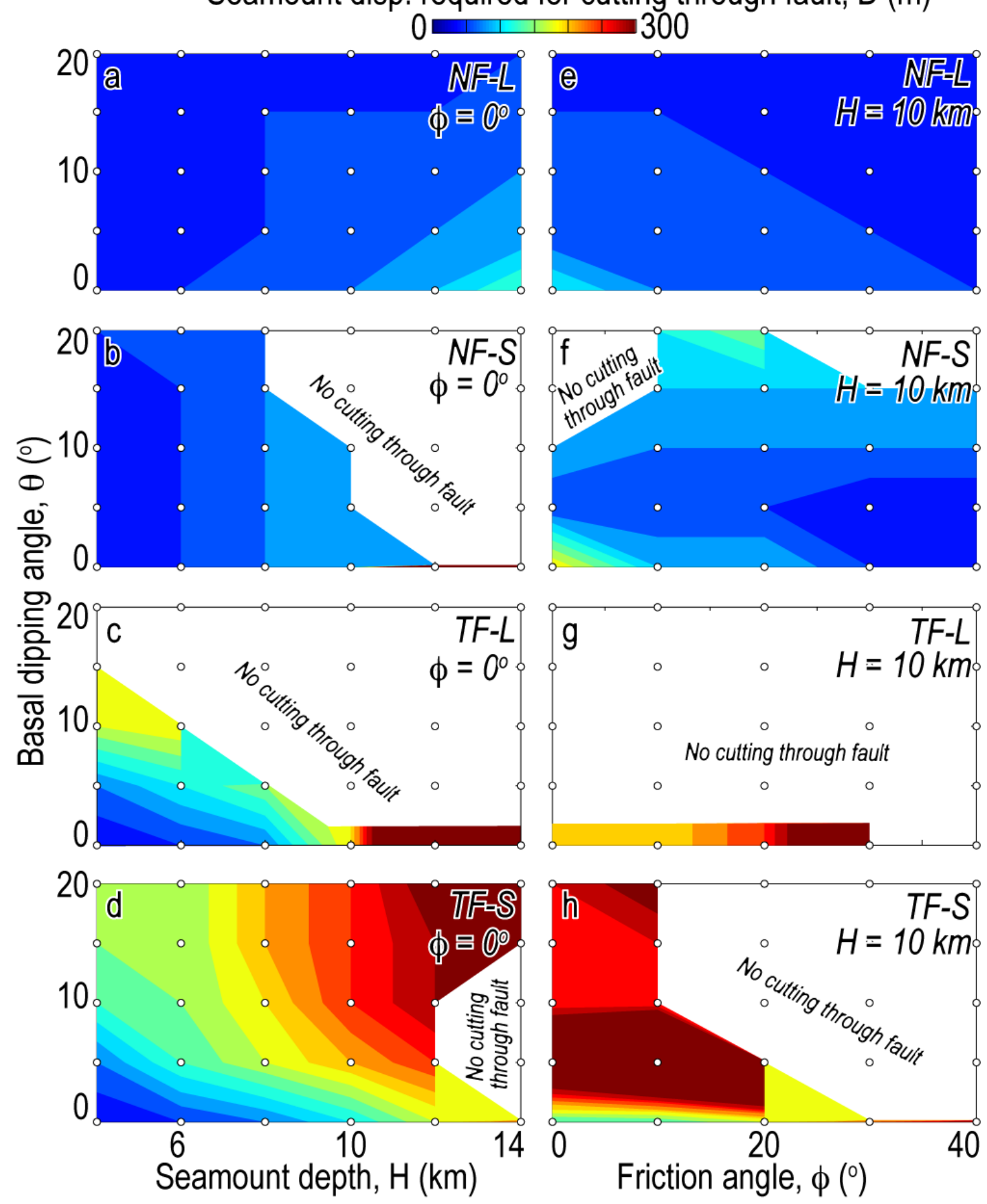

Figure 4. Seamount displacements required for the four sets of faults (NF-L, NF-S, TF-L, and TF-S) to cut through the entire overriding plate. (a-d) For various $\theta$ and $H$, assuming $\phi=0^{\circ}$; (e-h) For various $\theta$ and $\phi$, assuming $H=10 \mathrm{~km}$. Color indicates the required displacement, $D$, for faults to cut through the overriding plate. White region indicates that a specific fault cannot cut through the overriding plate. 

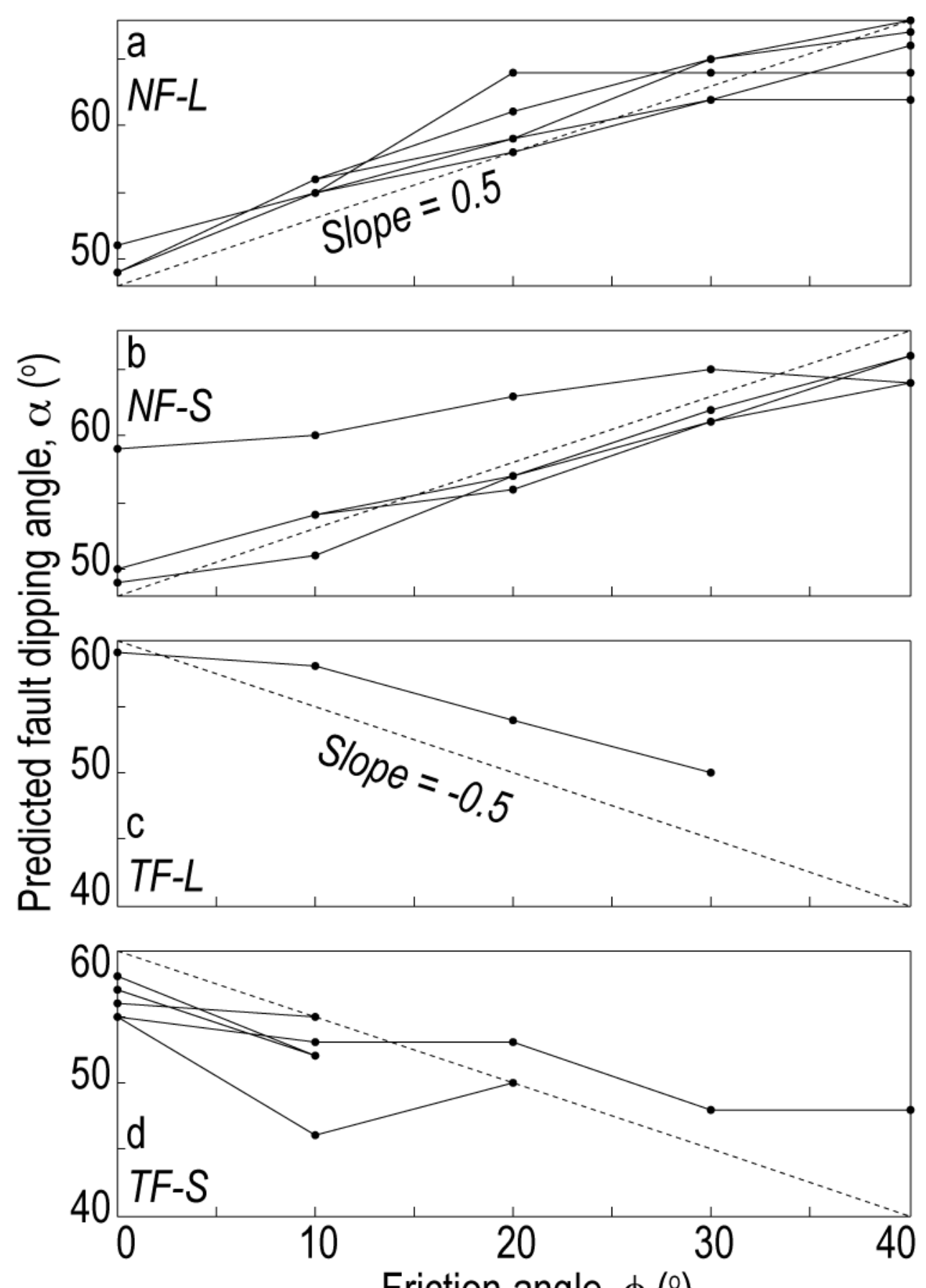

Figure 5. Predicted dipping angle $(\alpha)$ of faults that cut through the overriding plate for various $\phi$ values, while $H$ is fixed at $10 \mathrm{~km}$. Each line corresponds to a same $\theta$ value of $0,5,10,15$, or $20^{\circ}$. 

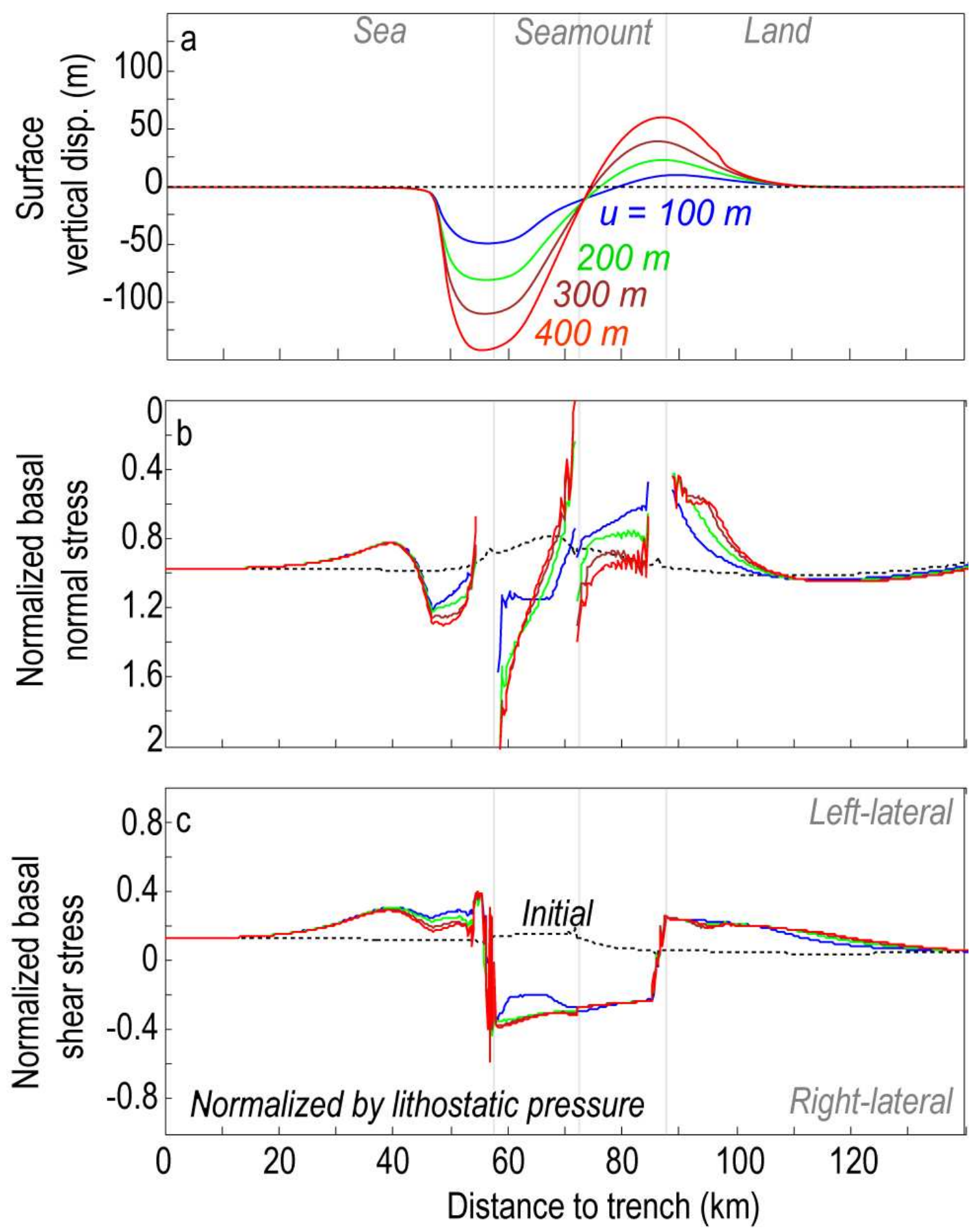

Figure 6. Results for models with $H=10 \mathrm{~km}, \theta=10^{\circ}$ and $\phi=0^{\circ}$. (a) Surface vertical displacements. (b) Basal normal stress normalized by the lithostatic pressure, $\rho g h$. (c) Basal shear stress normalized by the lithostatic pressure. Gray lines indicate the location of the seaward base, crest, and landward base of the seamount, respectively. Dashed lines indicates the initial state when $u=0 \mathrm{~m}$. Blue, green, magenta, and red colors are for increasing seamount displacement, $u=100,200,300$, and $400 \mathrm{~m}$, respectively. 


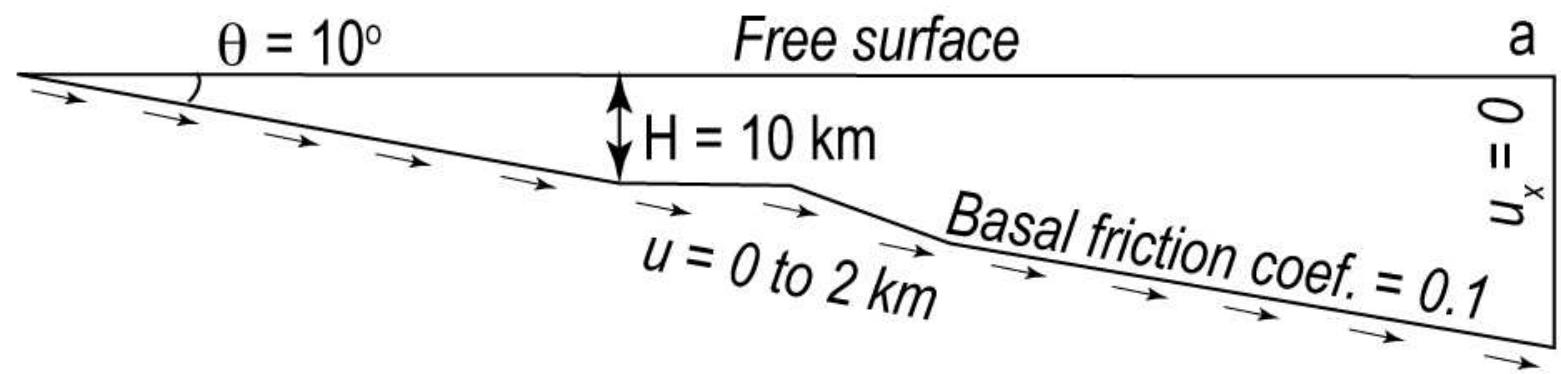

TF-L

TF-S1
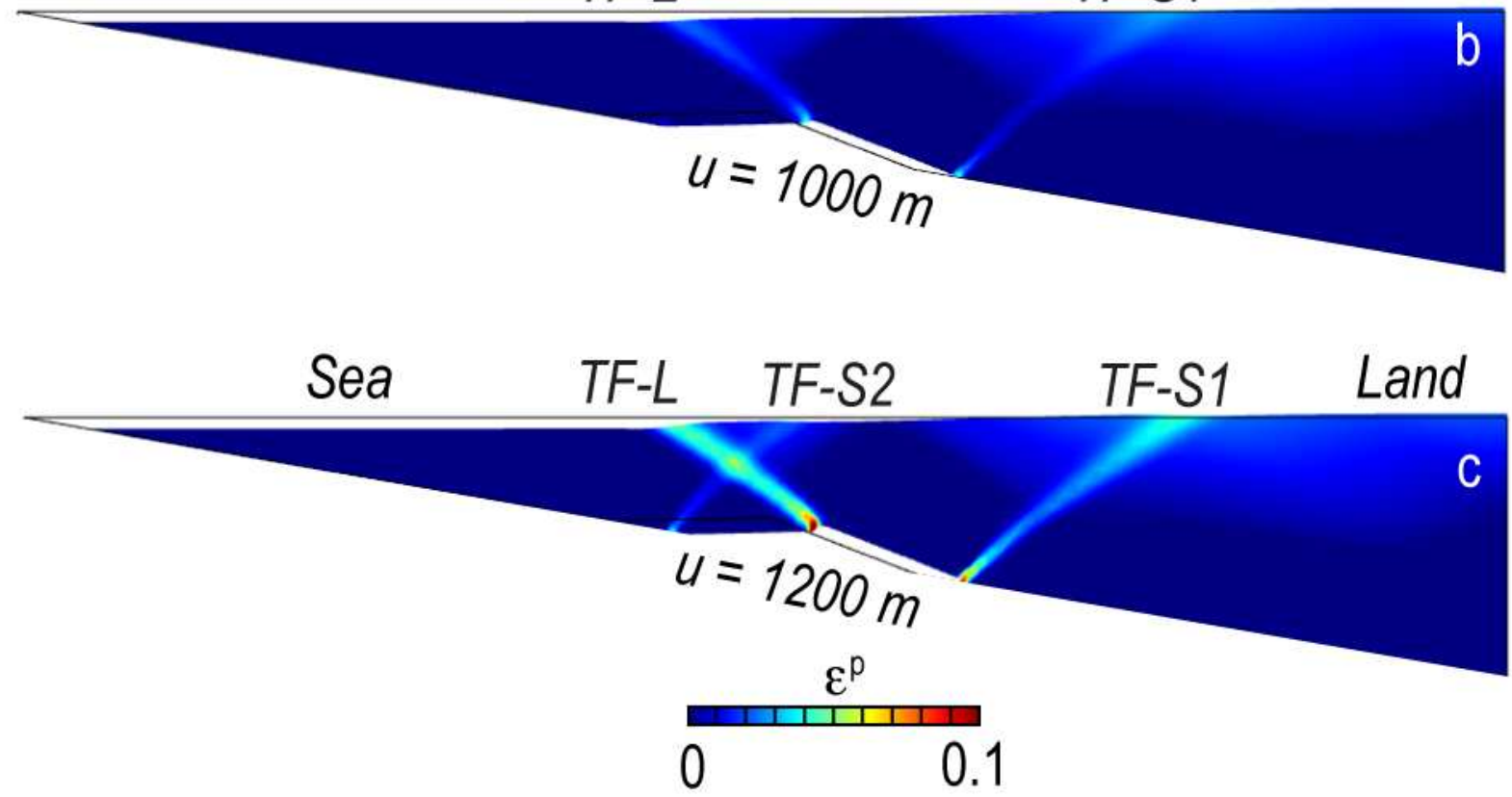

Figure 7. Basal friction model. (a) Model set-up. (b-c) Snapshots showing a sequence of thrust faults (TF-L, TF-S1, and TF-S2) that cut through the overriding plate. $\varepsilon_{\mathrm{p}}$ is effective plastic strain, with dark blue color indicating elastic regions. $u$ indicates the seamount displacement for each snapshot. 


\title{
Chapter 4: Variations in Lithospheric Strength and Sub-surface Loading on
}

\section{Mars $^{3}$}

\begin{abstract}
We conduct localized gravity/topography admittance and correlation analysis to investigate the lithospheric strength and tectonic loading of 20 tectonic sub-regions on Mars, using the latest Martian gravity model JGMRO110c. We investigated five categories of tectonic sub-region: polar regions, plain regions, volcanic regions, rift valley system, and impact basins. For each sub-region, we derive three best-fitting parameters, including the effective lithospheric thickness ( $T e$ ), sub-surface/surface loading magnitude, and surface load density. Results of analysis reveal relatively small $T e$, of less than $40 \mathrm{~km}$, for the plain regions in the southern highland, including Terra Cimmeria, Terra Sirenum, Noachis Terra, Arabia Terra, Alba Patera, and Hellas Planitia. Meanwhile, moderate $T e$ values of $40-90 \mathrm{~km}$ are calculated for the southern polar region; for the volcanic regions in the Tharsis province, including Elysium, Arsia, Pavonis and Ascraeus Montes and Solis Planum; for the rift valley system Valles Marineris; and for the impact basins Isidis and Argyre Planitiae. In contrast, relatively large Te values of more than $90 \mathrm{~km}$ are calculated for the northern polar region, as well as for Olympus Mons and Utopia Planitia. Our models suggest significant amount of sub-surface loading underneath most of the investigated plain regions and impact basins, including Plana Boreum and Australe, Vastitas Borealis, Acidalia, Utopia, Hellas, Argyre, and Isidis Planitiae. Relatively low surface load density estimated for Arabia Terra, Terra Cimmeria, Terra Sirenum, and Hellas Planitia suggests the presence of sediment deposits, hydrologic alteration, and/or erosion of basaltic material.
\end{abstract}

\footnotetext{
${ }^{3}$ Ding, M., J. Lin, and M. T. Zuber, Variations in lithospheric strength and sub-surface loading on Mars, manuscript for submission to J. Geophys. Res.: Planets.
} 


\section{Introduction}

The flexural response of the lithosphere to tectonic loading provides a key constraint to a planet's thermal state at the time of loading. On Mars, the effective elastic lithospheric thickness can be estimated by analyzing the relationship between gravity and topography observations. Mars Global Surveyor mission from 1996 to 2001 used MOLA (Mars Orbiter Laser Altimeter) to measure the topography of Mars [Zuber et al., 1992]. The measured topography has a spatial block size resolution of $0.16 \mathrm{~km}$ [Smith et al., 2001] (Figure 1a, based on the spherical harmonic model MarsTopo719 included in the SHTOOLS2.8 package, retrieved 1 December 2013 from http://sourceforge.net/projects/shtools/). In comparison with the topography, the resolution of the available gravity data on Mars is much lower. Gravity models with spherical harmonic degrees less than 60 , which corresponds to a spatial block size resolution of $\sim 176 \mathrm{~km}$, were used in previous lithospheric studies [e.g., Zuber at al., 2000; McGovern et al., 2002, 2004; McKenzie et al., 2002; Belleguic et al., 2005]. Our analysis uses the most recent gravity model, JGMRO110c, from the Mars Reconnaissance Orbiter mission. The model was released in 2012 and retrieved on 1 December 2013 from http://pds-geosciences.wustl.edu/mro/mro-m-rss-5-sdpv1/mrors_1xxx/data/shadr/. This spherical harmonic model is interpretable to degree 85, corresponding to a spatial block size resolution of $\sim 123 \mathrm{~km}$ (Figure 1b). It enables us to resolve interior density structure at higher spatial resolution than previous studies. A comparison for admittance and correlation spectra and for current and previous Mars gravitational field models is shown in Figure 2.

The relationship between gravity and topography has commonly been quantified by gravity/topography admittance and correlation in the spectral domain. In a global view, admittance and correlation spectra for the long-wavelength features (e.g., spherical harmonic 
degrees from 2 to 4 ) are too large to be explained by lithospheric flexure alone (Figure 2); they are at least partially associated with density variations caused by mantle convection [Zhong and Zuber, 2001; Zhong, 2002]. However, the global admittance and correlation spectra from degree 5 to 85 (red curves in Figure 2) are consistent with the flexural response of an elastic lithosphere to tectonic loading. In this study, we constrain flexural models for 20 tectonic sub-regions, each of $1770 \mathrm{~km}$ (i.e., $30^{\circ}$ ) in diameter (dashed circles in Figure 1a), using the technique of spatiospectral localization [Wieczorek and Simons, 2005].

For the regional spectral analysis, previous studies of Mars considered only the admittance [McGovern et al., 2002, 2004; McKenzie et al., 2002; Belleguic et al., 2005] or only the correlation [Zuber et al., 2000]. When using the admittance, McKenzie et al. [2002] assumed that there is no sub-surface loading. McGovern et al. [2002] and Belleguic et al. [2005] amended this model by considering the presence of sub-surface loading that is perfectly in phase with the surface loading. In contrast, Forsyth [1985] provided an alternative generic model, in which the sub-surface and surface loading are random in phase due to long-term erosion and sedimentation

processes. In this study, we make the same assumption of random-phase loading as Forsyth [1985] by holding the nominal phase difference between sub-surface and surface loading, $\alpha$, to be fixed at 0 [Wieczorek, 2007]. We search for flexural models to simultaneously explain the full spectra of admittance and correlation. We demonstrate that random-phase loading models could explain both admittance and correlation spectra for most of the selected regions, except for Isidis Planitia where substantial amount of in-phase sub-surface loading is indicated.

\section{Data Analysis}

To estimate spatial variations in the lithosphere strength and tectonic loading, we apply the spatio-spectral localization technique of Wieczorek and Simons [2005], which allows us to 
narrow in on the gravity and topography data of selected sub-regions. For a given cap region with an angular diameter of $2 \theta_{0}$, a localization cap window of a given bandwidth, $L_{w i n}$, is constructed to optimize the signal within the region, resulting in a concentration factor of more than $99 \%$. Using the localization window, original gravity and topography data are retained in the center of the given cap region, but gradually filtered out to zero outside the region, yielding localized gravity (e.g., Figure 3a) and topography (e.g., Figure 3b), respectively. In this study, we use the SHTOOLS2.8 software to construct localization windows with $2 \theta_{0}=30^{\circ}$ and $L_{\text {win }}=$ 17 (Figure 3a) for 20 sub-regions of distinct physiographical features.

For each of the 20 physiographic regions, we first transform the localized free-air gravity and topography to the spherical harmonic domain, and then calculate the corresponding admittance and correlation spectra between gravity and topography. To maintain consistency with our linear lithospheric flexure models, the terrain correction is applied ahead of time by subtracting higherorder topography terms from the total free-air gravity [Wieczorek, 2007]. In the spherical harmonic domain, the admittance is defined as the cross-power spectrum between the gravity and topography, being normalized by the power spectrum of the topography [Wieczorek, 2007]:

$$
\begin{aligned}
& Z(l)=S_{h g}(l) / S_{h h}(l), \\
& S_{h g}(l)=\sum_{m=-l}^{l} h_{l m} g_{l m}, \\
& S_{h h}(l)=\sum_{m=-l}^{l} h_{l m}^{2},
\end{aligned}
$$

where $h_{l m}$ and $g_{l m}$ are the coefficients in spherical harmonic degree $l$ and order $m$ of the gravity and topography fields, respectively. The parameter $S_{h g}(l)$ is the cross-power spectrum of the gravity and topography, and $S_{h h}(l)$ is the power spectrum of the topography.

The correlation between topography and gravity takes the form: 


$$
\begin{aligned}
& \gamma(l)=S_{h g}(l) / \sqrt{S_{h h}(l)} \sqrt{S_{g g}(l)}, \\
& S_{g g}(l)=\sum_{m=-l}^{l} g_{l m}^{2},
\end{aligned}
$$

where $S_{g g}(l)$ is the power spectrum of the gravity anomaly.

The Bouguer gravity anomaly is calculated by subtracting from the observed free-air anomaly the gravitational effects of the observed topography, assuming a uniform crustal density $\rho_{c}=2,900 \mathrm{~kg} / \mathrm{m}^{3}$. The Bouguer gravity anomaly reflects the gravity signal caused by sub-surface density anomaly. For example, positive Bouguer anomalies in the northern hemisphere indicate thin crust and/or sub-surface material of high density (Figure 1c). In comparison, negative Bouguer anomalies in the southern hemisphere indicate thick crust and/or sub-surface material of low density. Using spherical harmonic coefficients of the Bouguer anomaly, the admittance and correlation spectra between the Bouguer anomaly and topography are calculated using Equations $1-5$.

\section{Lithospheric Flexural Model}

We calculate theoretical gravity/topography admittance and correlation for a series of lithospheric flexural models including the presence of both surface and sub-surface loading. We modify the formulation of McGovern et al. [2002] by adding a parameter, $\alpha$, which is the phase difference between the sub-surface and surface loading. Details of calculations are given in Appendix A. The predicted admittance and correlation depend on the physical properties of and the characteristics of tectonic loading on the lithosphere [Wieczorek, 2007]:

$$
\begin{aligned}
& Z(l)=Z\left(T e, E, v, \rho_{c}, H_{c}, \rho_{m}, \rho_{t}, \Delta \rho_{b}, f, \alpha\right), \\
& \gamma(l)=\gamma\left(T e, E, v, \rho_{c}, H_{c}, \rho_{m}, \rho_{t}, \Delta \rho_{b}, f, \alpha\right),
\end{aligned}
$$


where Te, $E$ and $v$ are the effective thickness, Young's modulus and Poisson's ratio of the elastic lithosphere, respectively. $\rho_{c}, \rho_{m}$ and $\rho_{t}$ are densities of crust, mantle and surface loading, respectively; $\Delta \rho_{b}$ is the density contrast between the sub-surface load and the crust, which is assumed to be $\rho_{m}-\rho_{c}$. The parameter $H_{c}$ corresponds to the thickness of the crust. We assume that sub-surface loading is situated at the base of the crust. We hold $E, v, \rho_{c}, \rho_{m}, H_{c}$ and $\Delta \rho_{b}$ fixed (Table 1), while $T e$ and $\rho_{t}$ are varied for different regions. The parameters $f$ and $\alpha$ are defined as the relative magnitudes and the phase differences of the sub-surface versus the surface loading, respectively [Wieczorek, 2007]:

$$
\begin{gathered}
\alpha=\left(\sum_{m=-l}^{l} h_{l m}^{i} w_{l m}^{i}\right) /\left[\sqrt{\sum_{m=-l}^{l}\left(h_{l m}^{i}\right)^{2}} \sqrt{\sum_{m=-l}^{l}\left(w_{l m}^{i}\right)^{2}}\right] \\
f=\Delta \rho_{b} \sqrt{\sum_{m=-l}^{l}\left(w_{l m}^{i}\right)^{2}} / \rho_{t} \sqrt{\sum_{m=-l}^{l}\left(h_{l m}^{i}\right)^{2}},
\end{gathered}
$$

where $h_{l m}^{i}$ and $w_{l m}^{i}$ are spherical harmonic coefficients of the initial surface and sub-surface load thicknesses, respectively. We assume $\alpha$ and $f$ are the same for all the spherical harmonic degrees within a sub-region. Parameter values $\alpha=1$ and $\alpha=-1$ represent the cases when subsurface and surface loading are perfectly in and out of phase, respectively [McGovern et al., 2002; Belleguic et al., 2005]. $\alpha=0$ is when the loading is random in phase [Forsyth, 1985].

The predicted free-air and Bouguer admittance and correlation have different sensitivity to the parameters $T e, \rho_{t}, f$ and $\alpha$ (Figure 4). The predicted free-air admittance increases from close to zero in degree 2 , approaching $2 \pi G \rho_{t}$ above degree 80 (Figure $4 \mathrm{~b} 1$ ). The transition depends on values of $T e, f$ and $\alpha$. As Te or $\alpha$ increases, the transition shifts to lower degrees (Figures $4 \mathrm{a} 1$ and $\mathrm{d} 1$ ). At the same time, the transition slope increases. As $f$ increases, the transition occurs in higher degrees (Figure 4c1). The predicted Bouguer admittance has the 
similar shape as the free-air admittance, but is smaller by $2 \pi G \rho_{c} \sim 120 \mathrm{mGal}$ (e.g., comparing Figure 4a1 with a2). The free-air correlation is predicted to be close to 1 above degree 60 (Figure $4 \mathrm{a} 3, \mathrm{~b} 3, \mathrm{c} 3$ and $\mathrm{d} 3$ ). For low degrees, the existence of sub-surface loading (i.e., large $f$ and/or $\alpha$ ) makes the free-air correlation smaller. In extreme cases when $\alpha>0.8$, the predicted free-air correlation could be negative for degrees lower than 20 (Figure 4d3). The predicted Bouguer correlation increases from close to -1 in degree 2 , approaching 0 above degree 80 , for $\rho_{t}=\rho_{c}$ and $\alpha=0$ (Figures $4 \mathrm{a} 4$ and $\mathrm{c} 4$ ). As $\rho_{t}$ or $\alpha$ increases, the Bouguer correlation approaches larger value in high degrees (Figures $4 \mathrm{~b} 4$ and $\mathrm{d} 4$ ).

Regional flexural models are determined by minimizing the normalized misfits between models and observations for admittance and correlation spectra:

$R M S=\sqrt{\left.\frac{1}{4\left(85-2 L_{\text {win }}\right.}\right)_{l=L_{\text {win }}+1}^{85-L_{\text {win }}}\left[\left(\frac{Z_{\text {obs }}^{F A A}-Z_{\text {Model }}^{F A A}}{\Delta Z}\right)^{2}+\left(\frac{Z_{\text {Obs }}^{B A}-Z_{\text {Model }}^{B A}}{\Delta Z}\right)^{2}+\left(\gamma_{\text {obs }}^{F A A}-\gamma_{\text {Model }}^{F A A}\right)^{2}+\left(\gamma_{\text {obs }}^{B A}-\gamma_{\text {Model }}^{B A}\right)^{2}\right]}$,

where $Z_{\text {Obs }}^{F A A}$ and $Z_{\text {obs }}^{B A}$ are the observed free-air and Bouguer admittance; $\gamma_{O b s}^{F A A}$ and $\gamma_{o b s}^{B A}$ are the observed free-air and Bouguer correlation. $Z_{\text {Model }}^{F A A}$ and $Z_{\text {Model }}^{B A}$ are the predicted free-air and Bouguer admittance; $\gamma_{\text {Model }}^{F A A}$ and $\gamma_{\text {Model }}^{B A}$ are the predicted free-air and Bouguer correlation. $L_{\text {win }}=$ 17 is the bandwidth of localization windows. The misfits for admittance are normalized by $\Delta Z$. Our tests show that best-fitting results are consistent for $\Delta Z$ values from 100 to $200 \mathrm{mGal} / \mathrm{km}$, and thus we choose $\Delta Z=150 \mathrm{mGal} / \mathrm{km}$. The best-fitting flexural model is the solution yielding minimum RMS value, $\mathrm{RMS}_{\min }$, while the "acceptable" range is defined as solutions with RMS values less than $\mathrm{RMS}_{\min }+0.05$.

For most of investigated regions, the models are over-constrained when inverting for the four parameters: Te, $f, \rho_{t}$ and $\alpha$. We decrease the freedom of model by assuming $\alpha=0$ (i.e., assuming random-phase sub-surface loading). For a particular region, Isidis Planitia, model 
results show that larger $\alpha$ is required and we thus also solve for a best-fitting $\alpha$ value. We search for $T e$ in the range of $0-400 \mathrm{~km}$ with increment of $10 \mathrm{~km}$, and $f$ in the range of $0-2$ with increment of 0.1. Ranges of $\rho_{t}$ are assumed to be different for the five types of tectonic regions: $1,000-2,000 \mathrm{~kg} / \mathrm{m}^{3}$ for the polar regions, $2,500-2,900 \mathrm{~kg} / \mathrm{m}^{3}$ for the plain regions, $3,000-3,200$

$\mathrm{kg} / \mathrm{m}^{3}$ for the volcanic regions, $2,500-3,200 \mathrm{~kg} / \mathrm{m}^{3}$ for the impact basins, and $2,900 \mathrm{~kg} / \mathrm{m}^{3}$ for Valles Marineris. The parameter $\rho_{t}$ varies in increments of $25 \mathrm{~kg} / \mathrm{m}^{3}$ for the volcanic regions and $50 \mathrm{~kg} / \mathrm{m}^{3}$ for the other regions. For Isidis Planitia, $\alpha$ is solved from 0 to 1 with increment of 0.1.

\section{Results}

We search for flexural and loading parameters $T e, f$ and $\rho_{t}$ that best fit, in a root mean square sense, the observed admittance and correlation spectra for 20 sub-regions of distinct tectonic features (Figure 1a). Those regions are categorized into five tectonic types. (Type 1) Polar regions: Plana Boreum and Australe. (Type 2) Plain regions: Vastitas Borealis, Acidalia Planitia, Arabia Terra, Noachis Terra, Terra Cimmeria and Terra Sirenum. (Type 3) Volcanic regions: Alba, Olympus, Arsia, Pavonis, Ascraeus and Elysium Montes, as well as Solis Planum. (Type 4) Rift valley system: Melas Chasma (Valles Marineris). (Type 5) Impact basins: Utopia, Isidis, Hellas and Argyre Planitiae. We assume different ranges of surface load density $\rho_{t}$ for the five tectonic categories.

\subsection{Polar Regions}

The polar regions of Mars are loaded by mixtures of ice and sediment, which correspond to the $\rho_{t}$ range of $1,000-2,000 \mathrm{~kg} / \mathrm{m}^{3}$ [Johnson et al., 2000]. For the northern polar region, Planum Borealis, we estimate the best-fitting $T e$ solution to be about $100 \mathrm{~km}$ with a minimum RMS misfit of 0.28 (Figure 5a). The acceptable $T e$ range is $60-280 \mathrm{~km}$ (Figure B1a1), with RMS 
misfits less than 0.33 , which is consistent with $60-120 \mathrm{~km}$ obtained in the flexure analysis of Johnson et al. [2000]. We estimate $f$ to be more than 1.3 (Figure B1a2), indicating a significant amount of sub-surface loading that is required to explain the weak correlation between free-air gravity and topography (Figure 5a3). We estimate the range of $\rho_{t}$ to be $1,200-2,000 \mathrm{~kg} / \mathrm{m}^{3}$ with a best-fitting value of $1,950 \mathrm{~kg} / \mathrm{m}^{3}$ (Figure B1a1). Although the best-fitting solution matches well with the observed spectra in degrees 18-50 (Figures 5a), it can not explain the reduced signals in degrees 50-65. One possible explanation for the misfits is surface loading density $\rho_{t}$ as low as that of the pure-ice density of $1,000 \mathrm{~kg} / \mathrm{m}^{3}$ used by Johnson et al. [2000]. In addition, complex sub-surface loading or viscous relaxation might contribute to the signals in degrees 50-65.

For the southern cap region, Planum Australe, we estimate the best-fitting $T e, \rho_{t}$ and $f$ values to be $40 \mathrm{~km}, 1,950 \mathrm{~kg} / \mathrm{m}^{3}$ and 2, respectively, with a minimum RMS misfit of 0.20 (Figure 5b). There are two distinct acceptable zones for $T e$ and $\rho_{t}$ with RMS misfits of less than 0.25 (Figure B1b1). One corresponds to Te range of 30-50 km and $\rho_{t}$ range of 1,450-2,000 $\mathrm{kg} / \mathrm{m}^{3}$; the other corresponds to Te larger than $120 \mathrm{~km}$ and $\rho_{t}$ range of $1,000-1,150 \mathrm{~kg} / \mathrm{m}^{3}$. The latter case, large $T e$ in combination with small $\rho_{t}$, is similar to the solution of Zuber et al. [2007] based on analysis of spatial variation in gravity and topography within the southern layered deposits.

\subsection{Plain Regions}

The six plain regions that we investigated include two in northern lowlands (Vastitas Borealis and Acidalia Planitia) and four in southern highlands (Arabia Terra, Noachis Terra, Terra Cimmeria and Terra Sirenum). The assumed $\rho_{t}$ range of 2,500-2,900 kg/m $\mathrm{m}^{3}$ for the plain regions is consistent with sedimentary deposits or erosion of denser basaltic material. For the four regions in the southern highlands, we find well-constrained solutions with minimum RMS 
misfits of less than 0.16 (Figure 6c-f). However, the solutions are not well constrained for the two regions in the northern lowlands due to large fluctuations in the observed spectra (Figures $6 a-b)$.

For Arabia Terra, Terra Cimmeria and Terra Sirenum, admittance spectra are relatively flat with low magnitude (e.g., Figures 6c1), suggesting close to Airy isostatic state and low $T e$. For these three regions, $T e$ values are estimated to be smaller than $20 \mathrm{~km}$, consistent with solutions of McGovern et al. [2004] and Zuber et al. [2000] (Figure 9a). In comparison, the slightly steeper slope in the admittance spectra for Noachis Terra (Figure 6d1) suggests a slightly larger Te range of $30-40 \mathrm{~km}$ with a best-fitting value of $30 \mathrm{~km}$ (Figure $\mathrm{B} 2 \mathrm{~d} 1$ ). This $T e$ solution for Noachis Terra is slightly larger than the solutions of McGovern et al. [2004] and Zuber et al. [2000] (Figure 9a) because we incorporate the existence of sub-surface loading. Since subsurface loading is required to explain the free-air correlation observation, as discuss next, this $T e$ solution is more reliable than previous estimates.

The observed free-air correlation spectra are less than 1, for all plain regions (Figures 6a3, b3, c3, d3, e3 and f3), indicating significant amounts of sub-surface loading. We estimate $f$ values to be more than 0.2 for Vastitas Borealis and more than 0.4 for the other regions (Figure B2). Bouguer correlation spectra close to -1 are observed for Arabia Terra (Figure 6c4), Terra Cimmeria (Figure 6e4) and Terra Sirenum (Figure 6f4), even in the highest spherical harmonic degrees, suggesting small surface load density $\rho_{t}$. Our $\rho_{t}$ estimates are less than $2,650 \mathrm{~kg} / \mathrm{m}^{3}$ in Arabia Terra (Figure B2c1), less than $2,750 \mathrm{~kg} / \mathrm{m}^{3}$ in Terrea Cimmeria (Figure B2e1), and less than $2,700 \mathrm{~kg} / \mathrm{m}^{3}$ in Terra Sirenum (Figure B2f1). 


\subsection{Volcanic Regions}

The Tharsis province is a volcanic plateau in the western hemisphere, which is the home to the largest volcanic structure in the solar system, Olympus Mons, as well as home to other volcanic montes (Alba, Arsia, Pavonis and Ascraeus Montes) and volcanic plains (e.g., Solis Planum) (Figure 1a). For this tectonic category, we also investigate a volcanic mons outside the Tharsis province, Elysium Mons. For these volcanic regions, we assume $\rho_{t}$ varies from 3,000 to $3,200 \mathrm{~kg} / \mathrm{m}^{3}$, approximately the range of measured bulk densities of Martian shergottites [Britt and Consolmagno, 2001]. The observed spectra of volcanic montes reveal some similar characteristics. High magnitudes of the admittance spectra indicate relatively large $T e$ and/or $\rho_{t}$ (e.g., Figures 7b1-2). High magnitudes of the Bouguer correlation above degree 30 also suggest large $\rho_{t}$ (Figure 7b4). Free-air correlation close to 1 in all the spherical harmonic degrees (except for Alba Patera) can be explained by relatively large surface loading, i.e., $f$ close to 0 (Figures 7b3, c3, d3, e3 and f3).

Our estimated Te and $\rho_{t}$ are less than $10 \mathrm{~km}$ and 3,125-3,200 kg/m $\mathrm{m}^{3}$ for Alba Patera (Figure B3a1); more than $70 \mathrm{~km}$ and 3,075-3,200 kg/m³ for Olympus Mons (Figure B3b1); 60-70 km and 3,125-3,175 kg/m³ for Arsia Mons (Figure B3c1); $50-130 \mathrm{~km}$ and 3,125-3,200 kg/m $\mathrm{m}^{3}$ for Pavonis Mons (Figure B3d1); 60-180 km and 3,125-3,200 kg/m³ for Ascraeus Mons (Figure B3e1); and $40-90 \mathrm{~km}$ and $3,050-3,150 \mathrm{~kg} / \mathrm{m}^{3}$ for Elysium Mons (Figure B3f1). For all the volcanic montes, our estimated $f$ is less than 0.2 . Most of our Te estimates are consistent with the results of McGovern et al. [2004], Belleguic et al. [2005], or Zuber et al. [2000] except for Alba Patera (Figure 9a). Previous solutions for Alba Patera only explain the spectra in degrees lower than 35, which has deeper slope and therefore yields larger Te (Figure 7a1). In contrast, our model tends to fit the overall trend in all degrees. In degrees $35-70$, there is substantial subsidence for all the 
admittance and correlation spectra, probably indicating considerable sub-surface loading in the corresponding wavelength domain. Numerically, it suggests that $f$ might not be constant in all spherical harmonic degrees as we have assumed, but might be smaller in degrees 18-35 and larger in degrees 35-70.

For the volcanic plain Solis Planum, the observed free-air correlation is significantly less than 1 (Figure 7g3), which suggests the existence of sub-surface loading. We estimate $f$ to be more than 0.6 with RMS misfits of less than 0.28 (Figure B3g2). The best-fitting $f$ is estimated to be 1.2 with a corresponding RMS misfit of 0.23 . Our estimated $T e$ range of $40-80 \mathrm{~km}$ with a best-fitting value of $60 \mathrm{~km}$ is larger than 24-37 km from McGovern et al. [2004], mainly because we also take into account the correlation spectra.

\subsection{Valles Marineris}

For the rift valley system Valles Marineris, admittance spectra are observed to be flat up to the highest degree 68 (Figures 7h1-2). In addition, the observed free-air correlation spectra of close to 1 suggest relatively small $f$ value (Figure $7 \mathrm{~h} 3$ ), similar to that of the volcanic montes. Assuming $\rho_{t}=2,900 \mathrm{~kg} / \mathrm{m}^{3}$, we estimate $T e$ and $f$ to be $40-60 \mathrm{~km}$ and $0.1-0.2$, respectively. Our model fits well with the admittance spectra over spherical harmonic degree 50 (Figure 7h1). In comparison, Anderson and Grimm [1998] used gravity observations lower than degree 50 to derive $T e$ of less than $30 \mathrm{~km}$. If smaller $\rho_{t}$ is assumed, the trade-off between $\rho_{t}$ and $T e$ will give larger $T e$ estimates (e.g., Figure B3c1). For example, $\rho_{t}$ of smaller than $2,900 \mathrm{~kg} / \mathrm{m}^{3}$ in combination with $T e$ of larger than $60 \mathrm{~km}$ was proposed by McGovern et al. [2004]. They suggested that the lower $\rho_{t}$ is consistent with compacted sedimentary, ash deposits, hydrothermal alteration, dissolution of denser basaltic material or the presence of interstitial ice. 


\subsection{Impact Basins}

Major impact basins on Mars include Utopia, Isidis, Hellas and Argyre Planitiae. For the two impact basins in the northern hemisphere, Isidis and Utopia Planitiae, we observe clear bull's eye pattern in the free-air gravity (Figure 1b), which is similar to lunar mascon basins [Muller and Sjogren, 1968; Zuber et al., 1994; Neumann et al., 1996; Melosh et al., 2003]. The bull's eye pattern consists a central positive anomaly, a surrounding negative collar, and a positive outer annulus. This corresponds in a spectral sense to a transition from negative to positive free-air admittance with increasing spherical harmonic degree (Figure 8a). Both the spatial bull's eye patterns and spectral transitions suggest the existence of sub-surface loading, i.e., mascon feature. In our parameter tests, $f$ is estimated to be larger than 1.4 for Utopia Planitia (Figure B4a2). For Isidis Planitia, the rapid transition from less than $-100 \mathrm{mGal} / \mathrm{km}$ in degree 23 to 275 $\mathrm{mGal} / \mathrm{km}$ in degree 30 could not be explained by random phase in sub-surface loading, i.e., $\alpha=$ 0 . In this particular case, we test models with $\alpha$ ranging from 0 to 1 in increment of 0.1 . We find that $\alpha=0.9$ could fit the observed spectra well, suggesting that the sub-surface loading is closely in phase with the surface loading. Assuming $\alpha=0.9$, we estimate $f$ to be $1.5-1.9$ (Figure B4b2). For both Utopia and Isidis Planitiae, the high-magnitude free-air admittance over degree 35 suggests relatively large $T e$ and $\rho_{t}$ (Figures $8 \mathrm{a} 1$ and $\mathrm{b} 1$ ). Parameter analysis for Utopia Planitia yields $T e$ of $90-220 \mathrm{~km}$, but does not provide good constraint on $\rho_{t}$ (Figure B4a1). For Isidis Planitia, Te and $\rho_{t}$ are estimated to be about $80 \mathrm{~km}$ and in the range of 2,500$2,900 \mathrm{~kg} / \mathrm{m}^{3}$, respectively (Figure B4b1).

In the southern hemisphere, the central positive free-air anomaly is relatively mild for Argyre Planitia, and negligible for Hellas Planitia (Figure 1b). The absence of a central mascon in the large Hellas Planitia might indicate viscous relaxation, as suggested for the Moon's South Pole 
Aitken basin [Neumann et al., 1996; Garrick-Bethell and Zuber, 2009]. The observed admittance and correlation spectra for Hellas and Argyre Planitiae (Figures 8c-d) are relatively small with respect to Utopia Planitia, indicating smaller $T e$ and $\rho_{t}$. We estimated $T e$ of 70-100 km for Argyre Planitia (Figure B4c1), and less than $10 \mathrm{~km}$ for Hellas Planitia (Figure B4d1). $\rho_{t}$ for Argyre Planitia is not well constrained (Figure B4d1). $\rho_{t}$ for Hellas Planitia is estimated to be $2,500-2,900 \mathrm{~kg} / \mathrm{m}^{3}$, with a best-fitting value of $2,500 \mathrm{~kg} / \mathrm{m}^{3}$ (Figure B4c1). This low $\rho_{t}$ range indicates the presence of sedimentation or hydrologic alteration. The jagged patterns in admittance and spectra (e.g., Figure 8c) might indicate complex loading and viscous relaxation processes.

\section{Discussion}

\subsection{Wavelength Dependence of the Effective Lithospheric Thickness Estimates}

It is well known that the compensation state depends on the wavelength [e.g., Turcotte et al., 1981], which is equal to $\frac{2 \pi R}{\sqrt{l(l+1)}}$ and therefore inversely related with spherical harmonic degree $l$. The admittance and correlation spectra always approach Airy isostatic compensation at long wavelength and low spherical harmonic degree, and lack of compensation at small wavelength and high spherical harmonic degree (Figure 4a). The transition from Airy compenstation to uncompensation is expected to occur in lower degree for larger Te values. Our localized admittance and correlation analysis for sub-regions considers degrees greater than 18 , therefore can only resolve model differences in $T e$ less than about $200 \mathrm{~km}$. If lower degrees are included, it is possible that we could detect regions of larger $T e$ values. In order to test the sensitivity of $T e$ estimates to degrees, we apply a series of localization windows with increasing cap diameter $\left(2 \theta_{0}\right)$ up to $110^{\circ}$ to four selected regions of different tectonic types. With increasing $2 \theta_{0}$, the 
corresponding minimum spherical harmonic degree $L_{\text {win }}$ that can be resolved in the localization process decreases to as low as $L_{\text {win }}=4$. Results show that although the best-fitting $T e$ values do not stay the same, the estimated $T e$ ranges are consistent for different localization windows (Figure 11a). Therefore we conclude that our results are relatively robust in estimating the ranges of $T e$.

\subsection{Sub-surface Loading}

Free-air correlation spectra of less than 1 are clearly seen in most of the plain regions and impact basins, suggesting the presence of sub-surface loading. In an attempt to quantify the subsurface loading, McGovern et al. [2002 and 2004] and Belleguic et al. [2005] assumed that the sub-surface loading is perfectly in phase with the surface loading. However, Forsyth [1985] suggested that erosion and sedimentation processes could randomize the surface topography, yielding random phase between the surface and sub-surface loads. It is also possible that the subsurface loading is geologically independent of the surface loading, such as suggested by models of sub-surface dike intrusion in Tharsis province [Scott et al., 2002]. Under the assumption of random sub-surface loading, i.e., $\alpha=0$, we are able explain the gravity/topography relationship for most of the investigated regions except for Isidis Planitia. In Isidis Planitia, substantial amount of in-phase sub-surface loading (i.e., $\alpha=0.9$ ) is required. The in-phase sub-surface loading could imply that uplifted mantle material might have replaced the less dense crust during impact excavation and the subsequent unloading of the shock wave [Melosh, 1989]. This structure could have frozen in the lithosphere while the impact-heated mantle cools [Melosh et al., 2013], resulting in sub-surface loading that is in phase with the surface structure. 


\subsection{Surface Load Density}

Our Te estimates depend on the assumed ranges of surface load density $\rho_{t}$. When we solve for $T e$ and $\rho_{t}$ at the same time, there is a trade-off between the two parameters (e.g., Figure $\mathrm{B} 3 \mathrm{c} 1)$. Therefore, geological information for $\rho_{t}$ ranges could provide additional constraints. We consider the surface loads in polar regions, plain regions, volcanic regions, and impact basins to be consisted primarily of ice/sediment, sediment, lava basalt, and sediment/basalt, respectively, and use corresponding $\rho_{t}$ ranges for different tectonic types. These $\rho_{t}$ assumptions are proven to be important for our solutions. Chemical and mineral analysis from the Mars Odyssey and Mars Global Surveyor spacecraft provides global elemental and mineral abundances [McSween et al., 2009] that could be used in the future to calculate the surface rock densities [e.g., Huang and Wieczorek, 2012].

\subsection{Comparison with Previous Lithospheric Thickness Estimates}

We compare our estimates of $T e$ with previous studies using difference geophysical methods in Figure 9a. In the previous gravity-based studies, McKenzie [2002], Zuber et al. [2000], Johnson et al. [2000] and Anderson and Grimm [1998] did not consider sub-surface loading, except for Utopia Planitia in Zuber et al. [2000]. McGovern et al. [2002 and 2004], and Belleguic et al. [2005] assumed in-phase sub-surface loading. The results of this study demonstrate that random-phase sub-surface loading models could also explain the gravity/topography relationship in various regions. For the regions where sub-surface loading is insignificant, e.g., volcanic montes, our results are consistent with previous studies. For the regions with significant amount of random-phase sub-surface loading, e.g., Noachis Terra, our solutions might be more robust. For Isidis Planitia, we find a well-constrained solution with significant amount of in-phase subsurface loading, which can not be resolved in McGovern et al. [2002] due to their limited range 
of $f$. In addition to gravity studies, Comer et al. [1985] estimated $T e$ values for volcanic montes and Isidis Planitia by analyzing fault system concentric to the volcanic montes. Their estimated $T e$ values are close to our gravity-derived solutions.

\subsection{Comparison with Surface Age}

We compare the surface chronostratigraphic age [Tanaka et al., 2013] with our estimated Te for the 20 sub-regions in Figure 10. If $T e$ reflects the thermal state of the lithosphere at the time of loading [Zuber et al., 2000], the estimated Te less than $40 \mathrm{~km}$ in Terra Sirenum, Terra Cimmeria, Arabia Terra and Noachis Terra would be consistent with their crustal stabilization and loading at the earliest time of Martian evolution. The increase in $T e$ from the southern polar region, Planum Australe, to the northern polar region, Planum Boreum, might reflect global thermal cooling and lithospheric thickening between the loading periods of the two ice caps. For volcanic regions and impact basins, estimated $T e$ are highly diverse. Since $T e$ reflects the lithospheric thickness at the time of loading, increased Te values from Alba, Elysium, Arsia, Pavonis, Ascraceus, to Olympus Mons might suggest progressive loading times for these volcanic montes. However, we can not exclude the influence of viscous relaxation of the mantle [Courtney and Beaumont, 1983], nor spatial inhomogeneity of the thermal structure. In sum, the large variations in $T e$ values reflect both spatial and temporal changes in the thermal state of Mars.

\section{Conclusions}

We analyzed localized gravity/topography admittance and correlation spectra for 20 subregions of various tectonic characteristics on Mars. The best-fitting lithospheric flexural models are determined by inverting for effective elastic thickness $T e$, sub-surface/surface loading ratio 
$f$, and surface density $\rho_{t}$. We find substantial regional variations of the flexural and loading parameters:

1. The plain regions in the southern highlands, including Terra Cimmeria, Terra Sirenum, Noachis Terra, Arabia Terra, as well as Hellas Planitia, have relatively small $T e$ of less than 40 $\mathrm{km}$, suggesting thin lithosphere at the time of loading. The northern polar region and Utopia Planitia have relatively large $T e$, in excess of $90 \mathrm{~km}$, suggesting thick lithosphere at the time of loading. Variations in $T e$ for volcanic montes, from less than $10 \mathrm{~km}$ for Alba Patera to more than $70 \mathrm{~km}$ for Olympus Mons, might indicate differences in the loading time of volcanoes.

2. Substantial amounts of sub-surface loading might exist underneath several plain regions, including Plana Borealis and Australe, Vastitas Borealis, Acidalia, Utopia, Hellas and Argyre Planitiae with best-fitting $f$ values close to 2 . The sub-surface loading in Isidis Planitia is calculated to be almost in phase with the surface loading $(\alpha=0.9)$ with a best-fitting $f$ of 1.7 .

3. Relatively small surface load density $\rho_{t}$ close to $2,500 \mathrm{~kg} / \mathrm{m}^{3}$ is estimated for Arabia Terra, Terra Cimmeria, Terra Sirenum, and Hellas Planitia, possibly suggesting sediment deposits, hydrologic alteration, and/or erosion of basaltic material.

Acknowledgements. The gravity model JGMRO110c and the topography model MarsTopo719 used in this paper are retrieved from the Geosciences Node of NASA's Planetary Data System (http://pds-geosciences.wustl.edu/mro/mro-m-rss-5-sdp-v1/mrors_1xxx/data/shadr/) and from the SHTOOLS package (http://sourceforge.net/projects/shtools/), respectively. We are grateful to Mark Wieczorek for making available the SHTOOLS software online. We are also grateful to Pat McGovern and Oded Aharonson for providing spherical harmonic analysis and flexural modeling codes and technical consultation. We thank Ken Tanaka for providing digital map of Mars chronographic ages and Frederik Simons for sharing relevant software online. This study also benefitted from discussions with Peter James, Junlun Li, and Nan Zhang. This work was supported by the Radio Science Gravity investigation of the NASA Mars Reconnaissance Orbiter mission. 


\section{References}

Anderson, S. and R. E. Grimm (1998), Rift processes at the Valles Marineris: Constraints from gravity on necking and rate-dependent strength evolution, J. Geophys. Res., 103, 1111311124.

Andrews-Hanna, J. C. (2012), The formation of Valles Marineris: 2. Stress focusing along the buried dichotomy boundary, J. Geophys. Res., 117, E04009, doi:10.1029/2011JE003954.

Belleguic, V., P. Lognonné, and M. Wieczorek (2005), Constraints on the Martian lithosphere from gravity and topography data, J. Geophys. Res., 110, doi:200510.1029/2005JE002437.

Britt, D. T., and G. Consolmagno (2003), Stony meteorite porosities and densities: A review of the data through 2001, Meteor. Planet. Sci., 38, 1161-1180.

Comer, R. P., S. C. Solomon, and J. W. Head (1985), Mars: Thickness of the lithosphere from the tectonic response to volcanic loads, Rev. Geophys., 23, 61-92, doi:10.1029/RG023i001p00061.

Courtney, R. C., and C. Beaumont (1983), Thermally-activated creep and flexure of the oceanic lithosphere, Nature, 305, 201-204, doi:10.1038/305201a0.

Forsyth, D. W. (1985), Subsurface loading and estimates of the flexural rigidity of continental lithosphere, J. Geophys. Res., 90, 12623-12632, doi:10.1029/JB090iB14p12623.

Garrick-Bethell, I., and M.T. Zuber (2009), Elliptical structure of the lunar South PoleAitken basin, Icarus, 204, 399-408, doi:10.1016/j.icarus.2009.05.032

Huang, Q., and M. A. Wieczorek (2012), Density and porosity of the lunar crust from gravity and topography, J. Geophys. Res., 117, doi:10.1029/2012JE004062.

Konopliv, A. S., S. W. Asmar, W. M. Folkner, Ã. Karatekin, D. C. Nunes, S. E. Smrekar, C. F. Yoder, and M. T. Zuber (2011), Mars high resolution gravity fields from MRO, Mars seasonal gravity, and other dynamical parameters, Icarus, 211, 401-428, doi:10.1016/j.icarus.2010.10.004.

Johnson, C. L., S. C. Solomon, J. W. Head, R. J. Phillips, D. E. Smith and M. T. Zuber (2000), Lithospheric loading by the north polar cap of Mars, Icarus, 144, 313-328.

Melosh, H. J. (1989), Impact Cratering: A Geologic Process, pp. 245, Oxford Univ. Press, New York.

Melosh, H. J., A. M. Freed, B. C. Johnson, D. M. Blair, J. C. Andrews-Hanna, G. A. Neumann, R. J. Phillips, D. E. Smith, S. C. Solomon, M.A. Wieczorek and M. T. Zuber (2013), The origin of lunar mascon basins, Science, 340, 1552-1555, doi:10.1126/science.1235768.

McGill, G. E. (1989), Buried topography of Utopia, Mars: Persistence of a giant impact depression, J. Geophys. Res., 94, 2753-2759, doi:10.1029/JB094iB03p02753. 
McGovern, P. J., S. C. Solomon, D. E. Smith, M. T. Zuber, M. Simons, M. A. Wieczorek, R. J. Phillips, G. A. Neumann, O. Aharonson, and J. W. Head, Localized gravity/topography admittance and correlation spectra on Mars: Implications for regional and global evolution, J. Geophys. Res., 107, doi:10.1029/2002JE001854, 2002.

McGovern, P. J., S. C. Solomon, D. E. Smith, M. T. Zuber, M. Simons, M. A. Wieczorek, R. J. Phillips, G. A. Neumann, O. Aharonson, and J. W. Head (2004), Correction to "Localized gravity/topography admittance and correlation spectra on Mars: Implications for regional and global evolution”, J. Geophys. Res., 109, doi:10.1029/2004JE002286.

McKenzie, D., D. N. Barnett, and D.-N. Yuan (2002), The relationship between Martian gravity and topography, Earth Planet. Sci. Lett., 195, 1-16, doi:10.1016/S0012-821X(01)005556.

McSween, H. Y., G. J. Taylor, and M. B. Wyatt (2009), Elemental composition of the Martian crust, Science, 324, 736-739, doi:10.1126/science.1165871.

Muller, P. M. and W. L. Sjogren (1968), Mascons: Lunar mass concentrations, Science, 161, 680-684.

Neumann, G. A., M. T. Zuber, M. A. Wieczorek, P. J. McGovern, F. G. Lemoine, and D. E. Smith (2004), Crustal structure of Mars from gravity and topography, J. Geophys. Res., 109, E08002, doi:10.1029/2004JE002262.

Neumann, G. A., M. T. Zuber, D. E. Smith and F. G. Lemoine (1996), The lunar crust: Global structure and signature of major basins, J. Geophys. Res., 101, 16841-16843.

Scott, E. D., L. Wilson, and J. W. Head (2002), Emplacement of giant radial dikes in the northern Tharsis region of Mars, J. Geophys. Res., 107, doi:10.1029/2000JE001431.

Smith, D. E., M. T. Zuber, H. V. Frey, J. B. Garvin, J. W. Head, D. O. Muhleman, G. H. Pettengill, R. J. Phillips, S. C. Solomon, H. J. Zwally, W. B. Banerdt, T. C. Duxbuy, M. P. Golombek, F. G. Lemoine, G. A. Neumann, D. D. Rowlands, O. Aharonson, P. G. Ford, A. B. Ivanov, P. J. McGovern, J. B. Abshire, R. S. Afzal and X. Sun (2001), Mars Orbiter Laser Altimeter (MOLA): Experiment summary after the first year of global mapping of Mars, J. Geophys. Res., 106, 23,689-23,722.

Spohn, T., M. H. Acuña, D. Breuer, M. Golombek, R. Greeley, A. Halliday, E. Hauber, R. Jaumann, and F. Sohl (2001), Geophysical constraints on the evolution of Mars, in Chronology and Evolution of Mars, edited by R. Kallenbach et al., pp. 231-262, Springer, Netherlands.

Tanaka, K. L., S. J. Robbins, C. M. Fortezzo, J. A. Skinner, and T. M. Hare (2013), The digital global geologic map of Mars: Chronostratigraphic ages, topographic and crater morphologic characteristics, and updated resurfacing history, Planet. Space Sci., doi:10.1016/j.pss.2013.03.006.

Turcotte, D. L., R. J. Willemann, W. F. Haxby, and J. Norberry (1981), Role of membrane stresses in the support of planetary topography, J. Geophys. Res., 86, 3951-3959, doi:10.1029/JB086iB05p03951. 
Wieczorek, M. A. (2007), The gravity and topography of the terrestrial planets, Treatise on Geophys., 10, 165-206.

Wieczorek, M. A., and F. J. Simons (2005), Localized spectral analysis on the sphere, Geophy. J. Int., 162, 655-675, doi:10.1111/j.1365-246X.2005.02687.x.

Wilson, L. and J. W. Head (1981), Ascent and eruption of basaltic magma on the Earth and Moon, J. Geophys. Res., 86, 2971-3001.

Wilson, L. and J. W. Head (1994), Review and analysis of volcanic eruption theory and observed landforms, Rev. Geophys., 19, 221-264.

Zhong, S. (2002), Effects of lithosphere on the long-wavelength gravity anomalies and their implications for the formation of the Tharsis rise on Mars, J. Geophys. Res., 107, doi:10.1029/2001JE001589.

Zhong, S., and M. T. Zuber (2001), Degree-1 mantle convection and the crustal dichotomy on Mars, Earth and Planet. Sci. Lett., 189, 75-84.

Zuber, M. T., D. E. Smith, F. G. Lemoine and G. A. Neumann (1994), The shape and internal structure of the Moon from the Clementine mission, Science, 266, 1839-1843.

Zuber, M. T., D. E. Smith, S. C. Solomon, D. O. Muhleman, J. W. Head, J. B. Garvin, J. B. Abshire and J.L. Bufton, (1992) The Mars Observer Laser Altimeter investigation, J. Geophys. Res., 97, 7781-7798.

Zuber, M. T., S. C. Solomon, R. J. Phillips, D. E. Smith, G. L. Tyler, O. Aharonson, G. Balmino, W. B. Banerdt, J. W. Head, C. L. Johnson, F. G. Lemoine, P. J. McGovern, G. A. Neumann, D. D. Rowlands, and S. Zhong (2000), Internal structure and early thermal evolution of Mars from Mars Global Surveyor topography and gravity, Science, 287, 1788-1793, doi:10.1126/science.287.5459.1788. 


\section{Table}

Table 1. Parameters for Flexural Admittance and Correlation Models

\begin{tabular}{lll}
\hline Parameters & Description & Value \\
\hline$T e$ & Effective thickness of elastic lithosphere, $\mathrm{km}$ & $0-400$ \\
$E$ & Young's modulus of elastic lithosphere, Pa & $1 \times 10^{11}$ \\
$\boldsymbol{V}$ & Poisson's ratio of elastic lithosphere & 0.25 \\
$\rho_{c}$ & Density of crust, $\mathrm{kg} / \mathrm{m}^{3}$ & 2,900 \\
$H_{c}$ & Thickness of crust, $\mathrm{km}$ & 50 \\
$\rho_{m}$ & Density of mantle, $\mathrm{kg} / \mathrm{m}^{3}$ & 3,500 \\
$\rho_{t}$ & Density of surface loading, kg/m ${ }^{3}$ & $1,000-3,200$ \\
$\Delta \rho_{b}$ & Density contrast of the sub-surface load to the crust, $\mathrm{kg} / \mathrm{m}^{3}$ & 600 \\
$f$ & Relative magnitude of sub-surface to surface loading & $0-2$ \\
$\alpha$ & Phase difference between the sub-surface and surface loading & $0 *$ \\
$R_{\text {obs }}$ & Observational radius of Martian gravity field, km & 3396 \\
$R$ & Average radius of Mars, km & 3389.5 \\
\hline
\end{tabular}

*Except for Isidis Planitia where an estimated value of 0.9 is used. 


\section{Figures}
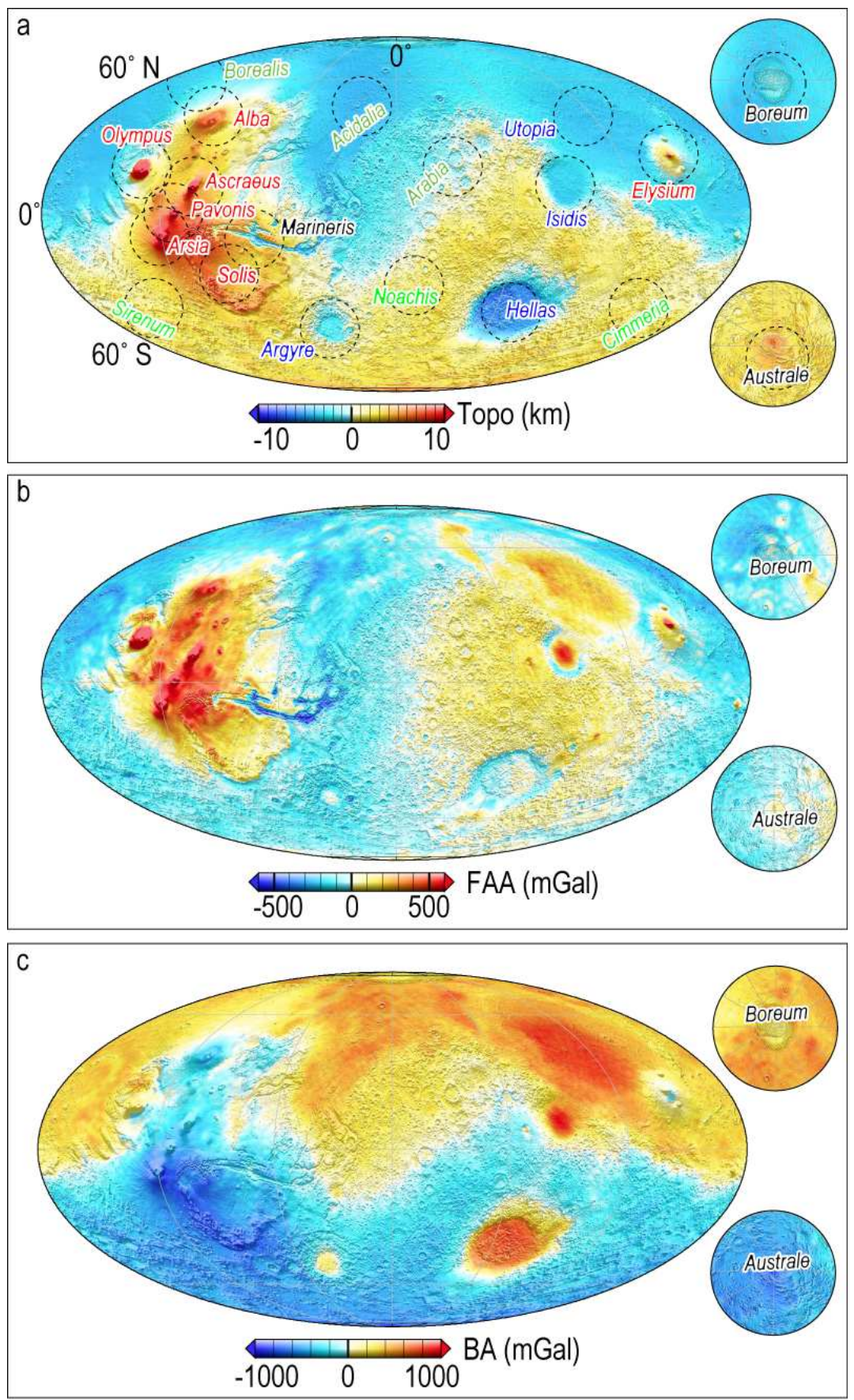

Figure 1. Global map views of (a) Topography of Mars from MarsTopo719, referenced to areoid; (b) Radial free-air gravity anomaly from JGMRO110c, assuming a reference radius of $3396 \mathrm{~km}$; and (c) Calculated Bouguer gravity anomaly, assuming a crustal density of $2,900 \mathrm{~kg} / \mathrm{m}^{3}$. 

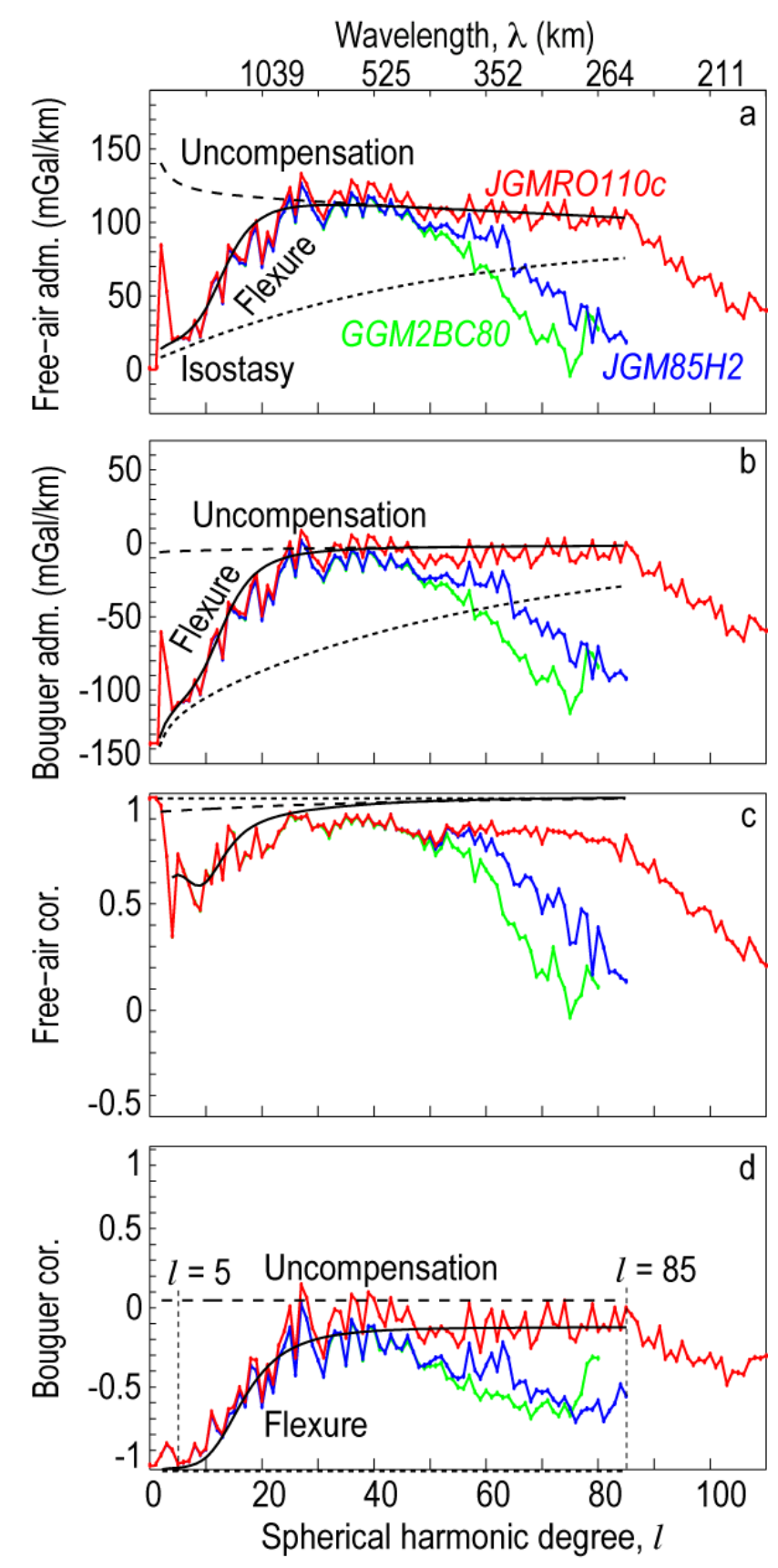

Figure 2. Global observed spectra of (a) Free-air admittance; (b) Bouguer admittance; (c) Freeair correlation; and (d) Bouguer correlation. Red, blue, and green curves indicate observed admittance and correlation of the gravity model, JGMRO110c (this study), JGM85H2 (used by Neumann et al. [2004] and Belleguic et al. [2005]), and GGM2BC80 (used by McGovern et al. [2002 and 2004]), respectively. Black solid lines indicate predicted spectral functions for a bestfitting lithospheric flexure model with $T e=160 \mathrm{~km}, \rho_{t}=2,900 \mathrm{~kg} / \mathrm{m}^{3}$, and $H c=50 \mathrm{~km}$. Black long and short dashes are the calculated curves of uncompensated and Airy isostatic compensated models, respectively. 

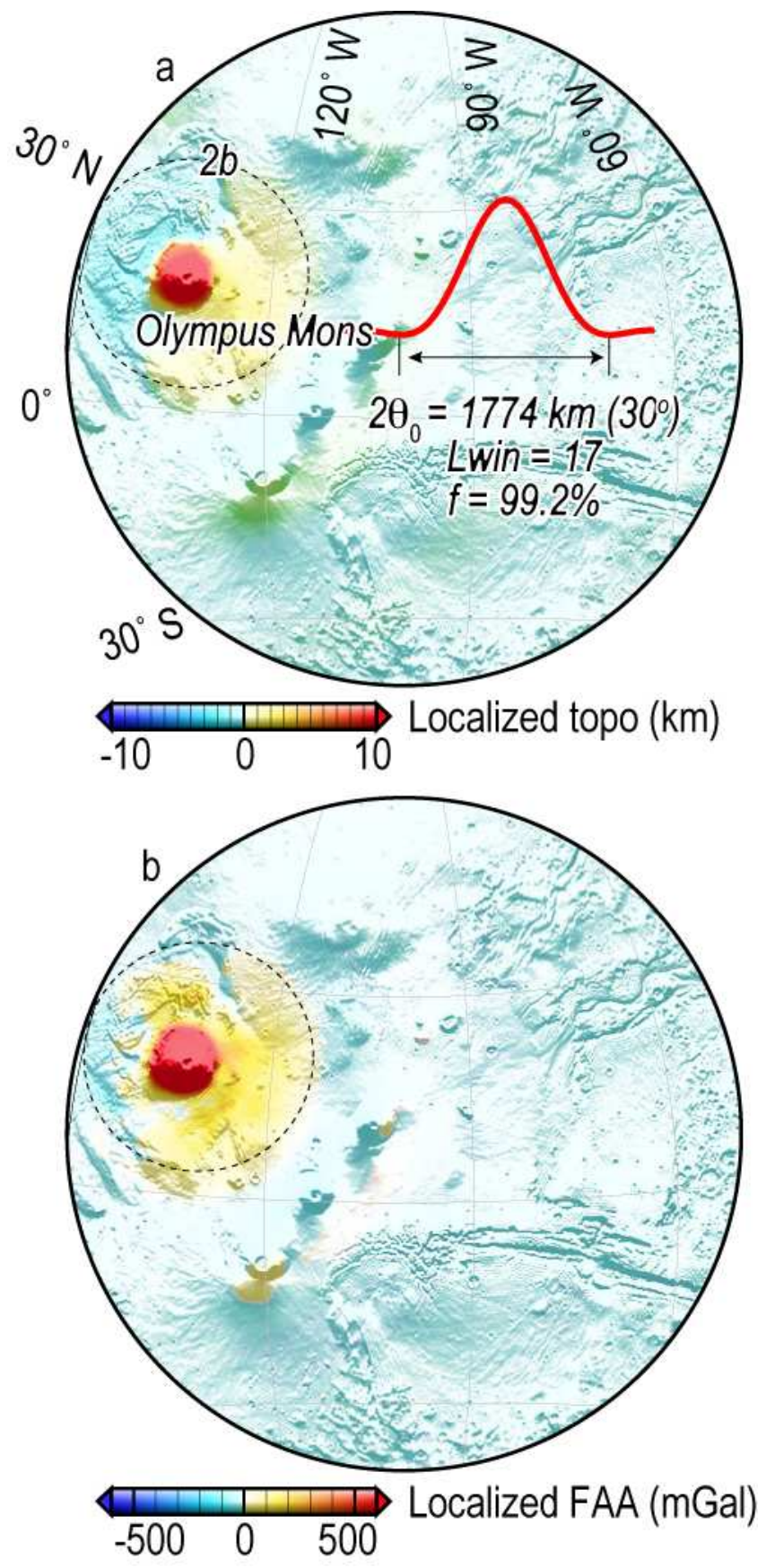

Figure 3. Global and regional map views of (a) localized topography and (b) localized free-air anomaly, after filtering the global signals by a localization cap window in Olympus Mons. Dashed lines indicate the boundary of the localized cap region. The red curve indicates the shape of the regional cap window across the cap center, with an angular diameter of $2 \theta_{0}=30^{\circ}$ and a spectral bandwidth of $L_{w i n}=17$. 

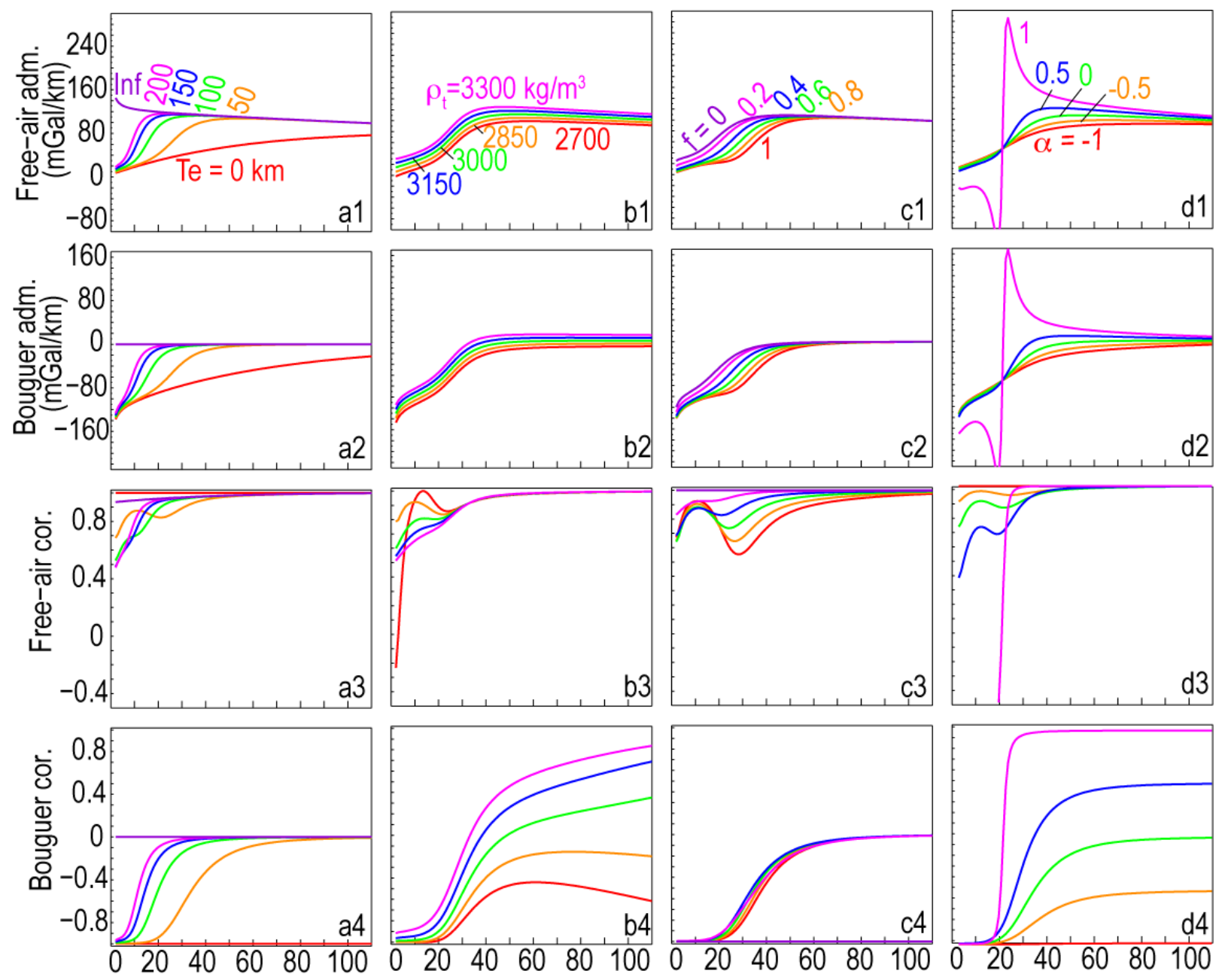

Spherical harmonic degree, $l$

Figure 4. Model spectral functions for a series of lithospheric flexure models: (a1-4) For various lithospheric thickness, Te; (b1-4) For various surface load density, $\rho_{t}$; (c1-4) For various subsurface/surface loading magnitude, $f$; (d1-4) For various sub-surface/surface phase difference, $\alpha$. The influence of each variable is shown by letting the other three variables fixed at values of: $T e=50 \mathrm{~km}, H c=45 \mathrm{~km}, \rho_{t}=2,900 \mathrm{~kg} / \mathrm{m}^{3}, f=0.4$, and $\alpha=0$. The predicted spectral functions include (a1, b1, c1 and d1) free-air admittance, (a2, b2, c2 and d2) Bouguer admittance, (a3, b3, c3 and d3) free-air correlation, and (a4, b4, c4 and d4) Bouguer correlation. 

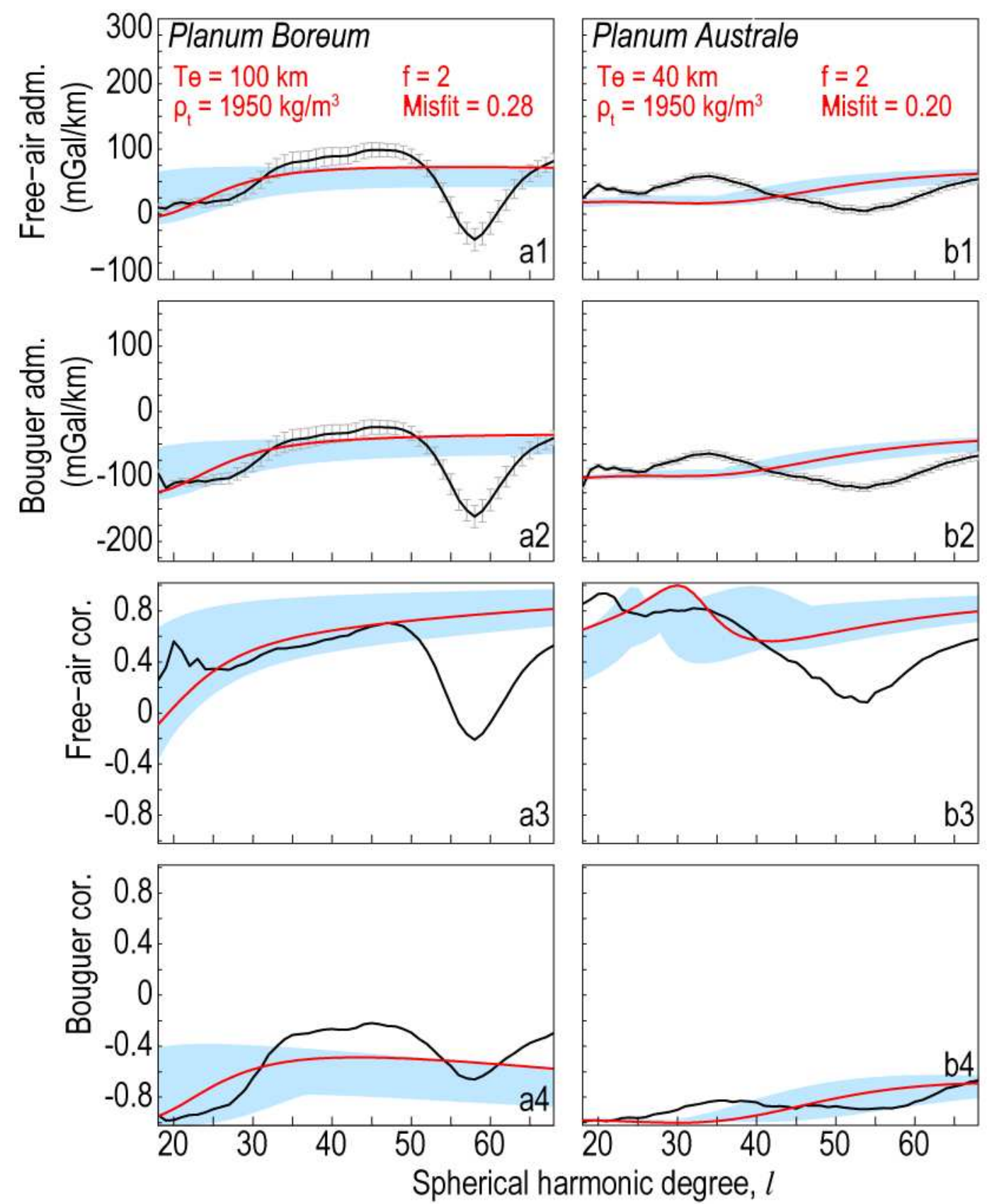

Figure 5. Comparisons between the observed spectra and best-fitting models for polar regions: (a1-4) Planum Boreum; and (b1-4) Planum Australe. For each region, four spectral curves are shown: (a1 and b1) Free-air admittance; (a2 and b2) Bouguer admittance; (a3 and b3) Free-air correlation; and (a4 and b4) Bouguer correlation. Black lines indicate observed regional spectra. Gray error bars in the top two panels indicate the admittance uncertainty caused by the uncorrelated-ness between the gravity and topography. Red lines are predicted spectra for the best-fitting regional models with minimum RMS misfits, $\mathrm{RMS}_{\min }$. Blue regions correspond to acceptable flexural models with RMS values less than $\mathrm{RMS}_{\min }+0.05$. 

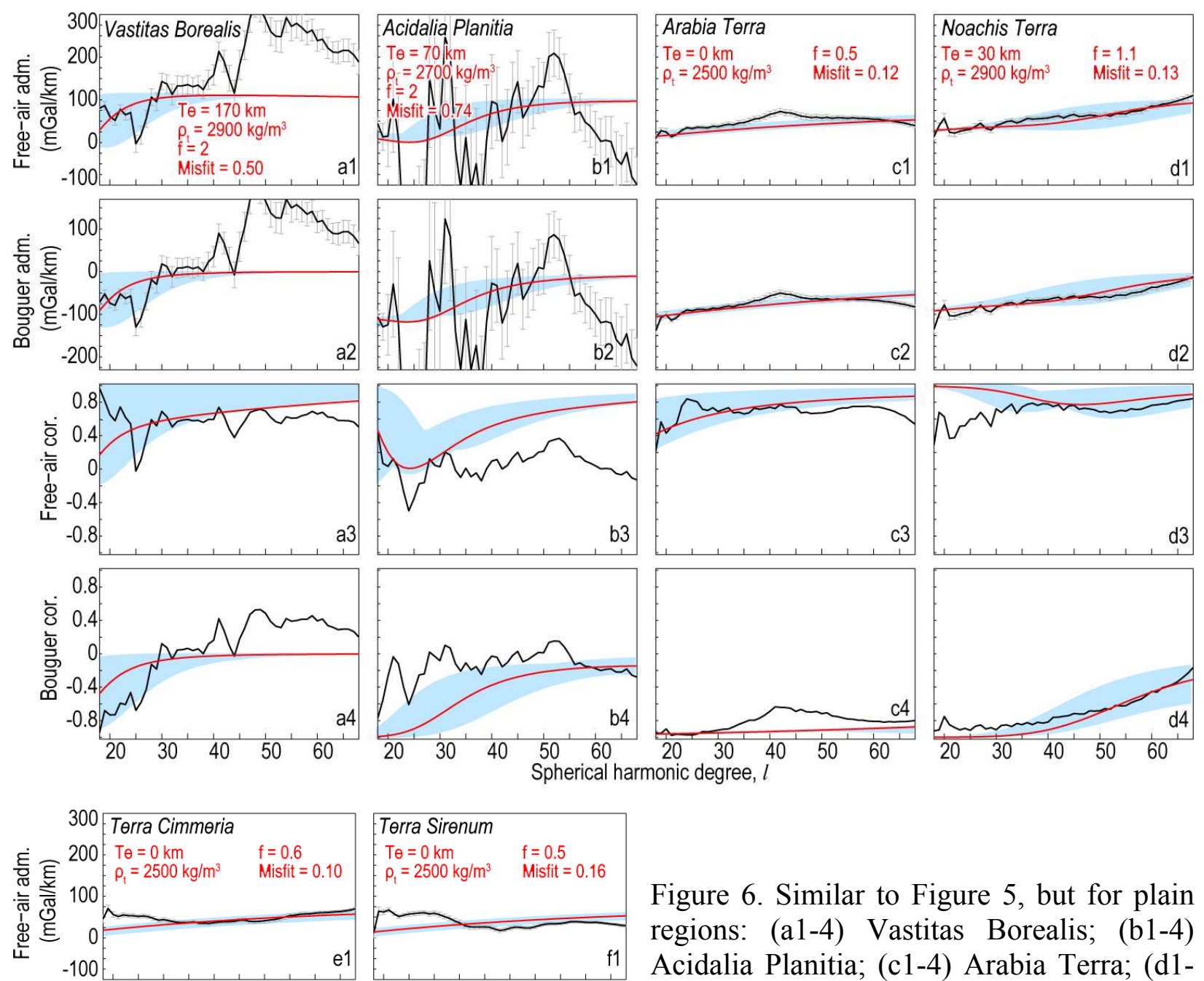

Figure 6. Similar to Figure 5, but for plain regions: (a1-4) Vastitas Borealis; (b1-4) Acidalia Planitia; (c1-4) Arabia Terra; (d1-

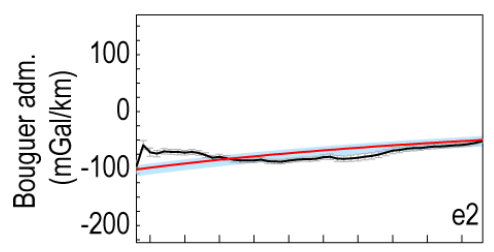
4) Noachis Terra; (e1-4) Terra Cimmeria; and (f1-4) Terra Sirenum.
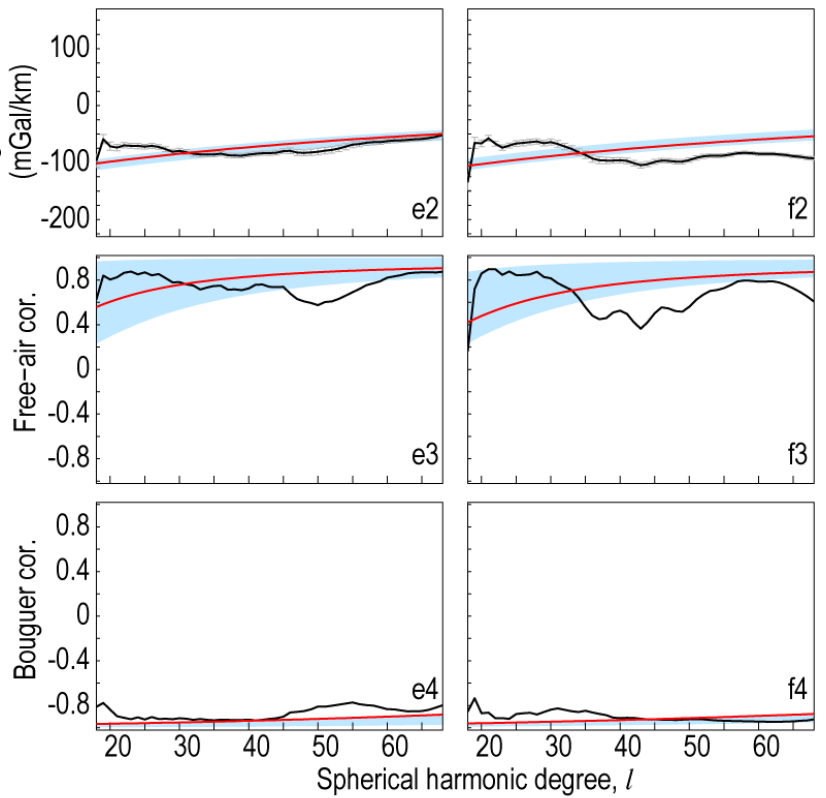

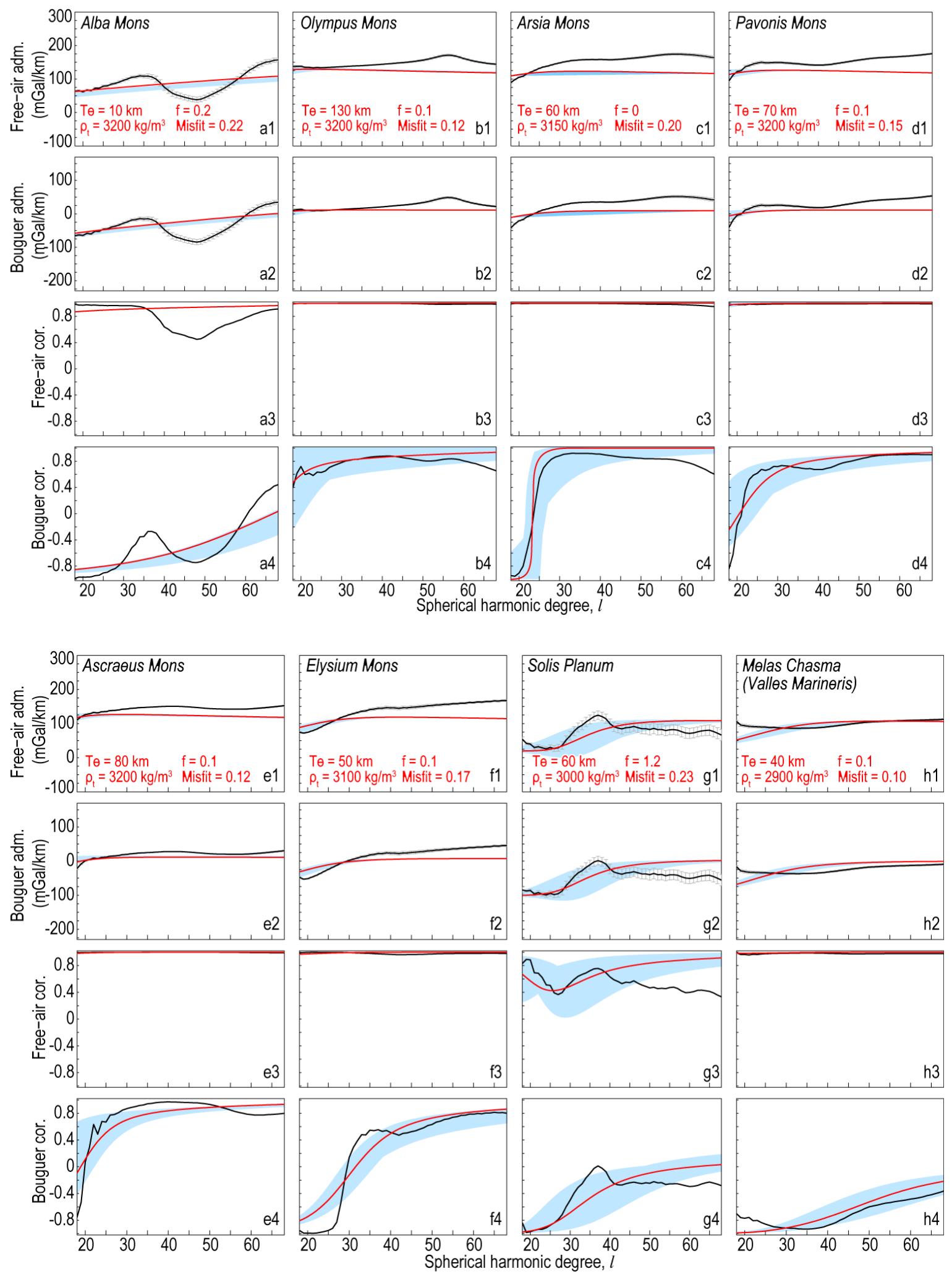

Figure 7. Similar to Figure 5, but for volcanic regions and rift region Valles Marineris: (a1-4) Alba Patera; (b1-4) Olympus Mons; (c1-4) Arsia Mons; (d1-4) Pavonis Mons; (e1-4) Ascraeus Mons; (f1-4) Elysium Mons; (g1-4) Solis Planum; and (h1-4) Melas Chasma (Valles Marineris). 

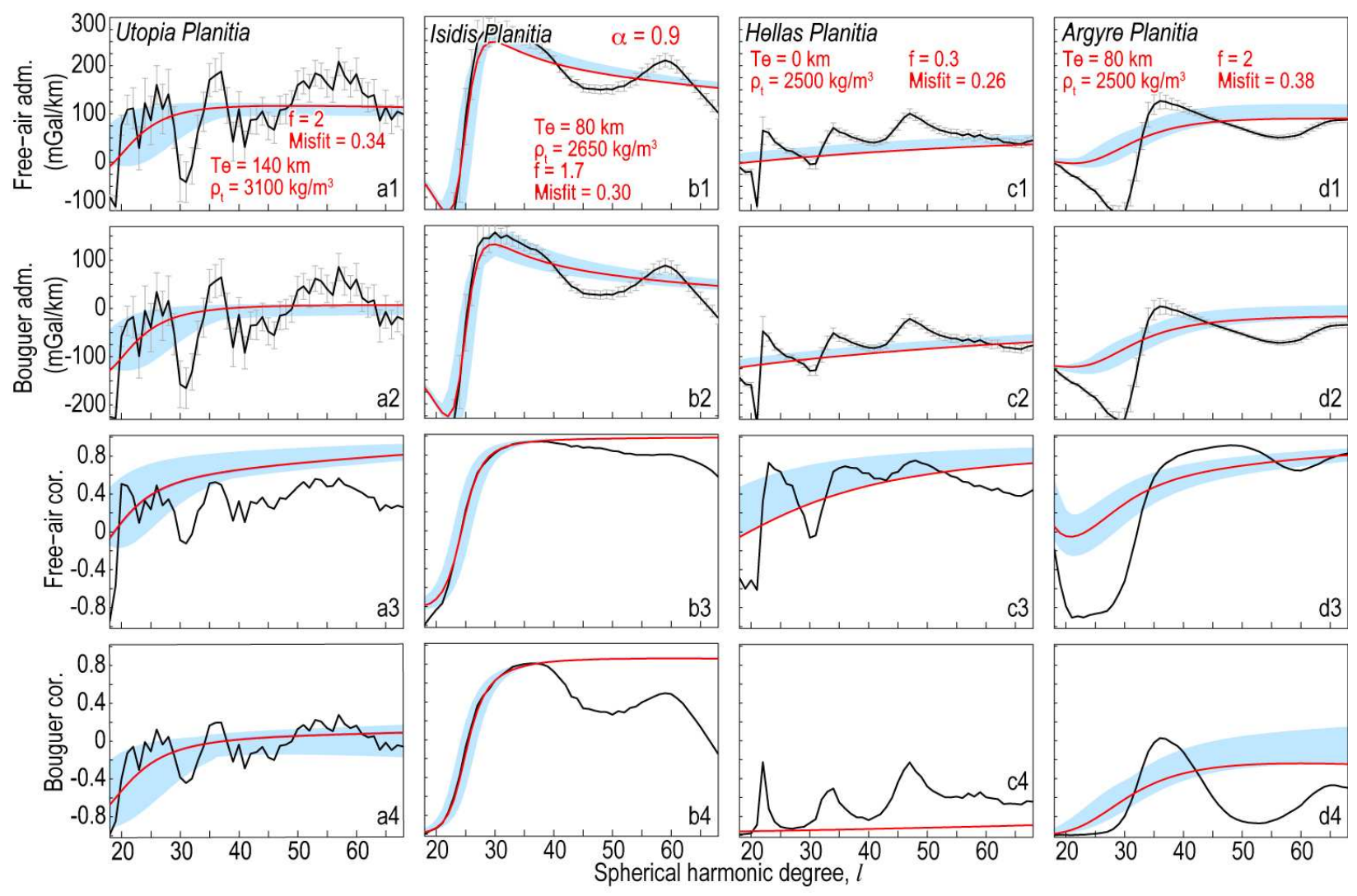

Figure 8. Similar to Figure 5, but for impact basin regions: (a1-4) Utopia Planitia; (b1-4) Isidis Planitia; (c1-4) Hellas Planitia; and (d1-4) Argyre Planitia. 

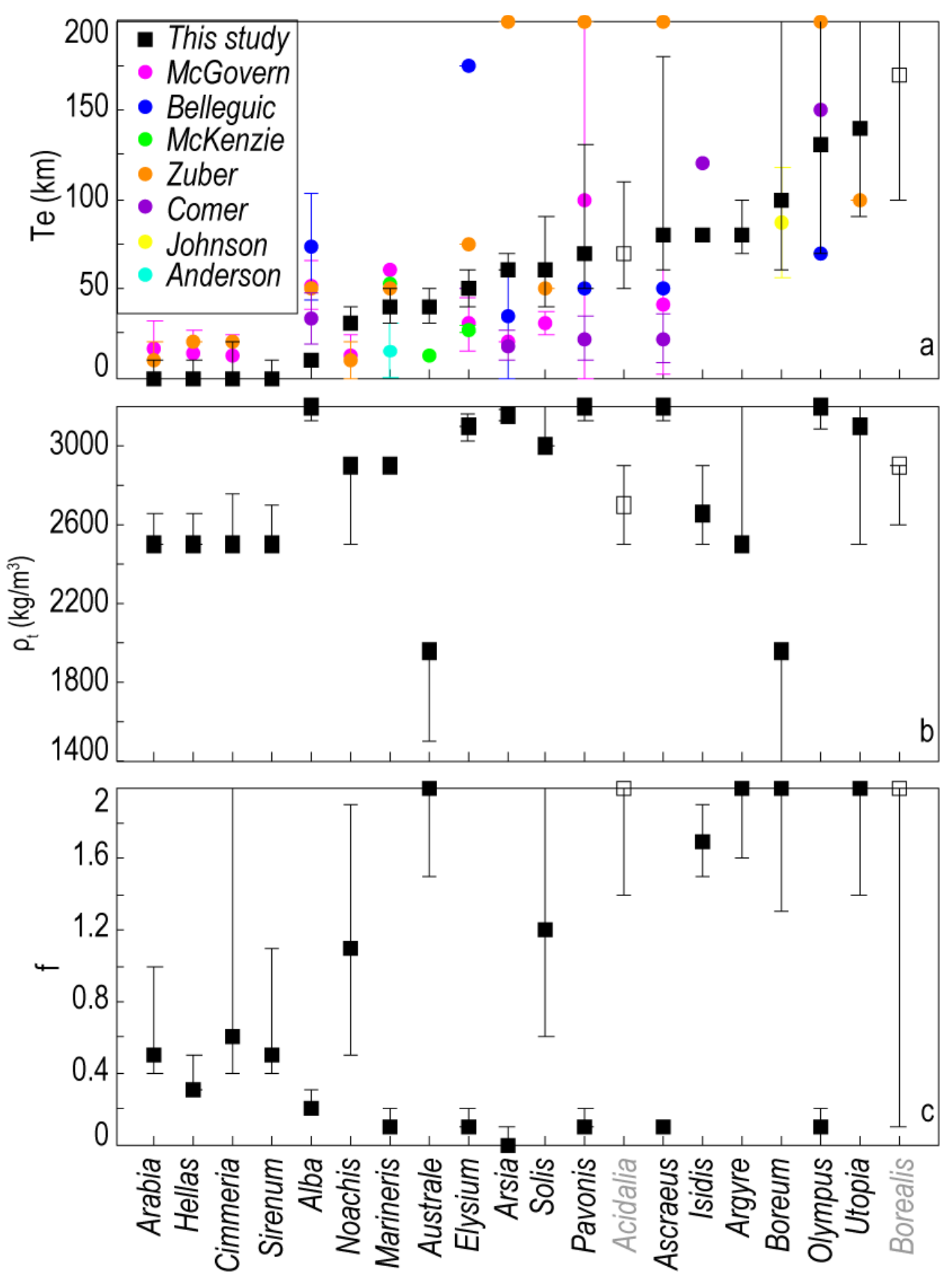

Figure 9. Summary of the regional flexural models: (a) Effective lithospheric thickness, Te; (b) Surface load density, $\rho_{t}$; and (c) Sub-surface/surface loading magnitude, $f$. The back rectangles and associated error bars indicate best-fitting solutions and acceptable ranges, respectively. The white rectangles are for Acidalia Planitia and Vastitas Boralis where flexural models are not well constrained with minimum RMS misfits of larger than 0.5. In Panel a, we compare our estimates with previous studies: McGovern et al. [2004], Belleguic et al. [2005], McKenzie et al. [2002], Zuber et al. [2000], Comer et al. [1985], Johnson et al. [2000] and Anderson and Grimm [1998]. 


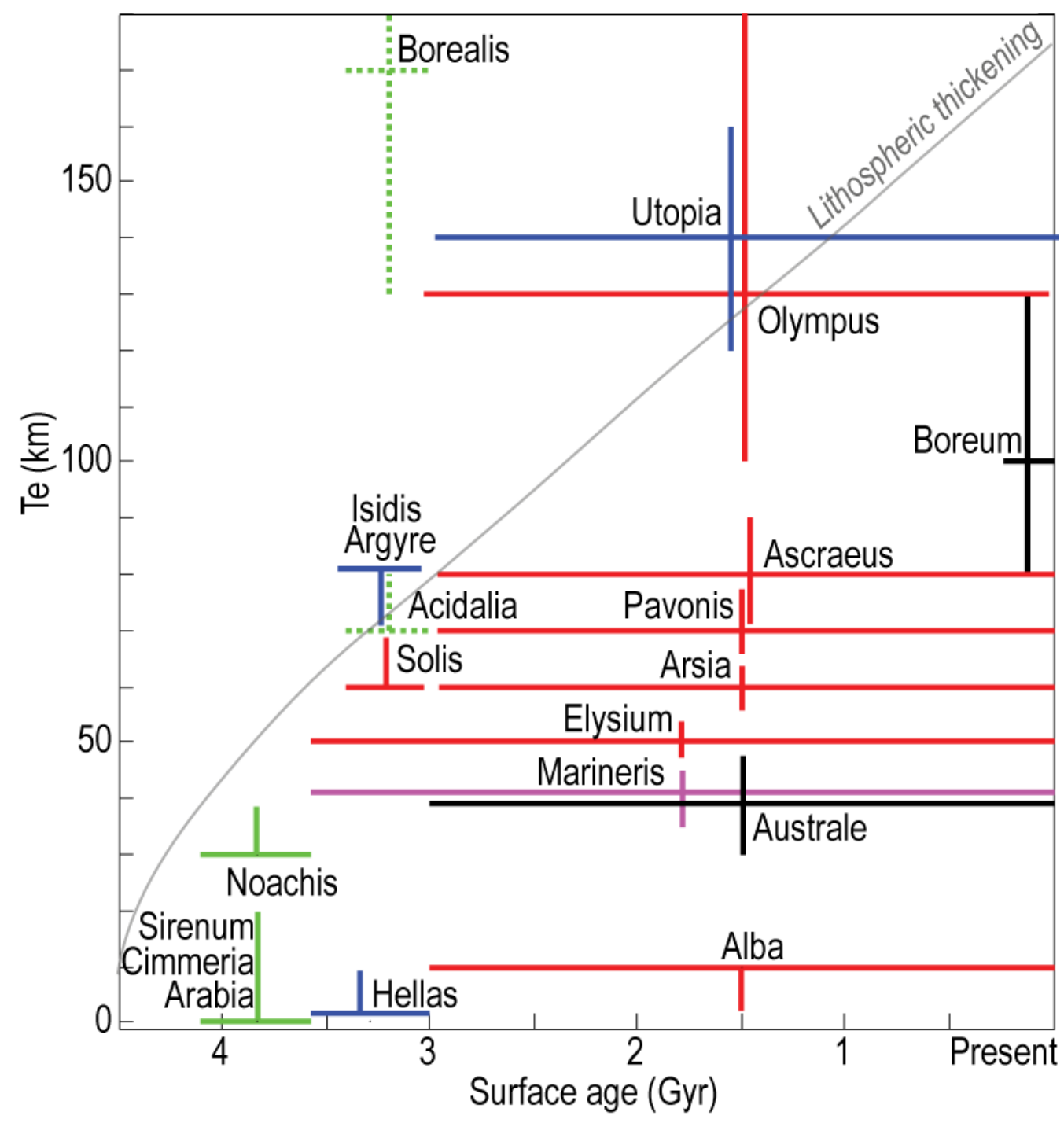

Figure 10. Surface age and estimated effective lithospheric thickness, Te. Error bars indicate the ranges of surface age and the estimated ranges of regional Te values. Black, green, red, magenta and blue colors represent polar regions, plain regions, volcanic regions, valley system, and impact basins, respectively. Dashed lines indicate two regions where $T e$ values are not well constrained. Gray line indicates a simple global model of planet cooling and lithospheric thickening [Spohn et al., 2001]. 

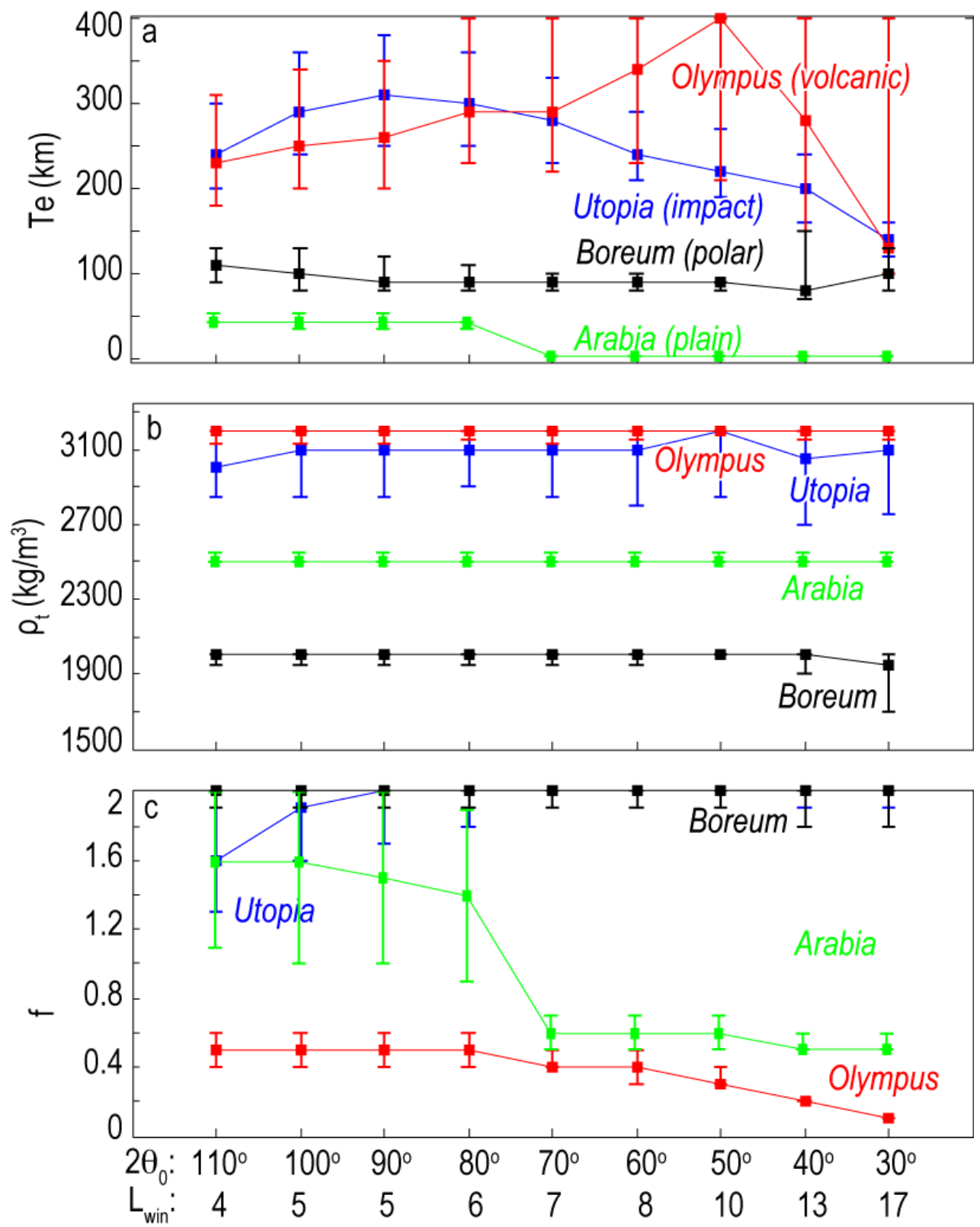

Figure 11. Model sensitivity to the diameter of localization cap window. Regional flexural models for Planum Boreum (black), Arabia Terra (green), Utopia Planitia (blue), and Olympus Mons (red) are shown for the window diameter $2 \theta_{0}$ of $30-110^{\circ}$ and corresponding bandwidth $L_{\text {win }}$ of $17-4$. 


\section{Appendix A: Calculation of Flexural Admittance and Correlation}

We derive the analytical solutions for gravity/topography admittance and correlation for thinshell flexure under mass-sheet approximation with the existence of sub-surface loading, based on the formulation of McGovern et al. [2002, 2004]. The predicted admittance and correlation spectra depend on four variables: sub-surface/surface loading magnitude, $f$, (Equation 8 ), and phase difference, $\alpha$, (Equation 9); effective lithospheric thickness, Te; surface load density, $\rho_{t}$. We assume that the sub-surface loading is situated at the base of the crust, with a sub-surface load density, $\Delta \rho_{b}=\rho_{m}-\rho_{c}$.

The observed topography is assumed to be a linear combination of surface and sub-surface loading:

$$
h_{l m}=h_{l m}^{t}+h_{l m}^{b}
$$

where $h_{l m}^{t}$ and $h_{l m}^{b}$ are the spherical harmonic coefficients of the topography caused by surface and sub-surface loading, respectively. $h_{l m}^{b}$ equals to the plate deformation caused by sub-surface loading. The Moho relief is expressed similarly:

$$
w_{l m}=w_{l m}^{t}+w_{l m}^{b},
$$

where $w_{l m}^{t}$ and $w_{l m}^{b}$ are the spherical harmonic coefficients of the Moho relief caused by the surface and sub-surface loading, respectively. $w_{l m}^{t}$ equals to the plate deformation caused by the surface loading alone.

The layer thicknesses of the initial surface and sub-surface loading, $h_{l m}^{i}$ and $w_{l m}^{i}$, represent the thickness of interface density contrast before plate deformation:

$$
\begin{aligned}
& h_{i}=h_{l m}^{t}-w_{l m}^{t}, \\
& w_{i}=w_{l m}^{b}-h_{l m}^{b} .
\end{aligned}
$$


The plate deformation, $w_{l m}^{t}$ and $h_{l m}^{b}$, are caused by surface and sub-surface loading, respectively:

$$
w_{l m}^{t}=\alpha_{l}^{t} h_{l m}^{t}
$$

and

$$
w_{l m}^{b}=\alpha_{l}^{b} h_{l m}^{b},
$$

where $\alpha_{l}^{t}=\alpha_{l}\left(\rho_{t}, T e\right)$ and $\alpha_{l}^{b}=1 / \alpha_{l}\left(\rho_{b}, T e\right)$ are transfer functions in spherical harmonic degree $l$ , obtained by solving thin-shell flexure equation [McGovern et al., 2002]. $\alpha_{l}(\rho, T e)$ is given by:

$$
\alpha_{l}(\rho, T e)=-\left(\frac{\rho}{\rho_{m}-\rho}\right) \frac{l(l+1)-(1-v)}{\left\{\frac{l^{3}(l+1)^{3}-4 l^{2}(l+1)^{2}}{12\left(1-v^{2}\right)}\left(\frac{T e}{R}\right)^{2}+[l(l+1)-2]\right\} \frac{E T e}{R^{2} g\left(\rho_{m}-\rho\right)}+l(l+1)-(1-v)},
$$

where $\rho$ is the load density, i.e. $\rho_{t}$ or $\Delta \rho_{b}, \rho_{m}=3,500 \mathrm{~kg} / \mathrm{m}^{3}$ is the mantle density. Parameter $E=1 \times 10^{11} \mathrm{~Pa}$ is the Young's modulus, $v=0.25$ is the Poisson's ratio, $R=3389.5 \mathrm{~km}$ is the average radius of Mars, and $g=3.73 \mathrm{~m} / \mathrm{s}^{2}$ is the gravity acceleration at the radius of $R$ (Table 1).

Thus the topography and Moho relief are related to the initial surface and sub-surface loading:

$$
\begin{aligned}
& h_{l m}=\frac{1}{1-\alpha_{l}^{t}} h_{l m}^{i}+\frac{1}{\alpha_{l}^{b}-1} w_{l m}^{i}, \\
& w_{l m}=\frac{\alpha_{l}^{t}}{1-\alpha_{l}^{t}} h_{l m}^{i}+\frac{\alpha_{l}^{b}}{\alpha_{l}^{b}-1} w_{l m}^{i} .
\end{aligned}
$$

Using Equation A8, we could express the power of $h_{l m}$ as:

$$
\sum_{m=-l}^{m}\left(h_{l m}\right)^{2}=\frac{1}{\left(1-\alpha_{l}^{t}\right)^{2}} \sum_{m=-l}^{l}\left(h_{l m}^{i}\right)^{2}+\frac{1}{\left(1-\alpha_{l}^{b}\right)^{2}} \sum_{m=-l}^{l}\left(w_{l m}^{i}\right)^{2}+\frac{2}{\left(1-\alpha_{l}^{t}\right)\left(1-\alpha_{l}^{b}\right)} \sum_{m=-l}^{l} h_{l m}^{i} w_{l m}^{i} .
$$


We then use the definition of $\alpha$ and $f$ (Equations 8 and 9) to replace the sub-surface loading terms in the power and cross-power spectra. For simplicity, $f$ here is defined as the correlation between initial thickness of the sub-surface and surface loads, i.e., $f=\sqrt{\sum_{m=-l}^{l}\left(w_{l m}^{i}\right)^{2}} / \sqrt{\sum_{m=-l}^{l}\left(h_{l m}^{i}\right)^{2}}$. This definition of $f$ could be easily transformed to that used in the main text (Equation 9) by multiplying a density ratio $\Delta \rho_{b} / \rho_{t}$.

After using $\alpha$ and $f$, Equations A8-10 are transformed to:

$$
\begin{gathered}
\sum_{m=-l}^{l}\left(h_{l m}^{i}\right)^{2}=\left(\frac{1}{\left(1-\alpha_{l}^{t}\right)^{2}}+\frac{f^{2}}{\left(\alpha_{l}^{b}-1\right)^{2}}+\frac{2 \alpha f}{\left(1-\alpha_{l}^{t}\right)\left(1-\alpha_{l}^{b}\right)}\right) \sum_{m=-l}^{l}\left(h_{l m}\right)^{2} \\
\sum_{m=-l}^{l}\left(w_{l m}^{i}\right)^{2}=f^{2}\left(\frac{1}{\left(1-\alpha_{l}^{t}\right)^{2}}+\frac{f^{2}}{\left(\alpha_{l}^{b}-1\right)^{2}}+\frac{2 \alpha f}{\left(1-\alpha_{l}^{t}\right)\left(1-\alpha_{l}^{b}\right)}\right) \sum_{m=-l}^{l}\left(h_{l m}\right)^{2}, \\
\sum_{m=-l}^{l} h_{l m}^{i} w_{l m}^{i}=\alpha f^{2}\left(\frac{1}{\left(1-\alpha_{l}^{t}\right)^{2}}+\frac{f^{2}}{\left(\alpha_{l}^{b}-1\right)^{2}}+\frac{2 \alpha f}{\left(1-\alpha_{l}^{t}\right)\left(1-\alpha_{l}^{b}\right)}\right) \sum_{m=-l}^{l}\left(h_{l m}\right)^{2} \\
\sum_{m=-l}^{l} h_{l m} w_{l m}=\frac{\alpha_{l}^{t}}{\left(1-\alpha_{l}^{t}\right)^{2}} \sum_{m=-l}^{l}\left(h_{l m}^{i}\right)^{2}+\frac{\alpha_{l}^{b}}{\left(\alpha_{l}^{b}-1\right)^{2}} \sum_{m=-l}^{l}\left(w_{l m}^{i}\right)^{2}+\frac{\alpha_{l}^{t}+\alpha_{l}^{b}}{\left(1-\alpha_{l}^{t}\right)\left(\alpha_{l}^{b}-1\right)} \sum_{m=-l}^{l} h_{l m}^{i} w_{l m}^{i}, \\
\sum_{m=-l}^{l}\left(w_{l m}\right)^{2}=\frac{\left(\alpha_{l}^{t}\right)^{2}}{\left(1-\alpha_{l}^{t}\right)^{2}} \sum_{m=-l}^{l}\left(h_{l m}^{i}\right)^{2}+\frac{\left(\alpha_{l}^{b}\right)^{2}}{\left(\alpha_{l}^{b}-1\right)^{2}} \sum_{m=-l}^{l}\left(w_{l m}^{i}\right)^{2}+\frac{2 \alpha_{l}^{t} \alpha_{l}^{b}}{\left(1-\alpha_{l}^{t}\right)\left(\alpha_{l}^{b}-1\right)} \sum_{m=-l}^{l} h_{l m}^{i} w_{l m}^{i} .
\end{gathered}
$$

Inserting Equations A12-13 into Equations A14-15, we derive final expressions:

$$
\begin{gathered}
\sum_{m=-l}^{l} h_{l m} w_{l m}=\frac{\frac{\alpha_{l}^{t}}{\left(1-\alpha_{l}^{t}\right)^{2}}+\frac{\alpha_{l}^{b} f^{2}}{\left(\alpha_{l}^{b}-1\right)^{2}}+\frac{\left(\alpha_{l}^{t}+\alpha_{l}^{b}\right) \alpha f}{\left(1-\alpha_{l}^{t}\right)\left(\alpha_{l}^{b}-1\right)} \sum_{m=-l}^{l}\left(h_{l m}\right)^{2},}{\left(1-\alpha_{l}^{t}\right)^{2}}+\frac{f^{2}}{\left(\alpha_{l}^{b}-1\right)^{2}}+\frac{2 \alpha f}{\left(1-\alpha_{l}^{t}\right)\left(\alpha_{l}^{b}-1\right)} \\
\sum_{m=-l}^{l}\left(w_{l m}\right)^{2}=\frac{\frac{\left(\alpha_{l}^{t}\right)^{2}}{\left(1-\alpha_{l}^{t}\right)^{2}}+\frac{\left(\alpha_{l}^{b}\right)^{2} f^{2}}{\left(\alpha_{l}^{b}-1\right)^{2}}+\frac{2 \alpha_{l}^{t} \alpha_{l}^{b} \alpha f}{\left(1-\alpha_{l}^{t}\right)\left(\alpha_{l}^{b}-1\right)} \sum_{m=-l}^{l}\left(h_{l m}\right)^{2} .}{\left(1-\alpha_{l}^{t}\right)^{2}}+\frac{f^{2}}{\left(\alpha_{l}^{b}-1\right)^{2}}+\frac{2 \alpha f}{\left(1-\alpha_{l}^{t}\right)\left(\alpha_{l}^{b}-1\right)}
\end{gathered}
$$


Similarly, the other two cross-power spectra $\sum_{m=-l}^{l} h_{l m} h_{l m}^{i}$ and $\sum_{m=-l}^{l} h_{l m}^{i} w_{l m}$ could be derived using Equations A8-9 and A11-13.

Assuming a mass-sheet approximation, the surface and Moho density interfaces are linearly related to the free-air anomaly $g_{l m}^{F A A}$ and the Bouguer gravity anomaly $g_{l m}^{B A}$ at a reference radius of $R_{o b s}:$

$$
\begin{gathered}
g_{l m}^{F A A}=G_{l}^{t}\left[\rho_{t} h_{l m}+\left(\rho_{c}-\rho_{t}\right)\left(h_{l m}-h_{l m}^{i}\right)\right]+G_{l}^{b} \rho_{b} w_{l m}, \\
g_{l m}^{B A}=g_{l m}^{F A A}-G_{l}^{t} \rho_{c} h_{l m},
\end{gathered}
$$

where $G_{l}^{t}=\frac{4 \pi G(l+1)}{(2 l+1)}\left(\frac{R}{R_{o b s}}\right)^{l+2}$ and $G_{l}^{b}=\frac{4 \pi G(l+1)}{(2 l+1)}\left(\frac{R-H c}{R_{o b s}}\right)^{l+2}$ are transfer coefficients for density anomalies at the surface and Moho, respectively. $H c$ is both the crustal thickness and the depth of the sub-surface loading.

The final step is to calculate the power spectra of the gravity fields (Equation 5) as well as the cross-power spectra of the gravity and topography (Equation 2), and then the admittance and correlation spectra (Equations 1 and 4). The predicted admittance and correlation spectra will be independent of the power spectrum of topography. 


\section{Appendix B: Model Sensitivity to Flexural Parameters}

We show RMS misfits on two-parameter projections. The $x$-axis is the effective lithospheric thickness, while the $y$-axis is either surface load density or sub-surface/surface loading magnitude. White circles indicate the best-fitting solutions, with the corresponding parameters and RMS misfits are listed by red text. The error bars indicate acceptable ranges. Each panel shows the trade-off between two parameters, assuming the third parameter equals to its bestfitting value.

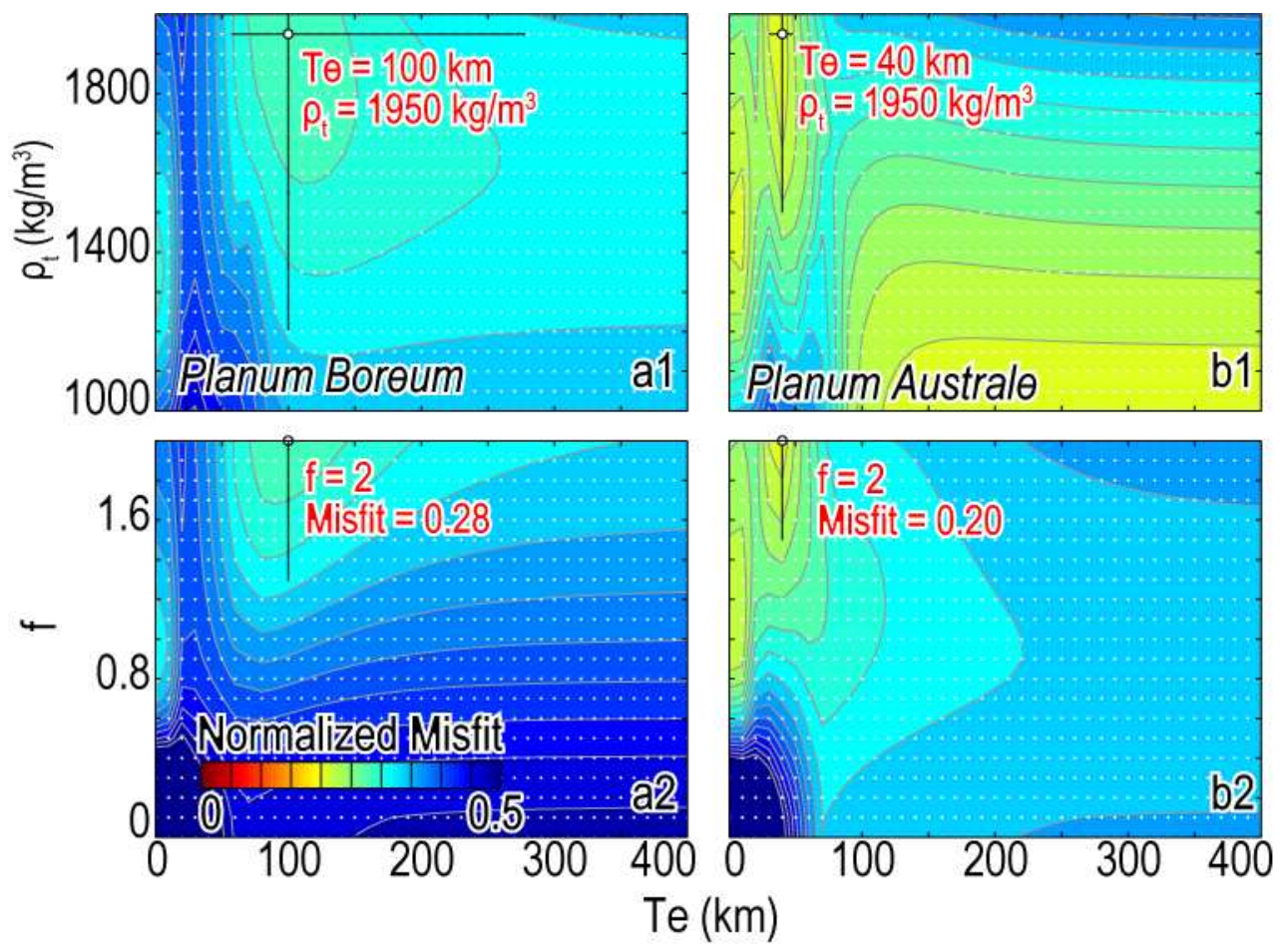

Figure B1. RMS misfits for two polar regions: (a1-2) Planum Boreum; and (b1-2) Planum Australe. 

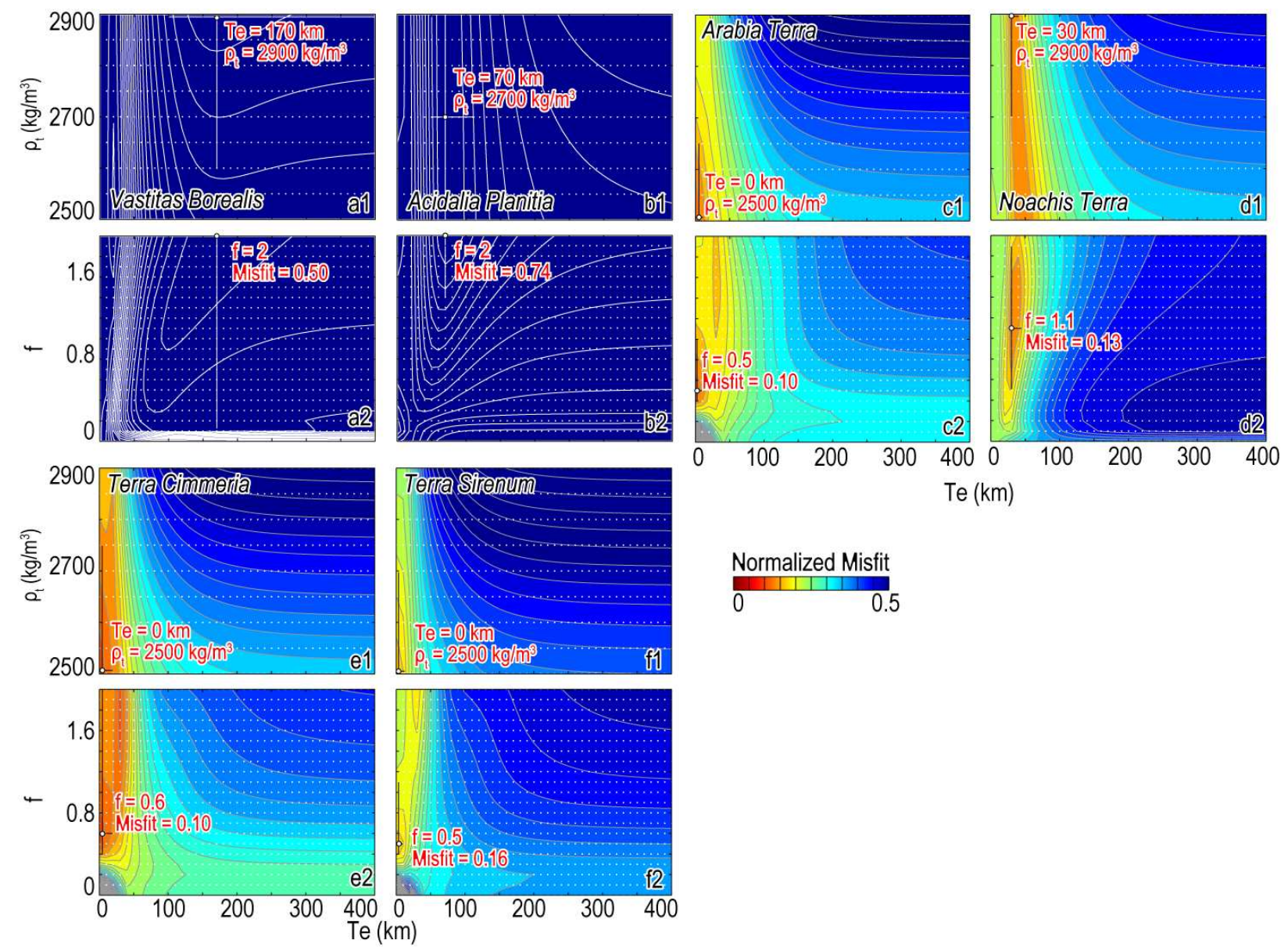

$\begin{array}{cc}\text { Normalized Misfit } \\ 0 & 0.5\end{array}$

Figure B2. RMS misfits for six plain regions: (a1-2) Vastitas Borealis; (b1-2) Acidalia Planitia; (c1-2) Arabia Terra; (d1-2) Noachis Terra; (e1-2) Terra Cimmeria; and (f1-2) Terra Sirenum. 

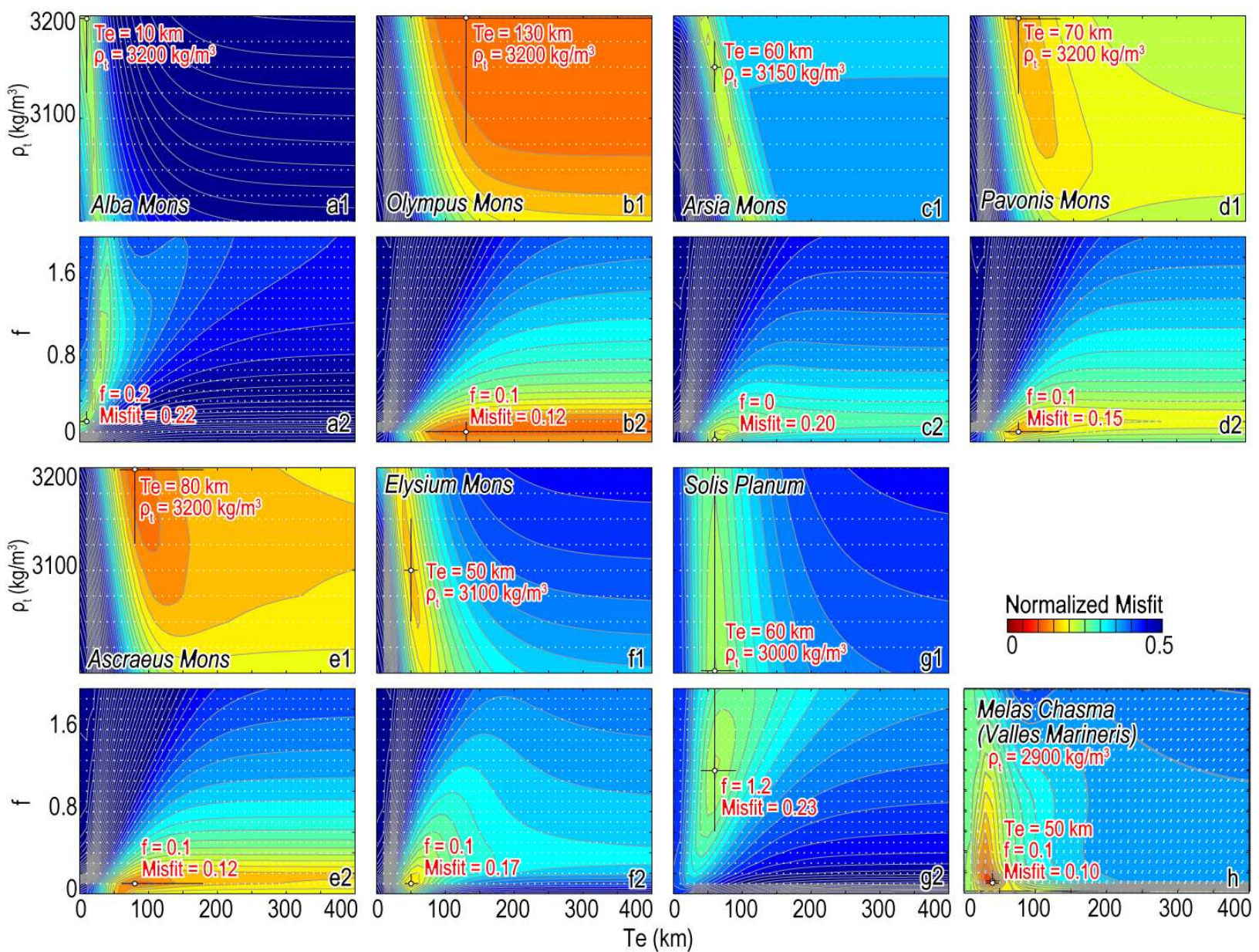

Figure B3. RMS misfits for seven volcanic regions and a rift valley system: (a1-2) Alba Patera; (b1-2) Olympus Mons; (c1-2) Arsia Mons; (d1-2) Pavonis Mons; (e1-2) Ascraeus Mons; (f1-2) Elysium Mons; (g1-2) Solis Planum; and (h1-2) Melas Chasma (Valles Marineris). 

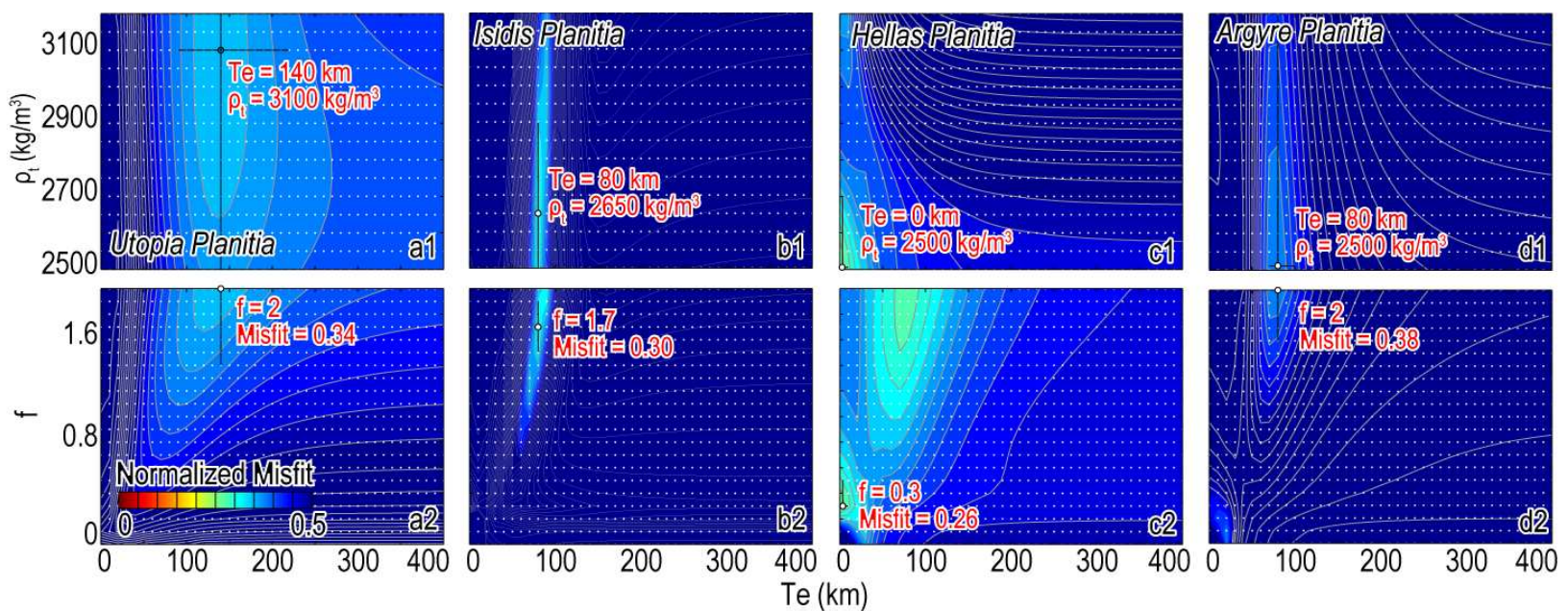

Figure B4. RMS misfits for four impact basins: (a1-2) Utopia Planitia; (b1-2) Isidis Planitia; (c12) Hellas Planitia; and (d1-2) Argyre Planitia. 